\title{
Assessment of WRF Land Surface Model Performance over West Africa
}

\author{
Ifeanyi C. Achugbu $\mathbb{D}^{1,2,3}$ Jimy Dudhia $\mathbb{D}^{1,},{ }^{3}$ Ayorinde A. Olufayo, ${ }^{2}$ Ifeoluwa A. Balogun, ${ }^{2}$ \\ Elijah A. Adefisan, ${ }^{2}$ and Imoleayo E. Gbode $\mathbb{1}^{2,3}$ \\ ${ }^{1}$ Department of Water Resources Management and Agrometeorology, Federal University Oye-Ekiti, Oye-Ekiti, Ekiti State, Nigeria \\ ${ }^{2}$ West African Science Service Center on Climate Change and Adapted Land-Use (WASCAL), \\ Federal University of Technology Akure, Akure, Ondo State, Nigeria \\ ${ }^{3}$ Mesoscale and Microscale Meteorology Laboratory, National Center for Atmospheric Research, Boulder, CO, USA
}

Correspondence should be addressed to Ifeanyi C. Achugbu; ifeanyi.chukwudi@fuoye.edu.ng

Received 19 December 2019; Revised 27 June 2020; Accepted 16 July 2020; Published 7 August 2020

Academic Editor: Eduardo García-Ortega

Copyright (c) 2020 Ifeanyi C. Achugbu et al. This is an open access article distributed under the Creative Commons Attribution License, which permits unrestricted use, distribution, and reproduction in any medium, provided the original work is properly cited.

\begin{abstract}
Simulations with four land surface models (LSMs) (i.e., Noah, Noah-MP, Noah-MP with ground water GW option, and CLM4) using the Weather Research and Forecasting (WRF) model at $12 \mathrm{~km}$ horizontal grid resolution were carried out as two sets for 3 months (December-February 2011/2012 and July-September 2012) over West Africa. The objective is to assess the performance of WRF LSMs in simulating meteorological parameters over West Africa. The model precipitation was assessed against TRMM while surface temperature was compared with the ERA-Interim reanalysis dataset. Results show that the LSMs performed differently for different variables in different land-surface conditions. Based on precipitation and temperature, Noah-MP GW is overall the best for all the variables and seasons in combination, while Noah came last. Specifically, Noah-MP GW performed best for JAS temperature and precipitation; CLM4 was the best in simulating DJF precipitation, while Noah was the best in simulating DJF temperature. Noah-MP GW has the wettest Sahel while Noah has the driest one. The strength of the Tropical Easterly Jet (TEJ) is strongest in Noah-MP GW and Noah-MP compared with that in CLM4 and Noah. The core of the African Easterly Jet (AEJ) lies around $12^{\circ} \mathrm{N}$ in Noah and $15^{\circ} \mathrm{N}$ for Noah-MP GW. Noah-MP GW and Noah-MP simulations have stronger influx of moisture advection from the southwesterly monsoonal wind than the CLM4 and Noah with Noah showing the least influx. Also, analysis of the evaporative fraction shows sharp gradient for Noah-MP GW and Noah-MP with wetter Sahel further to the north and further to the south for Noah. Noah-MP-GW has the highest amount of soil moisture, while the CLM4 has the least for both the JAS and DJF seasons. The CLM4 has the highest LH for both DJF and JAS seasons but however has the least SH for both DJF and JAS seasons. The principal difference between the LSMs is in the vegetation representation, description, and parameterization of the soil water column; hence, improvement is recommended in this regard.
\end{abstract}

\section{Introduction}

The land surface is the principal constituent located in the space separating the atmosphere and the lithosphere, and it obviously impacts the exchanges of energy and moisture with the boundary layer. Through the controlling of the surface energy balance and water balance, land-surface processes strongly affect the weather and climate from local to regional and global scales [1]. One of the ways in which the land surface affects the climate system is the fact that due to the direct contact of the land surface with the atmosphere, the land surface reacts as a source and sink of heat and moisture through the sensible heat flux and evaporation. The surface conditions regulate the important feedback cycles in the climate system [2]. Also, the partitioning of the surface net radiation into sensible and latent heat fluxes determines the soil wetness development. The surface energy fluxes to a large extent control the surface weather parameters such as the temperature, humidity, and wind speed and to a lesser extent, low-level cloudiness and precipitation [2]. According 
to Tiwari et al. [3], it is noteworthy to have a better representation of the surface boundary conditions in a model as much as that of the surface and the atmosphere have an effect on the prognostic variables.

The land surface and the atmosphere are inseparable and cannot be isolated as they are firmly coupled systems. The planetary boundary layer (layer where intense turbulence takes place) is the interface that regulates the feedbacks. Despite the significant influence of land-atmosphere exchange on the daytime planetary boundary layer (PBL), uncertainty remains in the parameterization of surface heat and moisture fluxes in numerical weather models [4]. The land surface model (LSM) provides heat and moisture fluxes over land to provide a lower boundary condition for vertical transport in the PBL scheme. These fluxes of sensible heat and latent energy are dependent on the surface meteorology, radiative forcing, soil properties, and land use type. Thus, an accurate description of the land surface and vegetation characteristics is needed in any numerical weather prediction model [5]. The surface energy exchange is determined by the terrestrial radiation budget, as shown in the following equation:

$$
R_{\text {net }}=\mathrm{SH}+\mathrm{LH}+\mathrm{G},
$$

where $R_{\text {net }}$ is the net radiation flux $\left(\mathrm{W} / \mathrm{m}^{2}\right), \mathrm{SH}$ is the sensible heat flux $\left(\mathrm{W} / \mathrm{m}^{2}\right), \mathrm{LH}$ is the latent heat flux $\left(\mathrm{W} / \mathrm{m}^{2}\right)$, and $G$ is the ground heat flux $\left(\mathrm{W} / \mathrm{m}^{2}\right)$. The surface available fluxes (i.e., $\mathrm{SH}$ and $\mathrm{LH}$ ) are net radiation minus ground heat flux. The net radiation is balanced by outgoing fluxes of $\mathrm{LH}$, $\mathrm{SH}$, and $G$, whose partitioning strongly depends on the prevailing surface conditions. Some energy is absorbed by the ground $G$, this is in fact much lower than average value of $\mathrm{LH}$ and $\mathrm{SH}$ for most plant canopies, as most part of available energy will be transferred back into the atmosphere as sensible and latent heat [6]. LH is the quantity of heat absorbed or released by water undergoing a change of state. $\mathrm{LH}$ is most often the heat released by water as it changes from a liquid to gaseous state over a plant canopy through evapotranspiration.

The partitioning of the energy available at the surface into latent and sensible heat depends crucially on the soil moisture [7]. Vegetated surfaces have the ability to draw water from a depth of order $1 \mathrm{~m}$ (the root layer), while for bare ground, only the water in the top few centimeters of soil contributes to evaporation. According to Zheng and Eltahir [8], vegetation cover and soil moisture content play a comparable role in the concept of land-atmosphere interactions. The main difference is that soil moisture anomaly patterns could last for many days to weeks, while vegetation is capable of mobilizing the root zone soil moisture that would otherwise not be in contact with the atmosphere. This consequently foists a lower boundary condition that could be in force for a longer time scale on the atmosphere. So, vegetation responds much slower on a single precipitation occurrence than the surface soil moisture.

The land-atmosphere interactions are modulated by the extent of the associated north-south gradient of heat and moisture in the lower atmosphere [9]. A number of regions in the world, for example, the Sahel [10, 11], Amazon [12], and Asian monsoon regions [13], have been identified as hot spots of land-atmosphere interactions, where interactions through feedback loops play a critical role in the surface water and energy balances as well as regional climate. In West Africa (WA) where we have strong land-atmosphere coupling, land surface processes, like soil-precipitation feedback [14], soil moisture initial conditions [14, 15], and vegetation feedbacks $[16,17]$, have significant impacts on the dynamic downscaling of regional climate models (RCMs). However, explanation of the results, from any one of such studies, ought to be tempered by the fact that there are considerable discrepancies in African land-atmosphere coupling strength among current state-of-the-art GCMs [18]. Li et al. [19] have demonstrated that land surface processes play a crucial role in the climate system.

The land surface has been shown to be an important factor in modulating the West African monsoon (WAM) [20]. Nicholson [21] stressed that the land surface characteristics and processes have been shown to have a significant impact on the interannual variability of rainfall in the Sahel region based on observations. Furthermore, the importance of surface-atmosphere interactions was one of the main principles of the international African Monsoon Multidisciplinary Analysis (AMMA) project [22] which was later investigated in several studies. According to Dirmeyer [23], the WA region typically appears as the one where the soil moisture feedbacks with the atmosphere are among the strongest over the globe. The Sahel region has been identified as one of strong soil moisture-atmosphere coupling [10]. Furthermore, it has been resolved to be the region of the world with the highest impact of biophysical processes on the climate [11]. As reviewed by Xue et al. [24], studies by Steiner et al. [25] and Lavender et al. [26] have shown the importance of the land surface on modulating the West African Monsoon (WAM). For example, previous studies have examined the role of changes in the surface albedo, e.g., [27-29], and the vegetation, e.g., [30-33], on modulating the WAM. All of these studies lead to the general conclusion that reduced vegetation leads to reduced rainfall.

Parameterization is a method of replacing processes that are of a very small scale or very complex to be physically represented in the model through a simplified process. Researchers have focused on the appropriate selection of Weather Research and Forecasting (WRF) parameterizations schemes for varying conditions and applications [34-47]. Some of these studies concluded that the performance of the physics schemes varies according to the region of study including the time of the year. Hence, care should be taken in applying each for a specific study area. However, different climate variables are found to be sensitive to different physical parameterizations [37] making the need for an all-inclusive sensitivity analyses more pressing and the procedure of physics parameterization selection more demanding [48]. WRF has a number of physics options, which includes options for selecting the radiation scheme, surface layer scheme, planetary boundary layer (PBL) scheme, microphysics scheme, convective scheme, and land-surface scheme. This study assesses the performance of recent WRF 
LSMs over West Africa for better simulations over the region.

Land surface models (LSMs) differ in the number of soil and canopy layers and in the treatment of vegetation-related processes and hence are able to perform differently. Changes in surface conditions are shown to affect the position and intensity of the African Easterly Jet (AEJ) [49]. The AMMA Land Surface Model Intercomparison (ALMIP) was designed as a step towards a better understanding and explanation of surface processes over West Africa [50]. The idea was to develop a forcing database with the best quality and highest spatial and temporal resolution data available and use this database to force state-of-the-art LSMs in order to better understand key processes at different scales [51]. Concerning the LSMs, the AMMA results showed that they have a tendency to underestimate surface sensible heat flux and perhaps baseflow runoff and overestimate evaporation from the vegetation canopy. During the monsoon season, evapotranspiration is generally the most significant component of the water budget, acting to recycle much of the rainfall, in particular, over the Sahel [51]. Nevertheless, qualitative estimates of recycling by the LSMs must be interpreted in view of the fact that the LSMs have a substantial intermodel scatter over the Sahel [51].

Steiner et al. [25] coupled the community land model (CLM3) and the biosphere-atmosphere transfer scheme (BATS) with the ICTP regional climate model (RegCM3) and found out that CLM3 improves the timing of the monsoon advance and retreat across the Guinean Coast and reduces a positive precipitation bias in the Sahel and Northern Africa. This results in a higher simulated temperature, and by that means, it reduces the negative temperature bias found in the Guinean Coast and Sahel in the BATS. They also emphasized that the improvement in CLM3 is triggered by drier soil conditions in the simulation.

In spite of the notable impact of the land-atmosphere exchange on the daytime planetary boundary layer, there are still some uncertainties in the parameterization of surface heat and moisture fluxes in numerical weather models (NWM) [4]. WRF has many LSM options that range from simple treatment of subsurface processes like absence of vegetation or snow cover prediction to advanced physical models with sophisticated vegetation and soil models and snow cover prediction. Moreover, WRF LSMs use seasonally adjusted or annually fixed land-use properties read from look-up tables in order to allocate surface variables; yet, some land cover parameters like vegetation can change often within a short time.

Several sensitivity and evaluation studies have been carried out in different regions $[5,19,52-56]$. This is necessary in order to help firstly the model developers for further improvements, secondly, the users in the selection of LSM options especially in the WRF model, and thirdly, improving the simulations for the area under study. Therefore, considering the number of LSMs currently in the WRF model, it remains a difficult task for researchers to choose a suitable land surface scheme that fits their needs [57] especially over a data sparse region like West Africa. Although, some researchers [58-60] have replaced the land- use data by incorporating remote sensing data into the LSMs for more updated and realistic land-use land-cover data in order to improve the models; this was not done in this research because we wanted to evaluate the performance of each WRF LSM in the same standard mode.

Researchers such as Evans et al. [37] examined the performance of various physics scheme combinations on the simulation of a series of rainfall events near the southeast coast of Australia. They created a thirty-six member multiphysics ensemble such that each member had a unique set of physics parameterizations. They found out that no single ensemble member was found to perform best for all events, variables, and metrics, and this also reflects the fact that different climate variables are found to be sensitive to different physical parameterizations.

Hagos et al. [61] performed different WRF simulations with NOAH, SSIB, and PLEIM-XIU LSMs and cumulus parameterization schemes over West Africa. They found out that the model simulations consistently differ from the observations over the Gulf of Guinea, with the model seemingly overestimating precipitation, and the simulations differ in their northward incursion of precipitation over land. Their analysis also showed that the African Easterly Jet (AEJ) position for the simulations was too far south for SSIB and too far north for PLEIM-XIU; hence, SSIB was too dry while PLEIM-XUI was too wet.

Wharton et al. [5] in their study found that the choice of land-surface model led to a $\sim 10 \%$ improvement in simulating hub-height wind speed and that the overall best performing models were Noah and Noah-MP. They emphasized that the variability of LSM performance across different soil moisture and vegetation canopy conditions suggests LSM representation of surface energy exchange processes in WRF remains a large source of model uncertainty.

Jin et al. [53] studied the sensitivity of four land surface schemes in the WRF, namely, the simple soil thermal diffusion (STD) scheme, Noah scheme, RUC scheme, and community land model version 3 (CLM3). They ran four simulations with four LSMs over the western United States. Their results show that land-surface processes strongly affect temperature simulations over the area. They also found out that WRF CLM3 with the highest complexity level significantly improves temperature simulations, except for the wintertime maximum temperature as compared with the observations. Also, precipitation was substantially overestimated by WRF with the LSMs over the area and does not show a close relationship with land-surface processes.

All these researchers and many more have performed different evaluations for different regions, but this research is focused on examining the role of land-surface processes in the simulation of some variables in West Africa by carrying out a series of WRF runs using four recent LSM options which includes Noah scheme, Noah-MP, Noah-MP GW, and Community Land Model Version 4 (CLM4), each having different complexity levels. There are only few extensive studies on the assessment of regional climate models sensitivity to multiple land surface models over West Africa. Therefore, the impact of different LSMs on West African 
Monsoon (WAM) and land surface energy balance is still a study of importance. Atmospheric simulations over a variety of land-surface conditions that would be affected by the surface energy budget, including wet and dry seasons, were carried out in order to study the impact of LSMs choice on some WRF simulated parameters. In particular, we evaluate how the change in LSMs affect the average simulation of precipitation and $2 \mathrm{~m}$ temperature and tried explaining some reasons behind the differences using the mean wind, soil moisture, and surface energy parameters.

\section{Materials and Methods}

2.1. WRF Model Description and Configuration. The Weather Research and Forecasting (WRF) model is a community nonhydrostatic and fully compressible atmospheric model, maintained by the National Center for Atmospheric Research (NCAR). In this study, version 3.9.1.1 the Advance Research dynamical core of WRF model (ARW) was used to run eight different simulations. Each simulation is a 3month run from December to February (DJF) 2011/2012 dry season and July to September (JAS) 2012 rainy season over West Africa with four different LSMs. This makes it 4 different simulations for each season (i.e., 4 separate simulations for DJF and JAS season amounting to 8 simulations in all). The periods were chosen to study the impact of choice of land surface model over different land surface conditions (i.e., wet and dry) that would affect the surface energy budget.

The simulations were performed with a $12 \mathrm{~km}$ horizontal resolution for a domain that encompasses latitude $10^{\circ} \mathrm{S}-30^{\circ} \mathrm{N}$ and longitude $28^{\circ} \mathrm{W}-28^{\circ} \mathrm{E}$ as shown in Figure 1(a). Initial and lateral boundary conditions are from European Center for Medium-Range Weather Forecasts (ECMWF) Interim 6 hourly Re-Analysis (ERA-Interim) data, which has a horizontal resolution of $0.75^{\circ}$ [62] and National Centers for Environmental Protection (NCEP) Final Analysis (FNL) 6 hourly initial soil data (sea surface temperature, soil moisture, and temperature) from the NCAR's Computational and Information System Laboratory Research Data Archive (CISL RDA) [63] with resolution of $1^{\circ}$. So, the initial and lateral boundary conditions were updated every 6 hours.

The first 15 days were used as spin-up, hence $16^{\text {th }}$ of July to $29^{\text {th }}$ of September 2012 (JAS), for the rainy season and $16^{\text {th }}$ of December 2011 to $28^{\text {th }}$ of February 2012 (DJF), for the dry season were analysed. The variables were analysed spatially within the $20^{\circ} \mathrm{W}-20^{\circ} \mathrm{E}$ and $0^{\circ}-20^{\circ} \mathrm{N}$ (the green box area) as shown in Figure 1, while the analysis involving time averages were within the $10^{\circ} \mathrm{W}-10^{\circ} \mathrm{E}$ and $5^{\circ}-15^{\circ} \mathrm{N}$ boundary as shown in Figure 1(a) so that the domain of interest is moved away from the errors introduced by boundary values. Figure 1(a) also shows the elevation of the study area revealing the highlands such as the Jos Plateau, Cameroon Mountains, and Fouta Djalon highlands. The geogrid program by default will interpolate land use land cover LULC categories from the MODIS IGBP 21-category data in the model. The LULC distribution derived from MODIS data is shown in Figure 1(b). It shows barren or sparsely vegetated surfaces spread across the northern area (from $16^{\circ} \mathrm{N}$ upwards) and Evergreen Broadleaf Forest around the coastal regions. Most part of the Sahel is covered by grasslands with scattered croplands and open shrublands between the Sahel-Sahara interface. The distribution of the dominant soil type in West Africa is also shown in Figure 1(c). The loamy sand, sandy loam, and loam are more dominant in the northern part, while the silty clay loam and clay loam are dominant in the southern part.

The roughness lengths in meters are in some table files MPTABLE.TBL for Noah-MP for each land use category. VEGPARM.TBL for Noah has minimum and maximum values for each category. The values depend on the range, which has a seasonal change, and depend on the vegetation fraction for each land use in the tables. From the land use in the models and considering the entire region, the most dominant land use categories in the study area include evergreen broadleaf forest, open shrublands, woody savannas, savannas, grasslands, croplands, barren or sparsely vegetated, and water with roughness lengths within the range of $0.5-0.5 \mathrm{~m}, 0.01-0.06 \mathrm{~m}, 0.01-0.05 \mathrm{~m}, 0.15-0.15 \mathrm{~m}$, $0.10-0.12 \mathrm{~m}, 0.05-0.15 \mathrm{~m}, 0.01-0.01 \mathrm{~m}$, and $0.0001-0.0001 \mathrm{~m}$ for Noah and CLM4, respectively, and $1.10 \mathrm{~m}, 0.06 \mathrm{~m}$, $0.60 \mathrm{~m}, 0.50 \mathrm{~m}, 0.12 \mathrm{~m}, 0.15 \mathrm{~m}, 0.00$, and 0.00 , respectively, for Noah-MP. Hence, Noah-MP has a constant roughness length for all seasons.

WRF version 3.9.1.1 has about seven different land surface physics options from the simple 5-layer soil model simply with thermal diffusion in soil layers and no vegetation or snow cover prediction to Noah LSM, Noah-MP, RUC LSM, PX LSM, CLM4, and SSiB LSMs with sophisticated vegetation models and snow cover prediction. The WRF LSMs are driven by surface energy and water fluxes and predict soil temperature and moisture in different layers depending on the LSM option in which Noah and Noah-MP has 4 layers, RUC has 9 layers, PX has 2 layers, and SSiB has 3 and 10 layers for CLM4. Noah-MP, RUC, SSiB, and CLM4 may predict snow water equivalent on ground. All the WRF land surface models utilize the wind and stability information from the atmospheric surface layer scheme.

The Noah LSM (as the most commonly used LSM) was used to test for four other different physics combinations (results not shown) in which the best combination was used with other three LSMs, which includes the Noah-MP, CLM4, and Noah-MP GW. The Noah-MP GW is a new option including a free drainage soil lower boundary condition, variable water table, and 1-dimensional interaction with horizontal aquifer transport but no river routing or overland flow scheme as in hydrological models. All parameterization schemes apart from the LSMs were the same for all simulations. The new version of rapid radiative transfer model (RRTMG) based on Iacono et al. [64] is selected for describing the long-wave and short-wave radiative transfer within the atmosphere and to the surface. The Mellor-Yamada Nakanishi and Niino Level 2.5 (MYNN2.5) scheme by Nakanishi and Niino [65] was used for boundarylayer processes with a consistent MYNN surface layer scheme. The new Tiedtke scheme [66] is applied to parameterise the unresolved deep cumulus clouds. The 

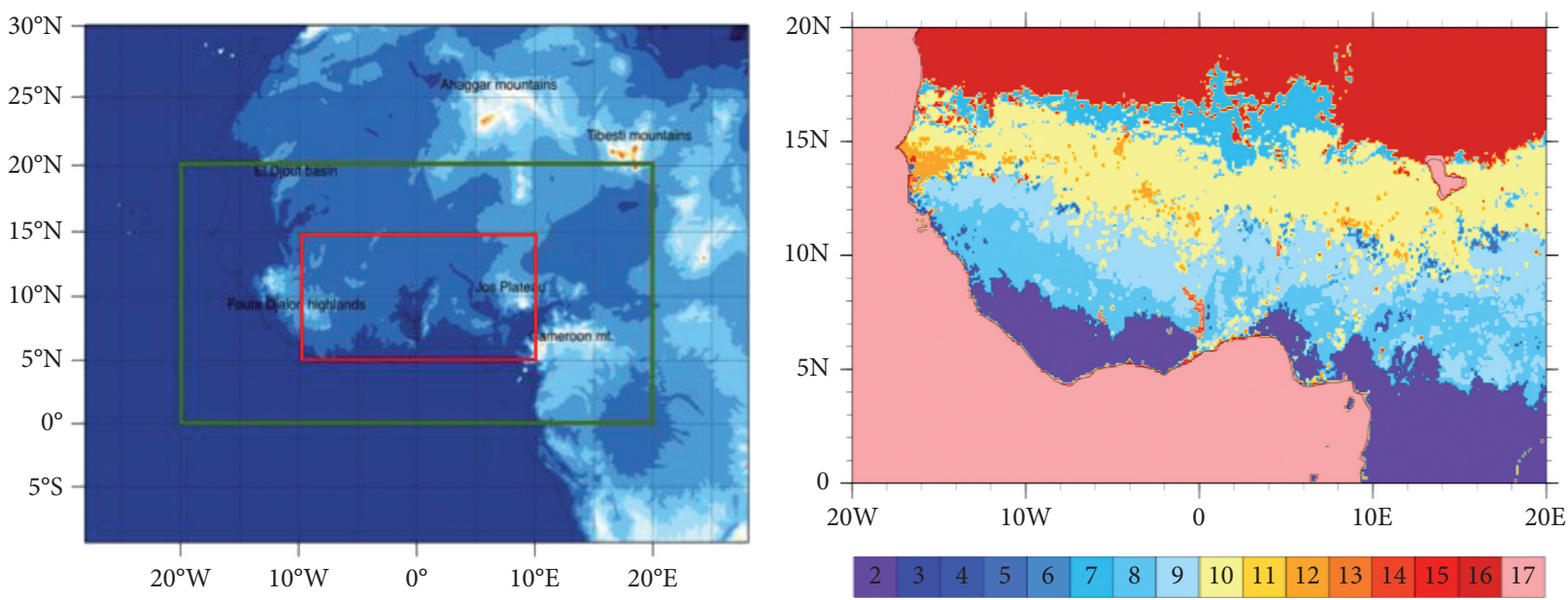

GMTED2010 30-arc-second topography height (meters MSL)

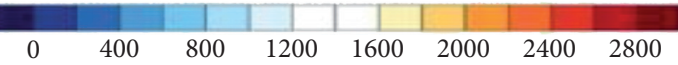

(a)

(b)

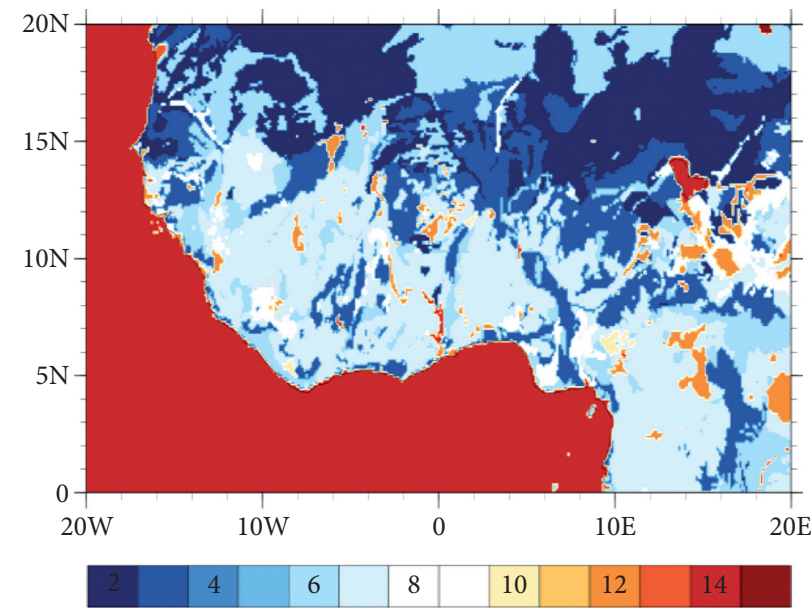

(c)

Figure 1: (a) Map showing the model domain with the elevation map of West Africa. The red box $\left(5^{\circ} \mathrm{N}-15^{\circ} \mathrm{N}\right.$ and $\left.10^{\circ} \mathrm{E}-10^{\circ} \mathrm{W}\right)$ is the domain for area average of the parameters while the green box is the evaluation area for the spatial plots; (b) land use category map of the study area (2. evergreen broadleaf forest; 3. deciduous needleleaf forest; 4. deciduous broadleaf forest; 5. mixed forests; 6. closed shrublands; 7. open shrublands; 8 . woody savannas; 9 . savannas; 10 . grasslands; 11 . permanent wetlands; 12 . croplands; 13 . urban and built-up; 14 . cropland/ natural vegetation mosaic; 15 . snow and ice; 16 . barren or sparsely vegetated; 17 . water); (c) soil type category map of the study area (2. loamy sand; 3 . sandy loam; 4. silt loam; 5 . silt; 6 . loam; 7. sandy clay loam; 8. silty clay loam; 9 . clay loam; 10 . sandy clay; 11 . silty clay; 12 . clay 13 . organic material; 14. Water; 15. bedrock).

microphysics scheme chosen is the WRF Single-Moment 6class (WSM6) scheme [67]. These were selected based on some preliminary tests that also agreed with the findings of Gbode et al. [68] who carried out a verification study of many atmospheric physics combinations over West Africa.

The Noah LSM [69] was developed jointly by National Center for Atmospheric Research (NCAR) and National Centers for Environmental Prediction (NCEP). It has been validated by many intercomparison studies both in coupled $[70,71]$ and uncoupled [72-74] modes. Its moderate complexity and computational efficiency have made it effective in both operational weather and climate models. It has the advantage of being compatible with the time-dependent soil fields made available by NCEP in the global analysis datasets. It has a 4-layer $(0.10,0.30,0.60$, and $1 \mathrm{~m}$ thick) soil temperature and moisture model in addition to canopy moisture and snow cover prediction. It has a rooting depth fixed at $1 \mathrm{~m}$ including three layers at the top and also has one snow layer and one canopy layer. The mass conservation law and the diffusive form of Richard's law controls the vertical water mass movement between soil layers, while a conceptual parameterization for the subgrid treatment of soil moisture and precipitation controls the infiltration [75]. Total evapotranspiration in Noah is the sum of the canopy intercepted water evaporation, transpiration from vegetation canopies, and evaporation from bare soil as weighted by the respective land surface coverage fractions [76]. The drainage is due to the gravitational percolation 
below the soil layers. The surface skin temperature is calculated from a surface energy balance equation. The surface energy fluxes of Noah are calculated over a combined surface layer of vegetation and bare soil surface. Such model hinders its further development as a process-based dynamic leaf model, because it cannot compute photosynthetically active radiation (PAR), canopy temperature, and related energy, water, and carbon fluxes explicitly [77]. Prediction includes a root zone, evapotranspiration, soil drainage, and runoff, taking into account vegetation categories, monthly vegetation fraction, and soil texture. It also predicts soil ice, and fractional snow cover effects, has urban treatment options, and takes surface emissivity and albedo properties into consideration.

Noah-MP (multiphysics) LSM [77] is an augmented version of the Noah LSM. The vital augmentation is the introduction of (a) a vegetation canopy layer for individually computing the canopy and the ground surface temperatures, achieved by introducing a semitile subgrid scheme to represent land surface heterogeneity [77], (b) a modified twostream scheme [78, 79] for transfer of radiation through vegetation canopy and considering the canopy gaps, (c) a Ball-Berry scheme for the canopy stomatal resistance [80-82] which connects stomatal resistance to the photosynthesis of sunlit and shaded leaves, and (d) a short-term dynamic vegetation model [83] with two options (off and on) in which leaf area index (LAI) and vegetation greenness fraction (GVF) can be predicted from the model when turned on. Also, a simple TOPMODEL runoff model for the computation of surface runoff and groundwater discharge, a 3-layer snow model, is given in [84], and a frozen soil scheme with exceptional soil permeability is discussed by Niu and Yang [85]. The Noah-MP uses multiple options for key landatmosphere interaction processes. It contains a separate vegetation canopy defined by a canopy top and bottom with leaf physical and radiometric properties used in a twostream canopy radiation transfer scheme that includes shading effects [77]. Noah-MP contains a multilayer snow pack with liquid water storage and melt/refreeze capability and a snow-interception model describing loading/ unloading, melt/refreeze, and sublimation of the canopyintercepted snow. Various options are available for surface water infiltration and runoff, and groundwater transfer and storage including water table depth to an unconfined aquifer. Horizontal and vertical vegetation density can be prescribed or predicted using prognostic photosynthesis and dynamic vegetation models that allocate carbon to vegetation (leaf, stem, wood, and root) and soil carbon pools (fast and slow) [77].

CLM4 (Community Land Model Version 4 [86] is a state of the science LSM more often used in climate applications, developed at NCAR in cooperation with many external collaborators and includes sophisticated handling of biogeophysics, hydrology, biogeochemistry, and dynamic vegetation. The vertical structure comprises of a single-layer vegetation canopy, a five-layer snowpack, and a ten-layer soil column [87]. It has $3.8 \mathrm{~m}$ soil depth divided into 10 layers approximately at $1.8 \mathrm{~cm}, 4.5 \mathrm{~cm}, 9.1 \mathrm{~cm}, 16.6 \mathrm{~cm}, 28.9 \mathrm{~cm}$, $49.3 \mathrm{~cm}, 82.9 \mathrm{~cm}, 138.3 \mathrm{~cm}, 229.6 \mathrm{~cm}$, and $342.3 \mathrm{~cm}$ below the surface. The soil water is predicted from the modified Richards equation by Zeng and Decker [88]. CLM4 centers on biogeophysics of land surface including vegetation dynamics modules. The overland flow is calculated with a simple conceptual TOPMODEL approach to parameterise the surface runoff. An exchange of water between an unconfined aquifer and the overlying soil column is incorporated in the soil hydrology scheme [85]. The parameterization schemes of Niu and Yang [89] and Wang and Zeng [90] is used to calculate the snow cover and snow burial fraction. Some of the major differences between the LSMs are highlighted in Table 1.

\subsection{Model Verification and Validation Datasets.} Simulated surface air temperature was assessed using the ERA-Interim dataset from the ECMWF and simulated precipitation using the Tropical Rainfall Measurement Mission (TRMM [92]). The $0.25^{\circ}$ resolution TRMM 3B42 product was used as the standard for evaluating the model outputs because of its reliability and also that it is a merged dataset (i.e., a combination of in situ and satellite products) with high-quality precipitation estimates [92]. The Global Precipitation Climatology Project (GPCP [93, 94]) is another genuine source for merged estimates computed from microwave, infrared, and sounder data observed by the international constellation of precipitation-related satellites and precipitation gauge analysis. This was also analysed to see how good it is in comparison with TRMM over West Africa. These datasets were used for the validation because the region (West Africa) is a data sparse region with a poorly spread synoptic weather station network, which is insufficient to validate the spatial and temporal spread of the model outputs. Hence, the use of several datasets for the model validation was necessary to examine their differences in order to clearly understand the model uncertainties.

2.3. Method of Model Evaluation. The model evaluation was also done using the Taylor diagram that can concisely summarize the degree of agreement between simulated and observed variables [95]. The correspondence amongst different patterns is quantified by their correlation, their centred root-mean-squared difference, and their standard deviations. Houghton et al. [96] stressed that the diagram is useful specifically in evaluating multiple aspects of complex models or in gauging the relative skills of many dissimilar models. The location of each model on the diagram describes how closely the model's output pattern corresponds with the observations. However, each model point in the diagram represents the correlation, the standard deviation, and the centered RMS and is related by the following equations:

$$
E_{2}^{\prime}=\sigma_{f}^{2}+\sigma_{o}^{2}-2 \sigma_{f} \sigma_{o} R
$$

where $R$ is the correlation coefficient between the forecast and observation fields; $E^{\prime}$ is the centered root-mean-squared (RMS) difference between the fields; and $\sigma_{f}^{2}$ and $\sigma_{o}^{2}$ are the variances of the forecast and the observation fields. 
TABLE 1: Highlights of some major differences between the LSMs.

\begin{tabular}{lccc}
\hline Description & Noah & Noah-MP & CLM4 \\
\hline Reference & {$[69]$} & {$[77]$} & {$[91]$} \\
No. of model soil layers & 4 & 4 & 10 \\
Depth of total soil column $(\mathrm{m})$ & 2 & 2 & 3.8 \\
Model soil layer thickness & $0.1,0.3,0.6,1.0$ & $0.1,0.3,0.6,1.0$ & $0.018,0.028,0.045,0.075,0.124,0.204,0.336,0.553,0.913,1.506$ \\
Tiling vegetation & Not present & Present & Present \\
Soil water vertical diffusion & Not present & Present & Present \\
No. of snow model layers & 1 & 3 & 5 \\
TOPMODEL for surface runoff & Not present & Present & Present \\
Dynamic vegetation & Not present & Present & Present \\
Explicit vegetation & Not present & Present & Present \\
\hline
\end{tabular}

\section{Results and Discussion}

3.1. Precipitation and Surface Temperature Analysis. From the plot of the average air temperature for JAS (Figure 2), all the simulations were in close resemblance to ERAinterim, which is used as the reference. FNL seems to have higher temperature than ERA-interim and all the models around $17^{\circ} \mathrm{N}$ and $20^{\circ} \mathrm{N}$. The areas of high and low values in ERA-interim were captured by all the four LSMs. From Figure 3, the average temperature bias between ERAInterim and the models for JAS shows that the outputs of all the model simulations agree with ERA-interim within the range of -4 to $3.5^{\circ} \mathrm{C}$. The maximum positive bias was shown around the EL Djouf basin in Mauritania and Northern Mali, while the maximum negative bias was found around Lake Chad, possibly due to a bias in the lake temperature in the model, for all simulations. But, Noah shows a cold bias relative to ERA-interim in areas above $16^{\circ} \mathrm{N}$ at the northeastern part which other models did not reveal. Areas below $15^{\circ} \mathrm{N}$ mostly showed bias value close to zero except for CLM4. Nevertheless, it shows that all the models could fairly predict rainy season air temperature.

Figure 4 shows that the spatial distribution of average $2 \mathrm{~m}$ surface temperature for DJF decreases with increasing latitude just like the reference from areas above $10^{\circ} \mathrm{N}$. All the models and ERA-interim were able to capture reasonably well the cooling around the highlands of Jos Plateau, Guinea, and Cameroon. However, FNL has higher temperature around the coastal areas than ERA-Interim.

From Figure 5, it is seen that the average temperature bias between ERA-Interim and the models for DJF ranges between $-4^{\circ}$ and $5^{\circ} \mathrm{C}$. There is a maximum warm bias around Fouta Djallon highlands in all the simulations. Noah LSM output tends to have the coldest bias while CLM4 LSM tends to have the warmest. Despite having the most sophisticated snow, soil, and vegetation physics among the LSMs, CLM4 has the strongest positive temperature bias in some major highlands and the El Djouf basin. The deep soil column and water table in CLM4 might however need a considerably long time period for temperature and soil moisture to reach equilibrium, mostly in the cold and dry regions [97]. This could make it require more spin-up time than other LSMs and might be the reason for having high bias around the semiarid/arid areas of the region for both temperature and rainfall in JAS season.
From the time series of JAS daily $2 \mathrm{~m}$ surface temperature averaged over $10^{\circ} \mathrm{W}-10^{\circ} \mathrm{E}$ and $5^{\circ}-15^{\circ} \mathrm{N}$ (as shown in Figure 6(a)), the general biases between ERA-Interim and the models can be clearly seen as ERA is predominantly cooler than the models. On average, August is the coolest period while September is the warmest, but the model tended to be too warm in September for all LSMs. From the time series of average daily temperature for DJF (Figure 6(b)), the model patterns were very similar to the reference. Noah-MP and the ground water option were the closest while Noah was the furthest being $1-2^{\circ} \mathrm{C}$ colder than ERA-Interim.

Figure 7 spatially displays the average JAS daily precipitation. There seems to be a more intense precipitation core formed around the Fouta Djallons in Guinea both in TRMM and GPCP and all the models. The orographic effect of the highlands is the reason the models deliver a high precipitation amount but it appears to be more than that of the reference in those areas. When air moves over a mountain, it will normally be forced to rise. The forced rising air cools and expands as the temperature and pressure drop and consequently condenses and form clouds, if moist. This will enhance the rainfall activities as seen for the simulations and the reference datasets. Outputs from Noah and CLM4 models showed almost no rainfall from latitude $17^{\circ} \mathrm{N}$ northwards, whereas TRMM, GPCP, Noah-MP, and Noah-MP GW displayed some amount of precipitation. Also, the models differ in their northward advance of precipitation as compared with the reference. The 1-3 mm/day precipitation belt stopped around $16^{\circ} \mathrm{N}$ for Noah, $17^{\circ} \mathrm{N}$ in CLM4, and $19-20^{\circ} \mathrm{N}$ for Noah-MP and the ground water option, and by implication, it shows that Noah is relatively dry in comparison with other LSMs understudy. Hagos et al. [61] did a similar comparison with Noah, SSIB, and Pleim-Xui LSMs in WRF and also found out that the simulations differ in their northward incursion of precipitation, where the $2-4 \mathrm{~mm}$ /day precipitation band reaches Lake Chad for Noah LSM, while Pleim Xui was further north and SSIB was a little to the south. From the spatial bias of JAS precipitation as presented in Figure 8, the difference between the models and TRMM ranges between 5 and $10 \mathrm{~mm} /$ day. Positive bias $>9 \mathrm{~mm} /$ day was noted around the Fouta Djallon highlands. Researchers like Jenkins et al. [98] and Jones et al. [99] have emphasized that orography plays an important role in West African precipitation patterns. Noah-MP GW showed the largest area of high precipitation bias among all the LSMs tested. 


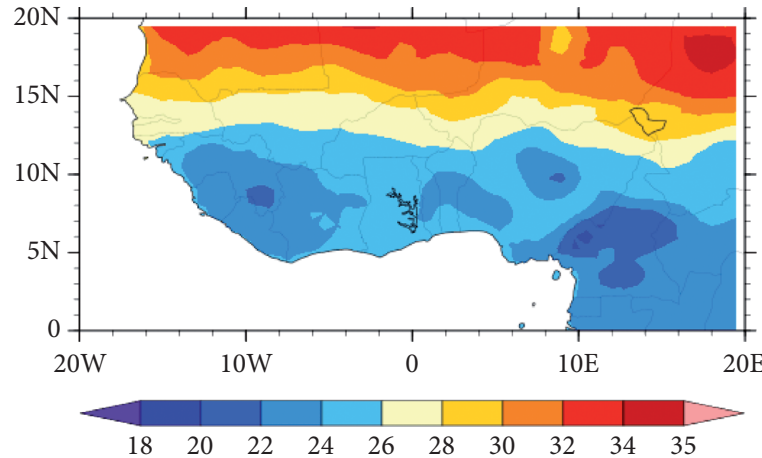

(a)

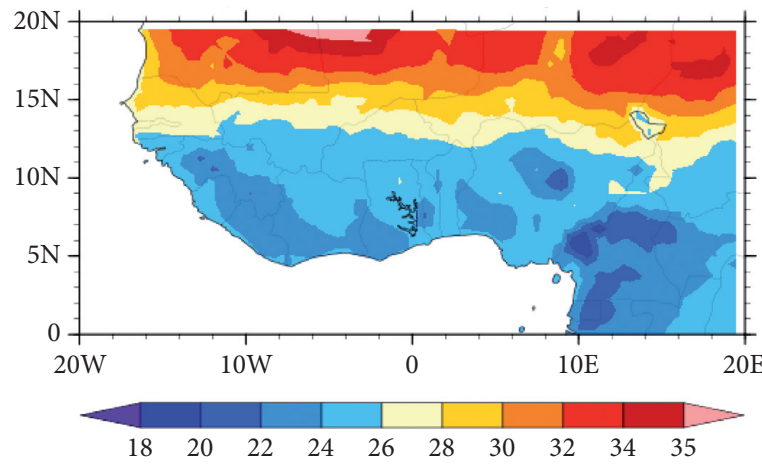

(c)

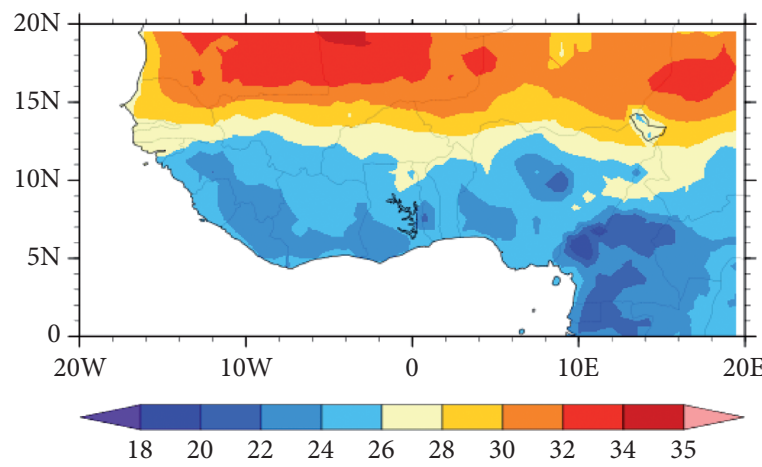

(e)

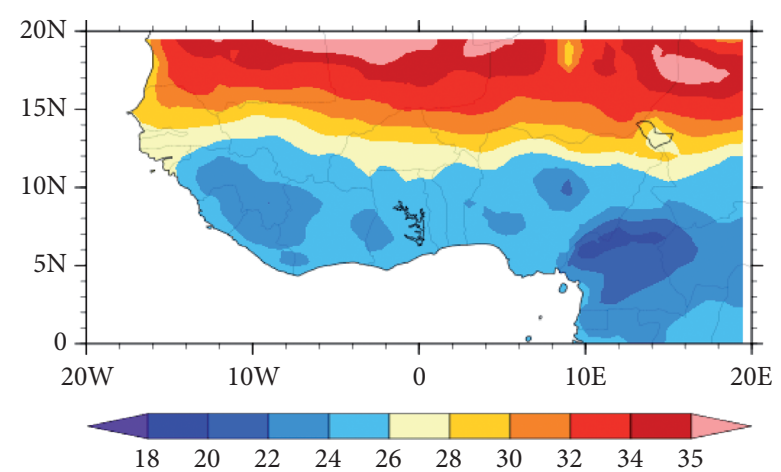

(b)

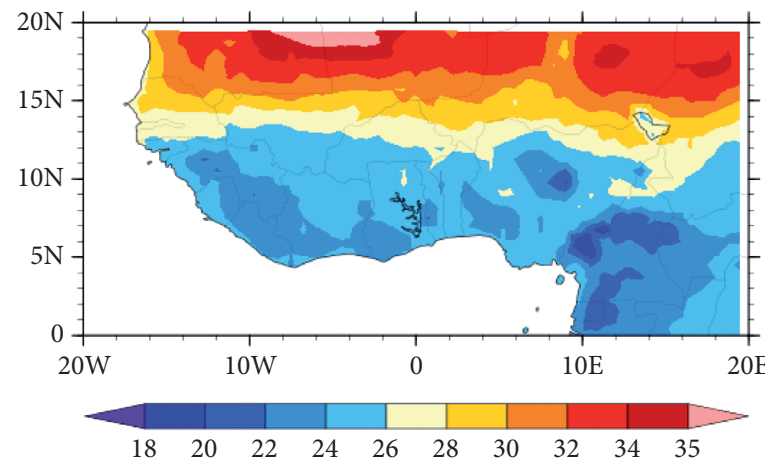

(d)

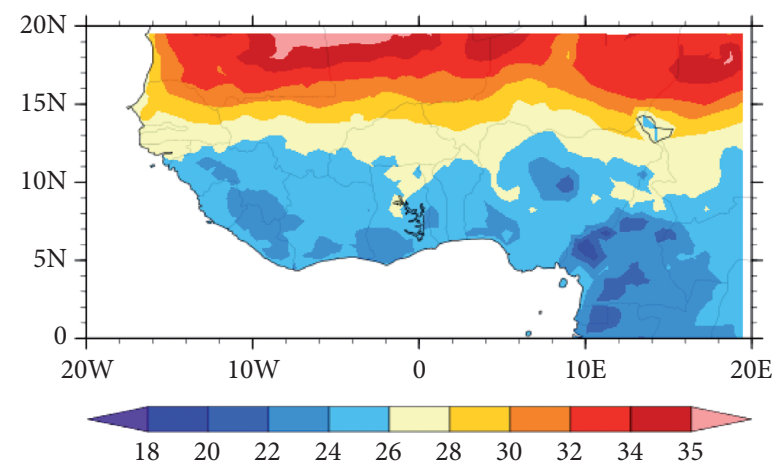

(f)

Figure 2: Spatial distribution of average 2 meter surface temperature $\left({ }^{\circ} \mathrm{C}\right)$ for July $16^{\text {th }}-$ Sept $29^{\text {th }}$, 2012. (a) ERA-interim. (b) FNL. (c) NoahMP groundwater option. (d) Noah-MP. (e) Noah. (f) CLM4.

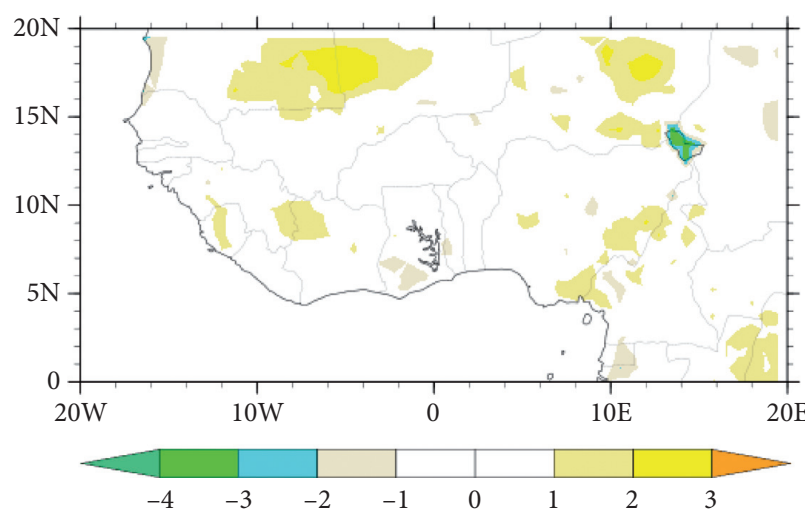

(a)

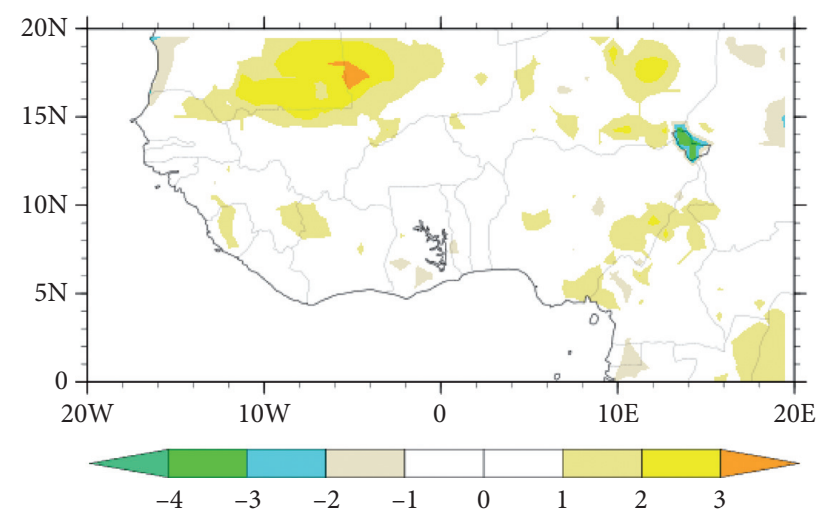

(b)

FIgUre 3: Continued. 


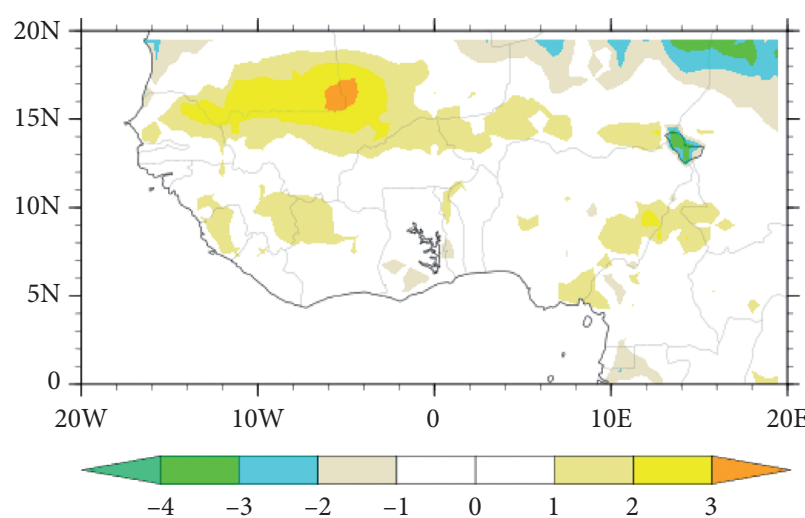

(c)

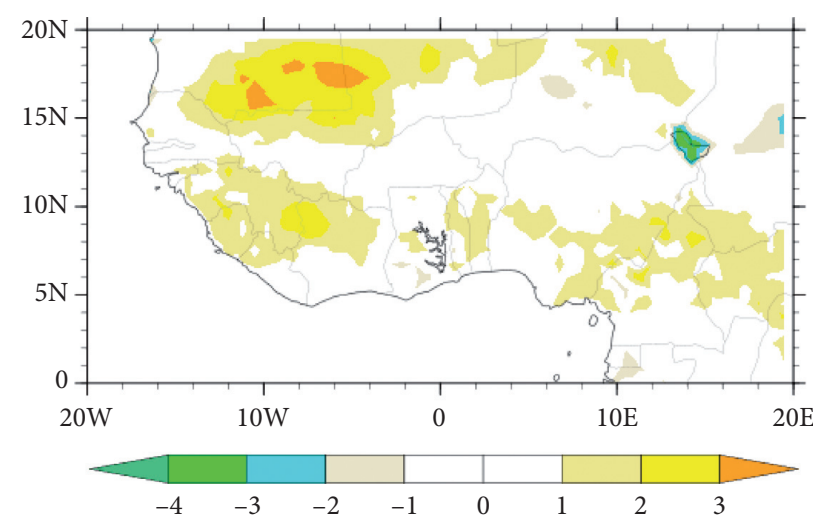

(d)

Figure 3: Spatial bias of average $2 \mathrm{~m}$ surface temperature $\left({ }^{\circ} \mathrm{C}\right)$ for July $16^{\text {th }}-$ Sept $29^{\text {th }}, 2012$. (a) Noah-MP groundwater option-ERA. (b) Noah-MP-ERA. (c) Noah-ERA. (d) CLM4-ERA.

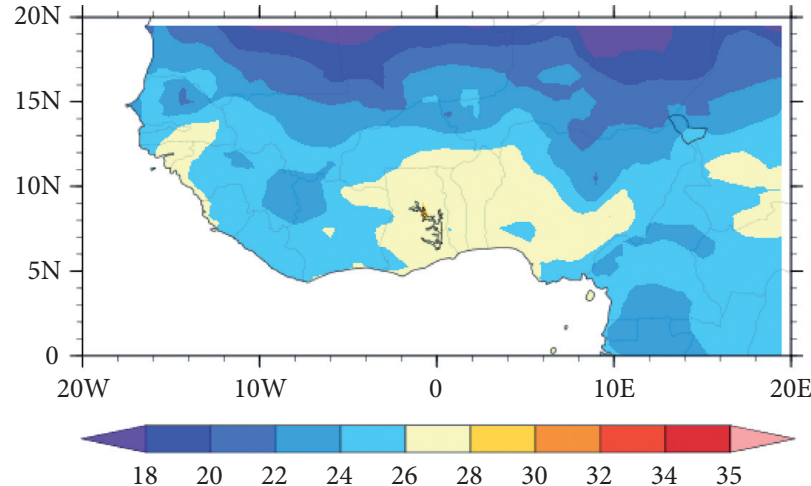

(a)

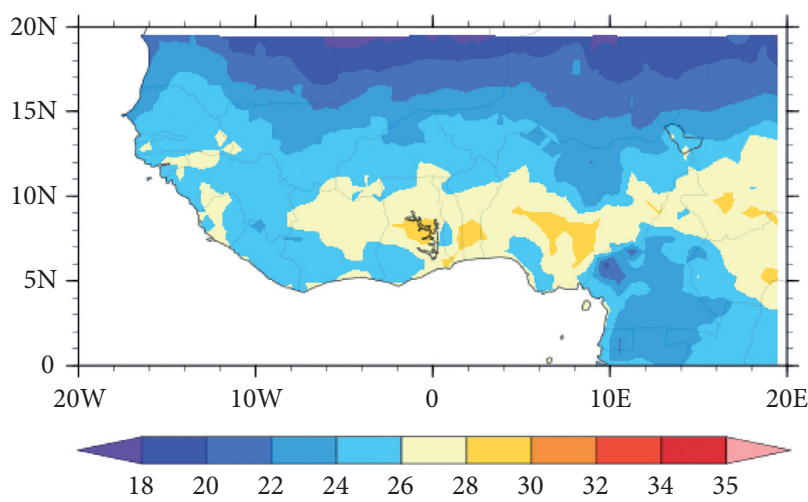

(c)

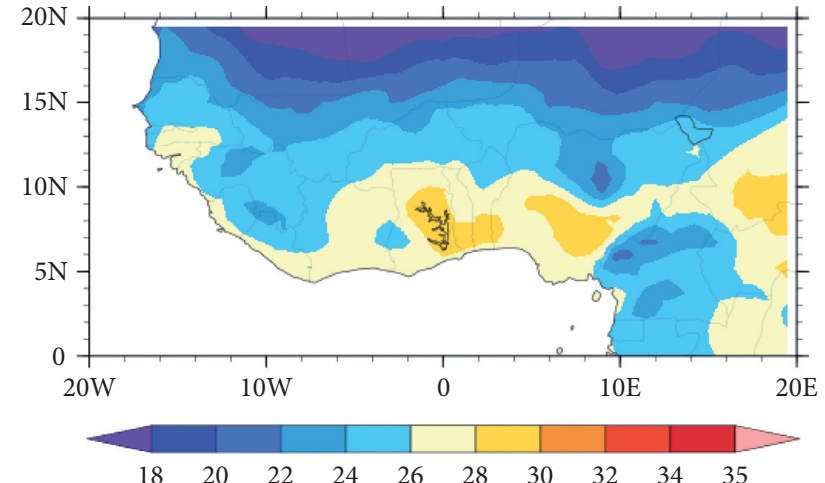

(b)

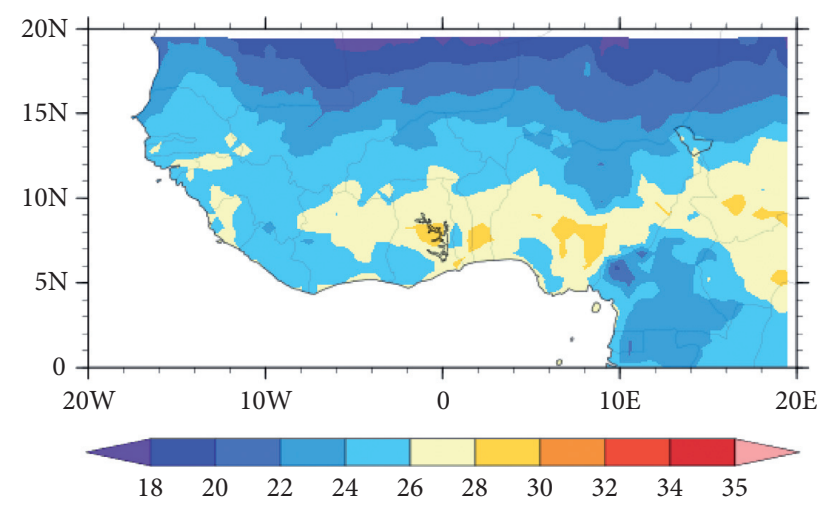

(d)

Figure 4: Continued. 


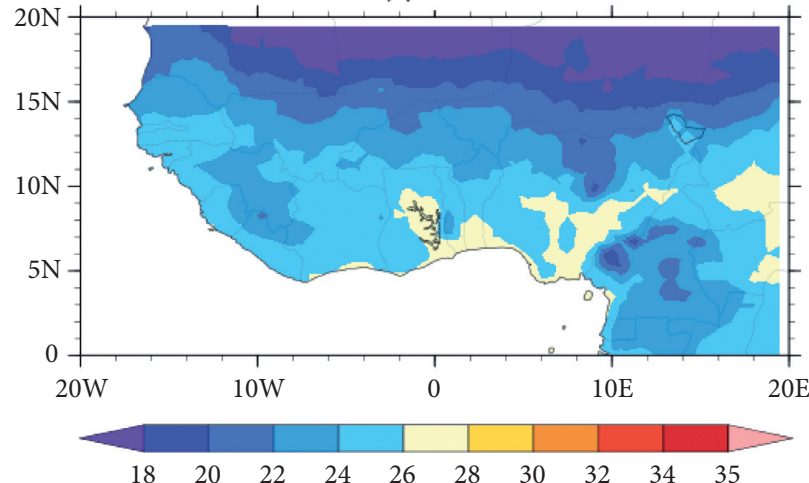

(e)

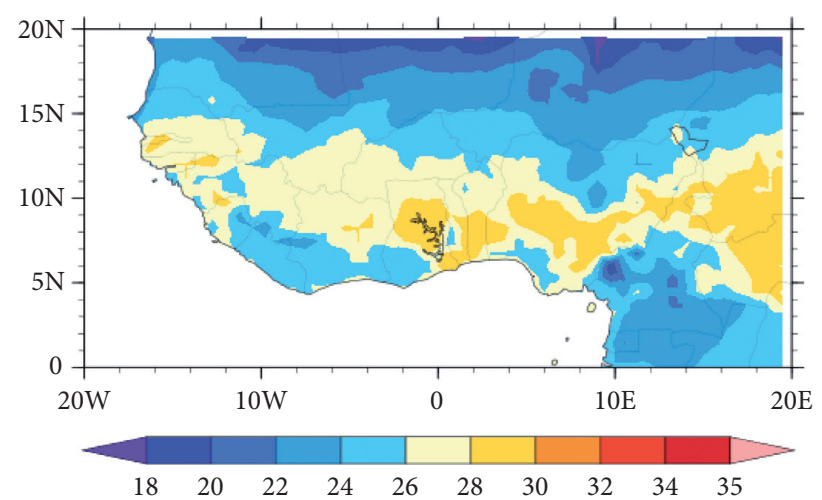

(f)

Figure 4: Spatial distribution of average $2 \mathrm{~m}$ surface temperature $\left({ }^{\circ} \mathrm{C}\right)$ for Dec $16^{\text {th }} 2011-\mathrm{Feb} 28^{\text {th }}$, 2012. (a) Era-interim. (b) FNL. (c) NoahMP groundwater option. (d) Noah-MP. (e) Noah. (f) CLM4.

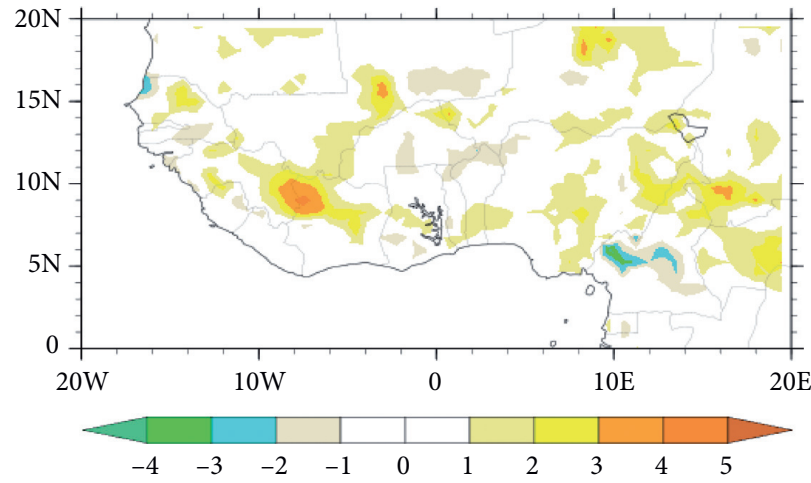

(a)

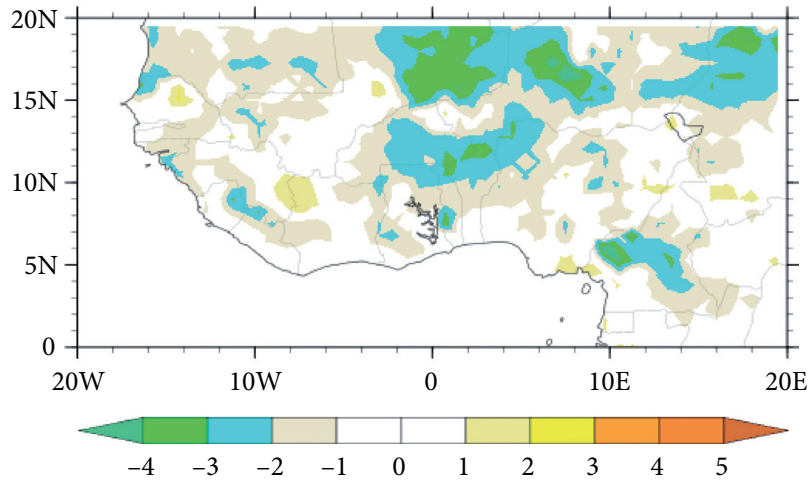

(c)

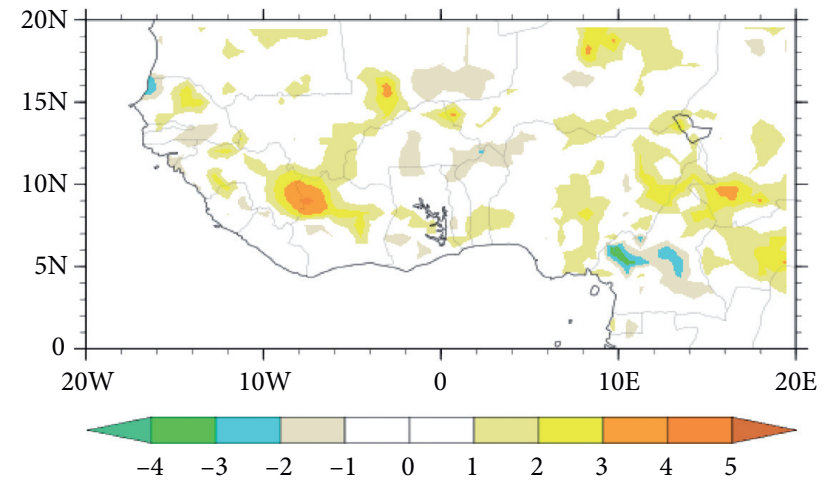

(b)

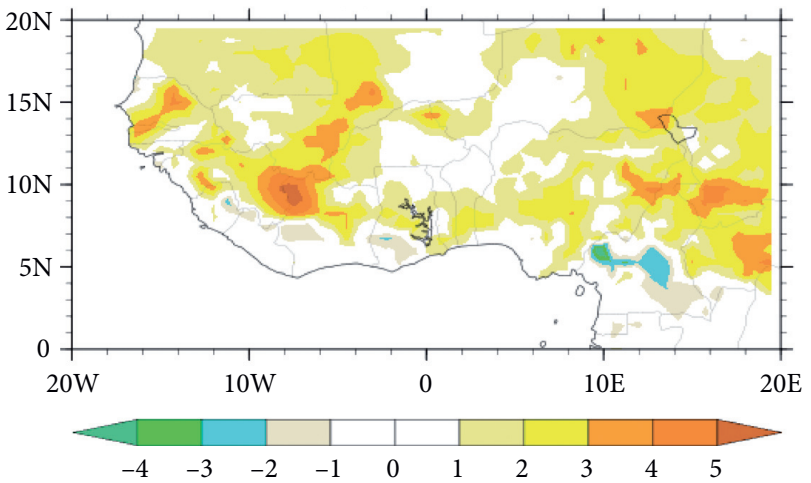

(d)

FiguRE 5: Spatial bias of average temperature $\left({ }^{\circ} \mathrm{C}\right)$ for December $16^{\text {th }}, 2011$, to February $28^{\text {th }}, 2012$. (a) Noah-MP groundwater option-ERA. (b) Noah-MP-ERA. (c) Noah-ERA. (d) CLM4-ERA.

From Figure 9, all the models showed a good pattern of the West African precipitation as areas above $7^{\circ} \mathrm{N}$ were dry. All the models were able to capture the coastal precipitation during this period. However, Noah-MP and the ground water option (Figures 9(c) and 9(d)) seem to overestimate the DJF precipitation as the entire coastal region has precipitation, whereas the dry coasts of Ghana, Togo, Benin, and some parts of Nigeria as seen in TRMM and GPCP were demonstrated in Noah and a little in CLM4. From the spatial bias of precipitation for DJF in Figure 10, there was a clear overestimation in Noah-MP and the ground water option, while Noah simulation has the least spatial bias.

All the models showed maximum positive temperature bias around the EL Djouf basin in Mauritania and Northern Mali which could be as a result of the effect of the West African heat low prevalent in this area. This is a low surface 


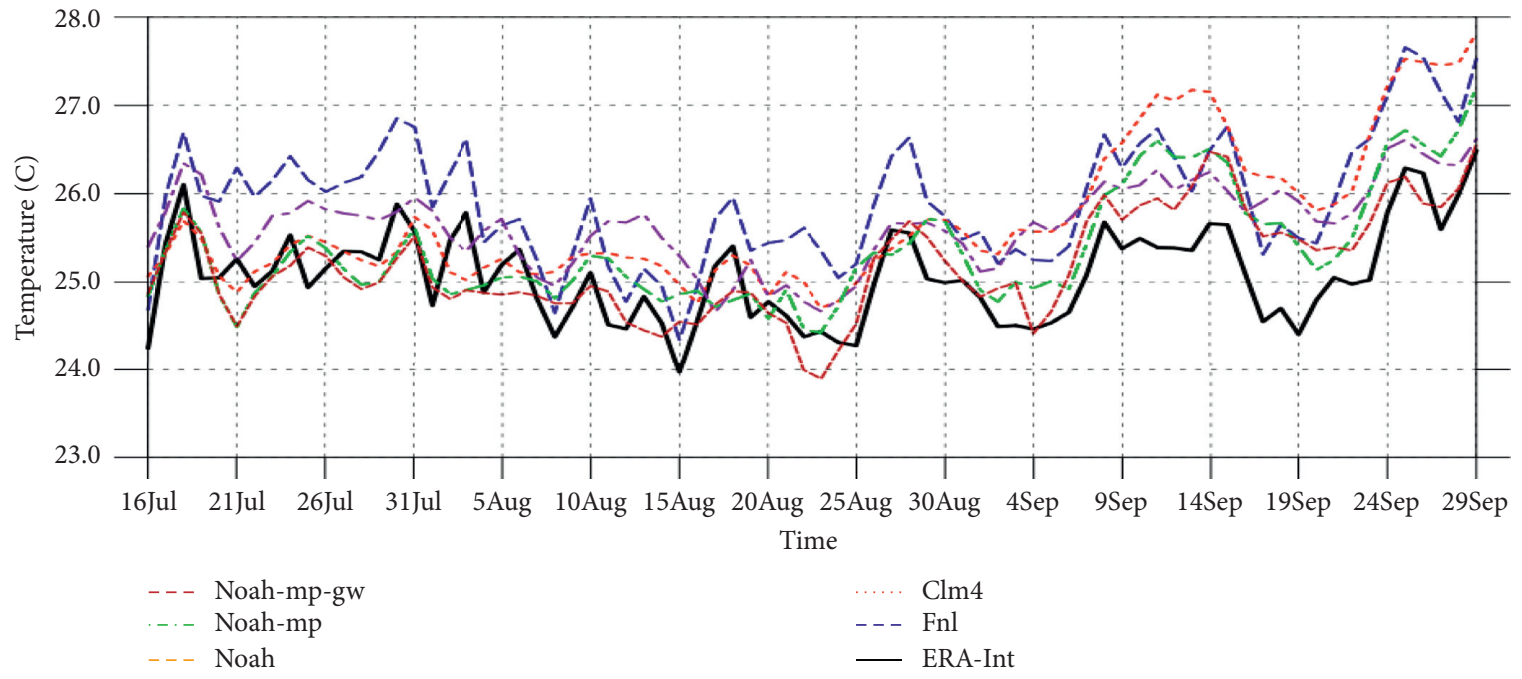

(a)
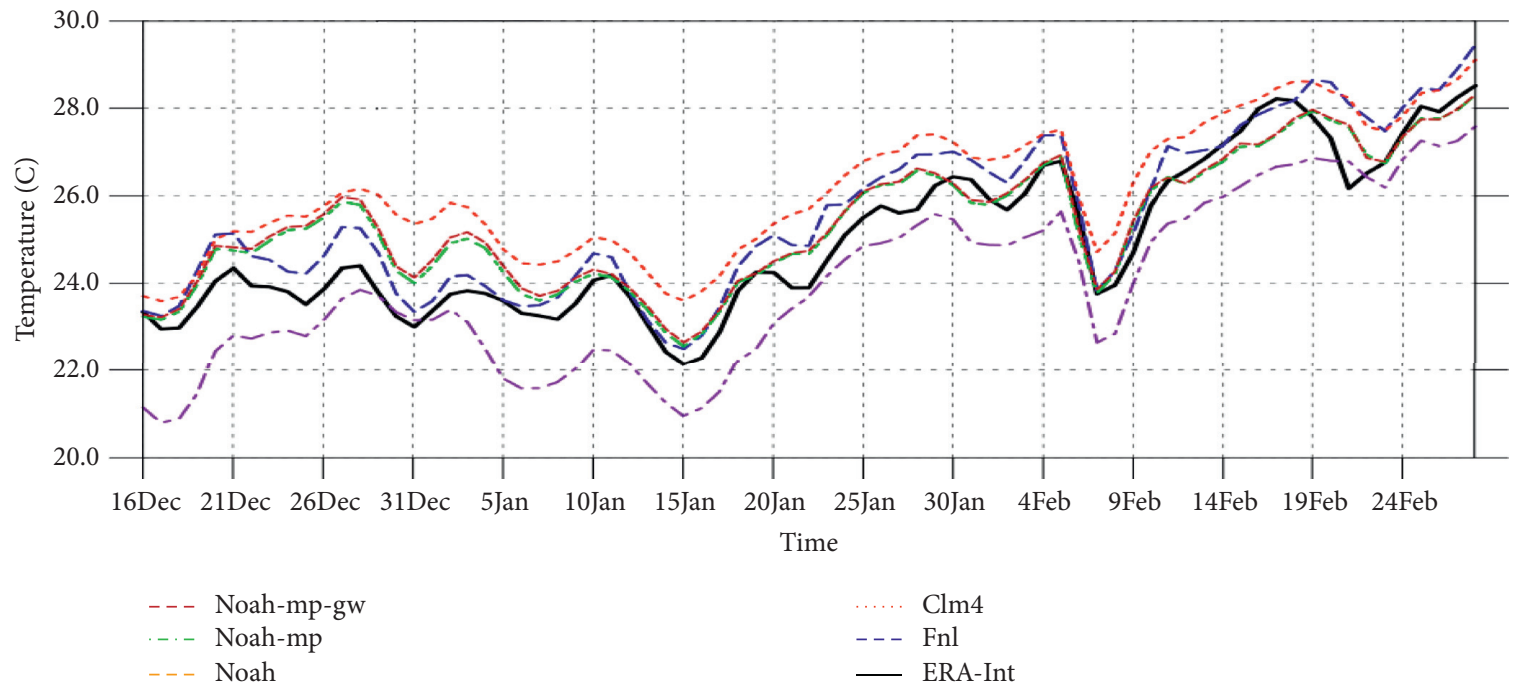

(b)

Figure 6: Time series of daily $2 \mathrm{~m}$ temperature averaged over $10^{\circ} \mathrm{W}-10^{\circ} \mathrm{E}$ and $5^{\circ}-15^{\circ} \mathrm{N}$ : (a) JAS; (b) DJF.

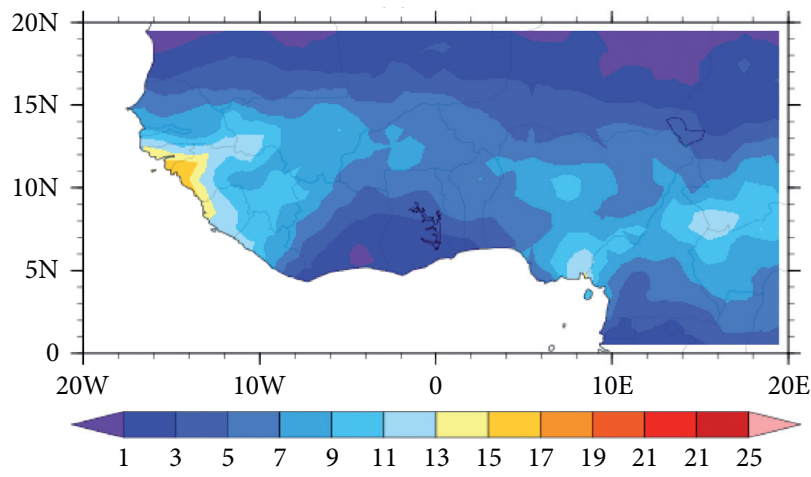

(a)

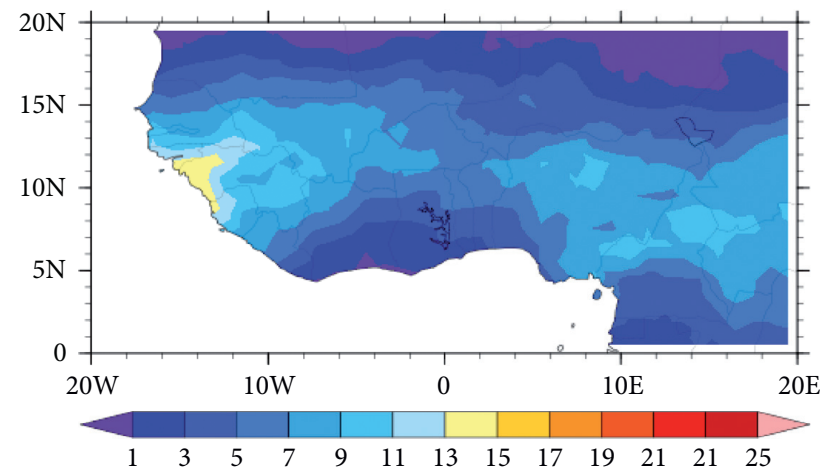

(b)

Figure 7: Continued. 


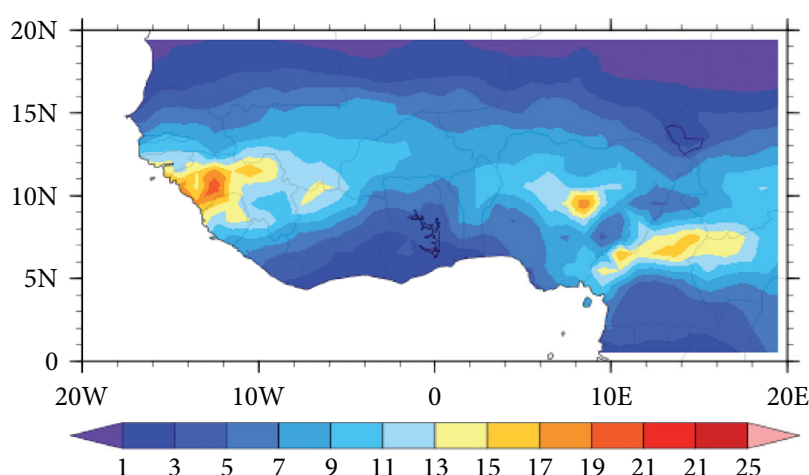

(c)

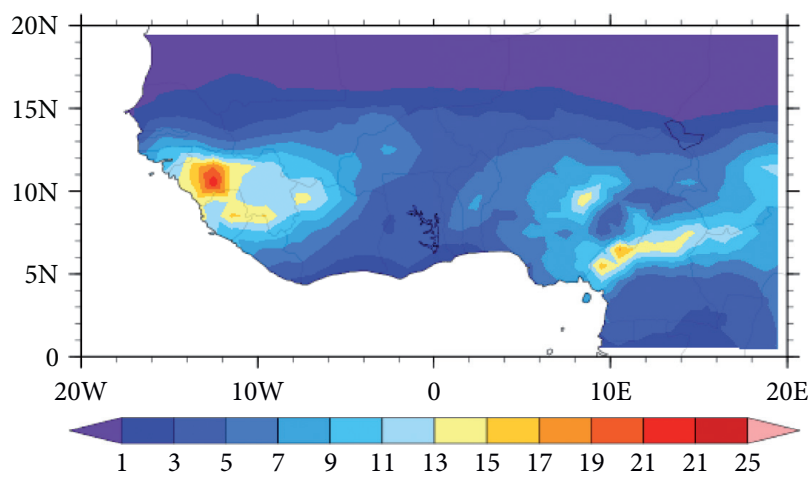

(e)

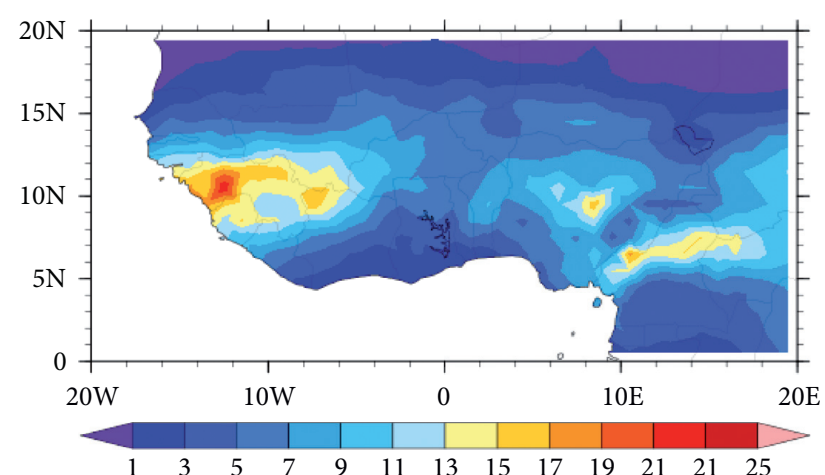

(d)

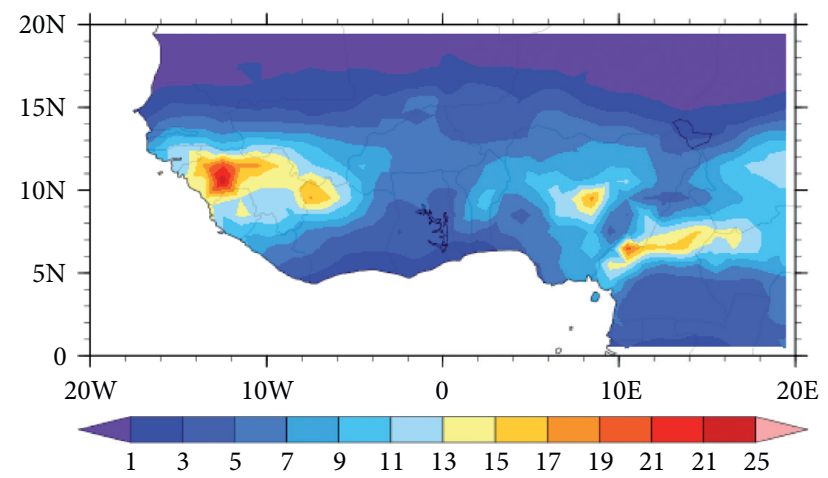

(f)

FIgURE 7: Spatial distribution of average precipitation for July $16^{\text {th }}-$ Sept $29^{\text {th }}$, 2012. (a) TRMM. (b) GPCP. (c) Noah-MP groundwater option. (d) Noah-MP. (e) Noah. (f) CLM4.

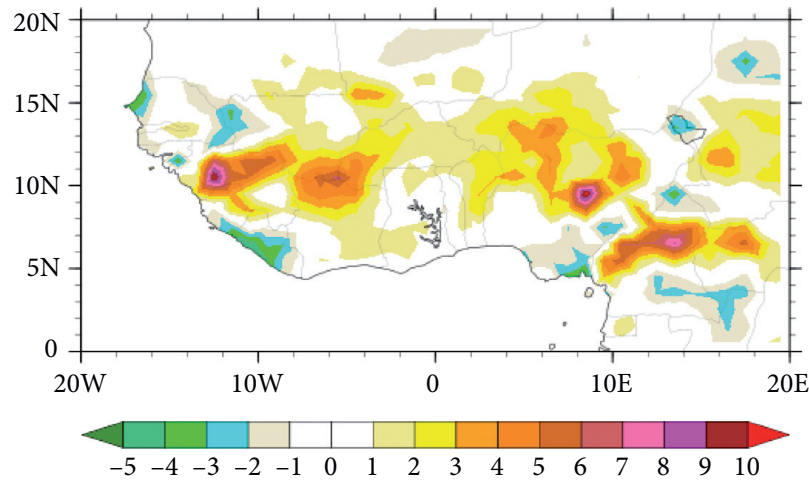

(a)

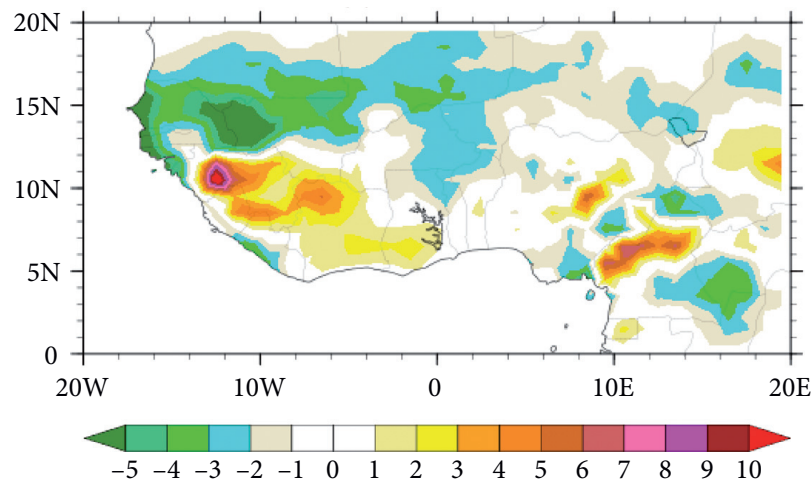

(c)

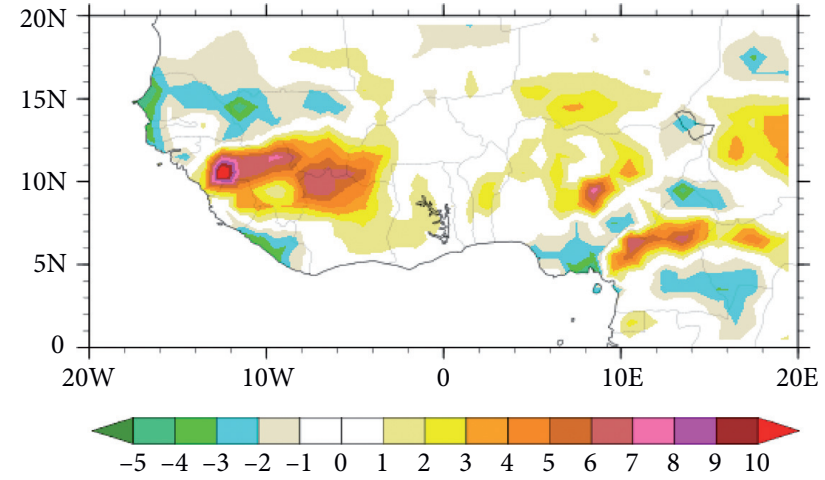

(b)

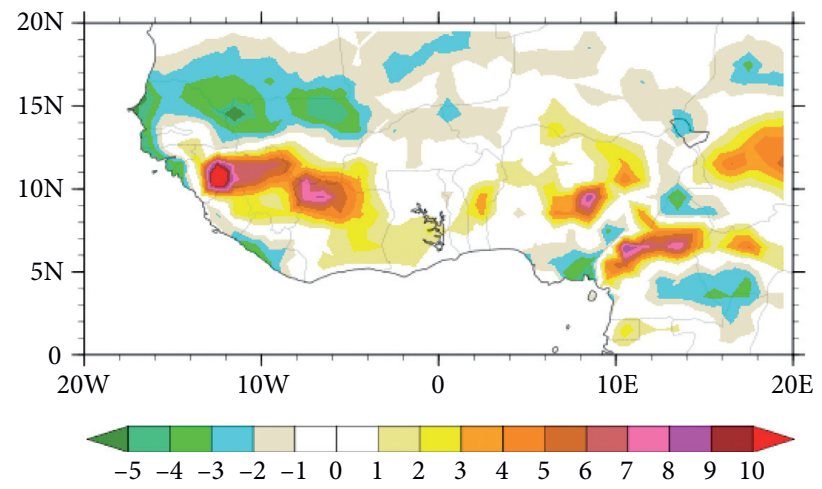

(d)

FIgURE 8: Spatial bias of precipitation for July $16^{\text {th }}-$ Sept $29^{\text {th }}, 2012$. (a) Noah-MP groundwater option-TRMM. (b) Noah-MP-TRMM. (c) Noah-TRMM. (d) CLM4-TRMM. 


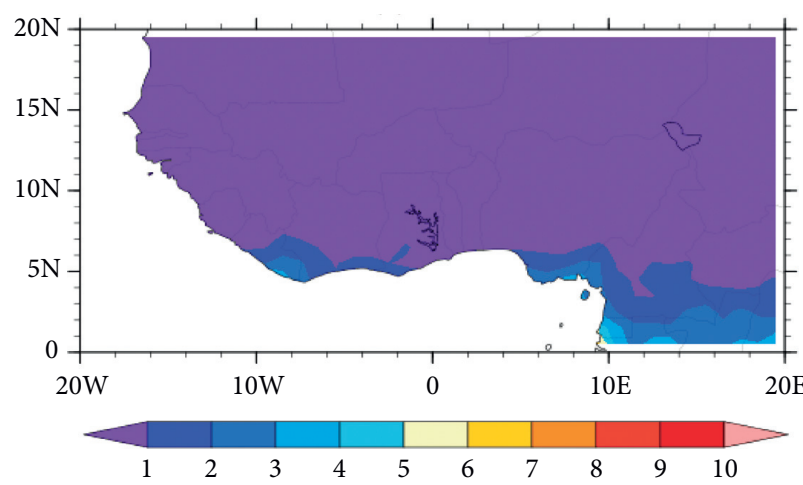

(a)

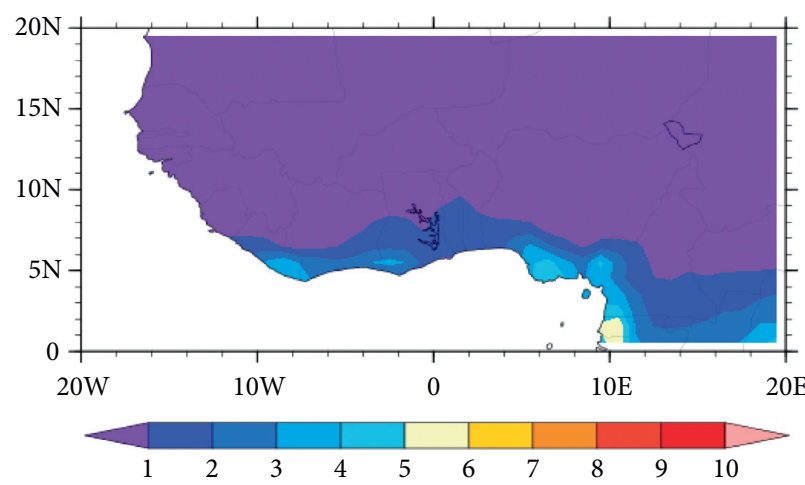

(c)

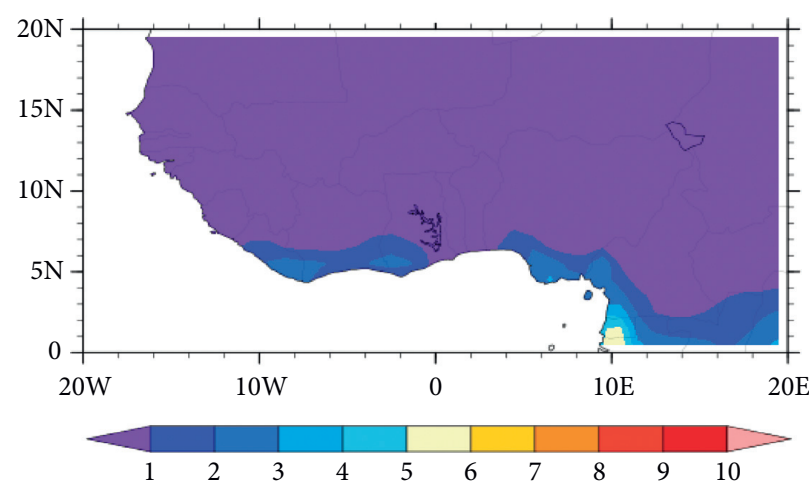

(e)

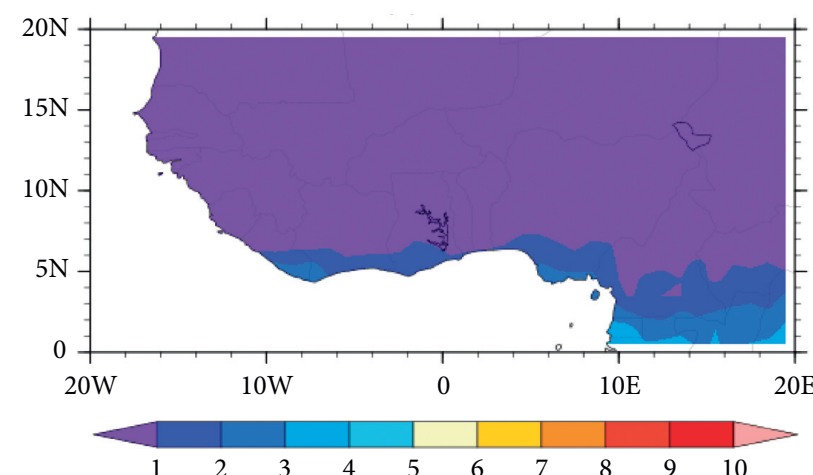

(b)

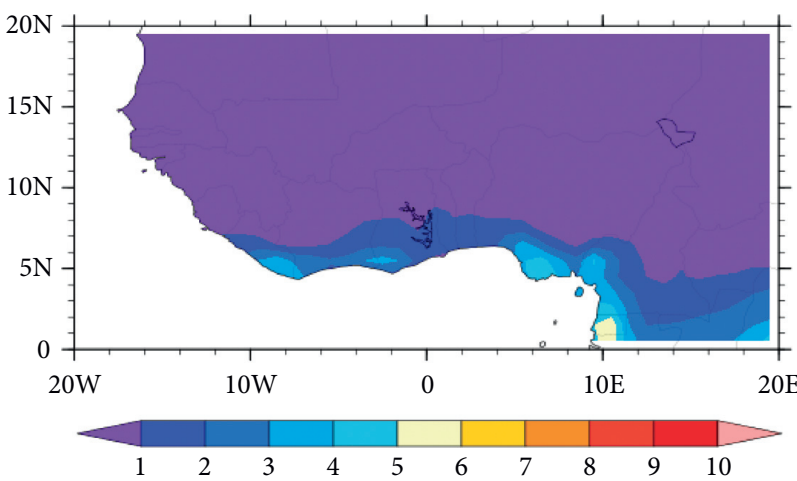

(d)

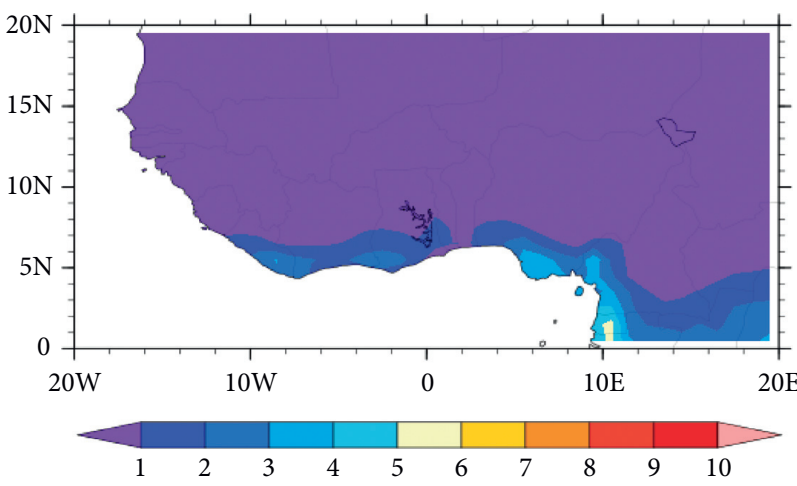

(f)

FIGURE 9: Spatial distribution of average precipitation for Dec $16^{\text {th }} 2011-F e b 28^{\text {th }}$, 2012. (a) TRMM. (b) GPCP. (c) Noah-MP groundwater option-ERA. (d) Noah-MP. (e) Noah. (f) CLM4.

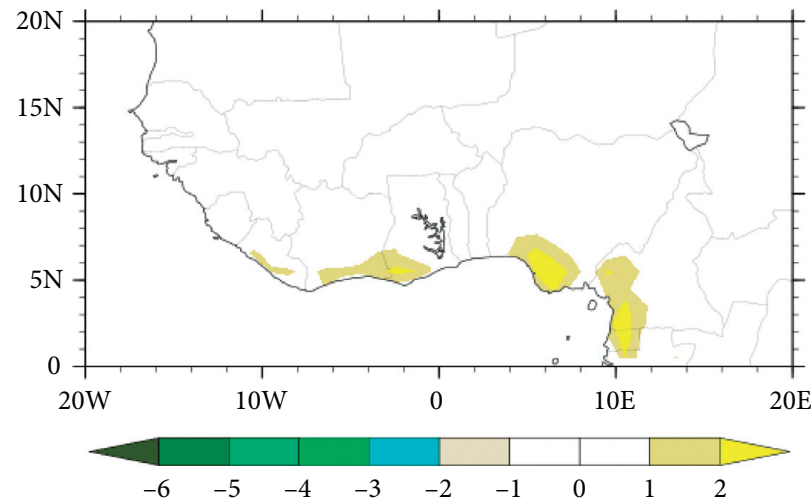

(a)

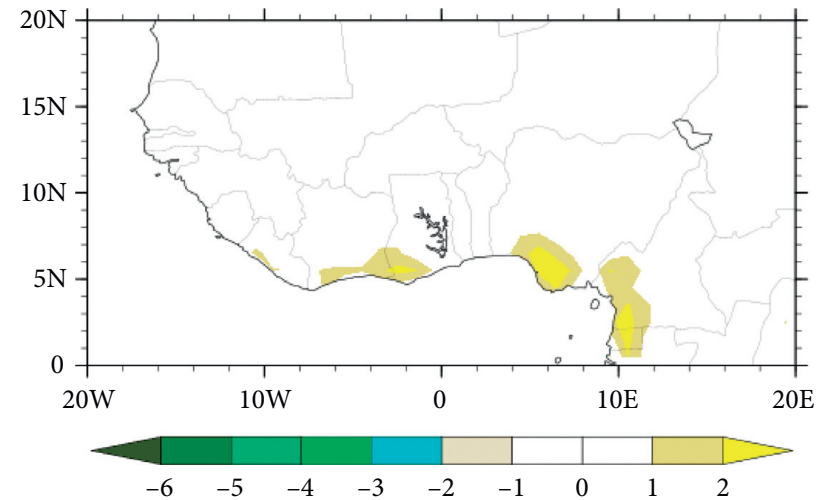

(b)

Figure 10: Continued. 


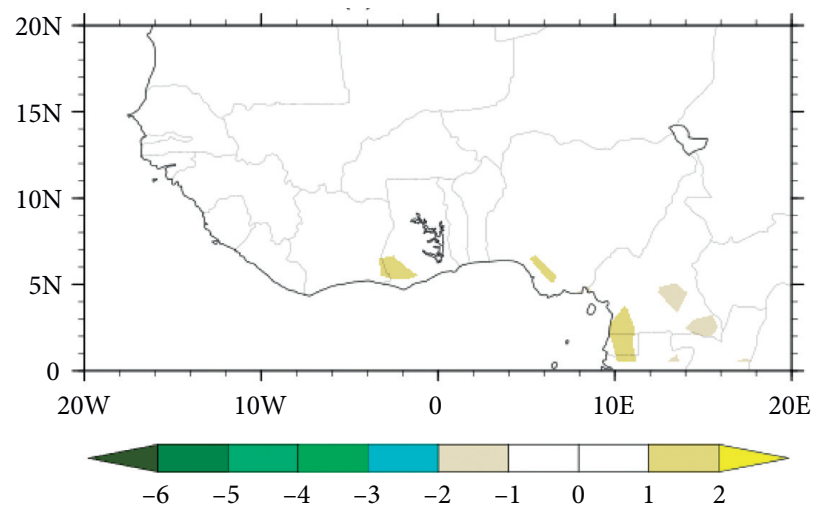

(c)

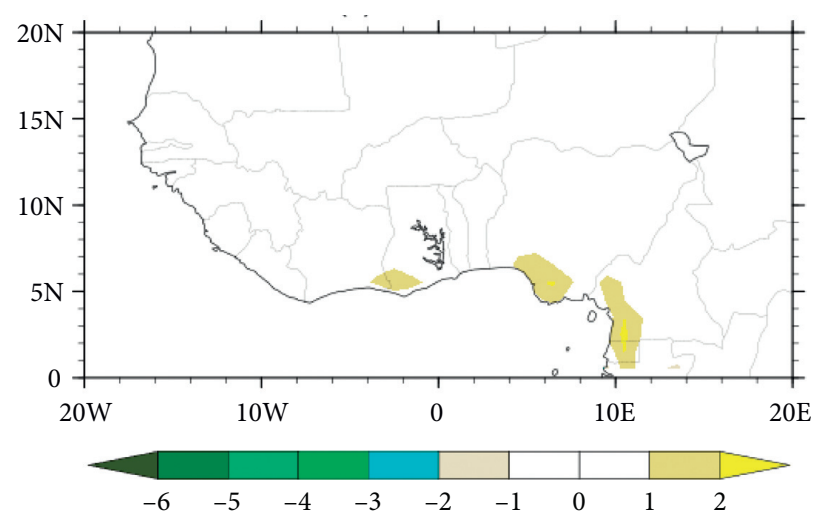

(d)

FIgURe 10: Spatial bias of precipitation for Dec. $16^{\text {th }}, 2011-F e b .28^{\text {th }}, 2012$. (a) Noah-MP groundwater option-TRMM. (b) Noah-MPTRMM. (c) Noah-TRMM. (d) CLM4-TRMM.

pressure region, which develops during the summer, linked with high insolation and seasonal surface temperatures. However, the lower bias prevalent for Noah-MP and NoahMP GW than Noah in areas between latitude $11^{\circ}$ and $14^{\circ} \mathrm{N}$ (which falls to the Savanna region) shows that the inclusion of a dynamic vegetation and groundwater process (as in the Noah-MP GW) can improve the simulation of temperature over this semiarid region of West Africa to some extent especially during the monsoon season. But, the area within $15^{\circ} \mathrm{N}$ and $20^{\circ} \mathrm{N}$ (the Sahel-Sahara interface) showed high positive bias more than any other region.

Figure 11(a) shows that the model precipitation patterns agree with the reference in some instances and disagree in others. All the model simulations were completely in disagreement with TRMM on July $20^{\text {th }}$ and $21^{\text {st }}$, August $2^{\text {nd }}$ and $24^{\text {th }}$, and September $1^{\text {st }}$. All the series have a similar pattern with the reference aside from the listed points. There was a clear overestimation from Noah-MP GW option on $21^{\text {st }}$ of August. From Figure 11(b), the simulated precipitation pattern disagrees with the reference on $29^{\text {th }}$ of January and $22^{\text {nd }}$ of February but has a similar pattern in other periods. The very little or no precipitation notable for this period of the year in the region was well captured in all the models.

From the table showing the average values of the reference and all the model outputs (Table 2), it can be seen that most of the simulations have average values close to the observed value both for rainy and dry season except for precipitation with a little wide range in some instances. Also, Noah LSM gives a little different average value from other LSM, which could be related to the fact that it is the least sophisticated LSM among the ones under the study. However, the change in WRF LSM does not significantly change the average output of temperature over the area, and this could mean that the differences in some values might be as a result of atmospheric changes and also the data used for the initial and boundary conditions. The Noah MP and the GW option better simulates the minimum temperature than the other LSMs. According to Niu et al. [77] and Milovac et al. [100], the reason for this could be attributed to the high values of exchange coefficient in the Noah as compared with
Noah MP. The high exchange coefficient leads to stronger ventilation from the surface and results in stronger surface cooling in the case of Noah [55]. The high exchange coefficient in Noah can overcome the blocking of ventilation by the moisture and create high temperature during the JAS season. During the DJF season, the temperature simulated by Noah MP was higher than that from Noah. For the JAS season, the Noah MP and Noah-MP GW simulated wetter condition that corresponds to a lower surface temperature than that from Noah. The mechanism behind this will be explained better in Section 3.2.

Using the same frequency and data as used in Figures 6 and 11 (i.e., daily averaged data series), Taylor diagrams [95] were used to evaluate the models performance in comparison with the ERA-interim (for surface temperature) and TRMM (for precipitation). The $2 \mathrm{~m}$ temperature and precipitation outputs from the eight different WRF runs at $12 \mathrm{~km}$ resolution for rainy (JAS) and dry (DJF) seasons with four different land surface schemes and options are compared in the diagrams as shown in Figures 12(a) and 12(b). For precipitation (Figure 12(a)), the correlation coefficient for dry season rainfall ranges from 0.69 to 0.74 for the simulations, while the GPCP has a correlation coefficient of 0.95 . Standard deviations range from 0.62 to 1.48 for the simulations. For the rainy season precipitation over the whole region, the correlation coefficient ranges from 0.09 to 0.22 for the models and 0.94 for the GPCP. The possible reason the correlation coefficients in surface air temperature are generally higher than those of precipitation is because precipitation is more variable in time and harder to simulate precisely [101]. According to Chotamonsak et al. [102] and Chawla et al. [103], the deficiency of rainfall simulation with regional climate models is generally a common occurrence. This results from the inability of the models to adequately tackle complex biogeochemical and biogeophysical processes [104] and the nonlinear interaction of the microphysics, cumulus, and planetary boundary layer schemes. Also, poor correlations with summer rainfall in major parts of the Guinea coast subregion in West Africa have also been 


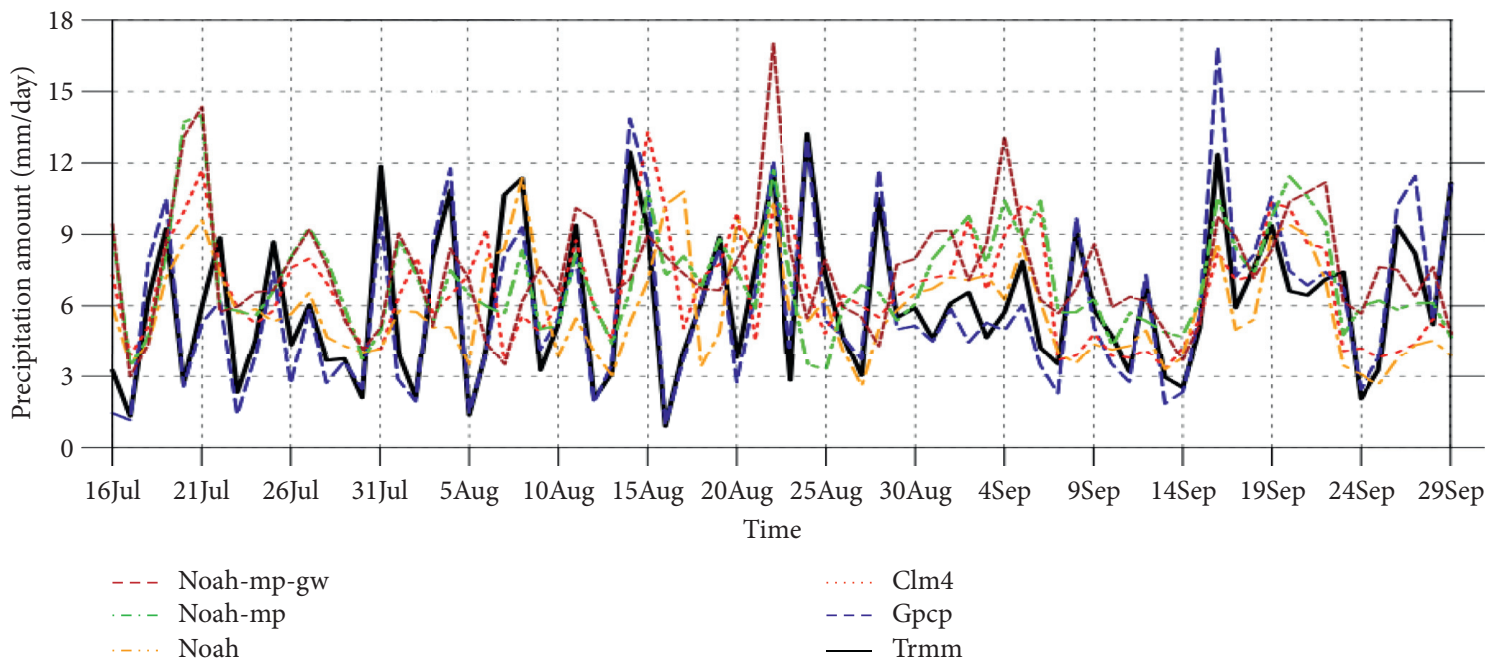

(a)

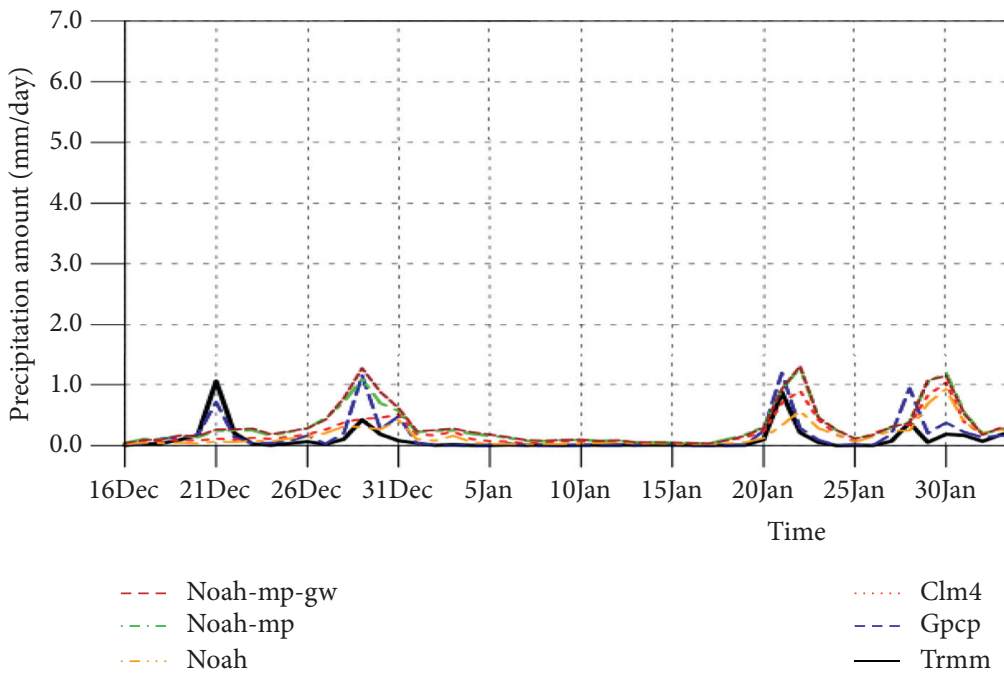

(b)

FIGURE 11: Time series of daily precipitation averaged over $10^{\circ} \mathrm{W}-10^{\circ} \mathrm{E}$ and $5^{\circ}-15^{\circ} \mathrm{N}$ : (a) JAS; (b) DJF.

TABLE 2: Average reference and simulations for temperature and precipitation.

\begin{tabular}{|c|c|c|c|c|c|}
\hline Variable & REF & Noah & CLM4 & Noah-MP & Noah-MP GW \\
\hline Air temperature $\left({ }^{\circ} \mathrm{C}\right) \mathrm{DJF}$ & 25.00 & 23.98 & 26.15 & 25.39 & 25.45 \\
\hline Air temperature $\left({ }^{\circ} \mathrm{C}\right) \mathrm{JAS}$ & 25.08 & 25.66 & 25.71 & 25.38 & 25.19 \\
\hline Precipitation (mm/day) DJF & 1.35 & 1.02 & 1.39 & 1.71 & 1.71 \\
\hline Precipitation (mm/day) JAS & 6.11 & 5.89 & 6.68 & 7.10 & 7.50 \\
\hline Min. temperature $\left({ }^{\circ} \mathrm{C}\right) \mathrm{DJF}$ & 22.14 & 20.8 & 23.6 & 22.56 & 22.65 \\
\hline Max. temperature $\left({ }^{\circ} \mathrm{C}\right) \mathrm{DJF}$ & 28.52 & 27.59 & 29.11 & 28.31 & 28.31 \\
\hline Min. temperature $\left({ }^{\circ} \mathrm{C}\right)$ JAS & 23.97 & 24.66 & 24.7 & 24.43 & 23.89 \\
\hline Max. temperature $\left({ }^{\circ} \mathrm{C}\right)$ JAS & 26.49 & 26.62 & 27.82 & 27.2 & 26.56 \\
\hline
\end{tabular}

suggested to be due the region's complexity associated with orographic and Atlantic Ocean Sea Surface Temperature (SST) influences [105]. Standard deviations range from 1.6 to 2.13 for the models and 0.8 for GPCP. Therefore, there were higher standard deviations for precipitation during the rainy season, whereas there were higher values for surface air temperature during the dry season. Rainy season precipitation is best simulated with the Noah-MP GW, while CLM4 and Noah-MP almost performed equally for dry season precipitation simulations over the study region.

For the $2 \mathrm{~m}$ temperature (Figure 12(b)), FNL shows a high correlation coefficient of 0.98 , while the simulations 


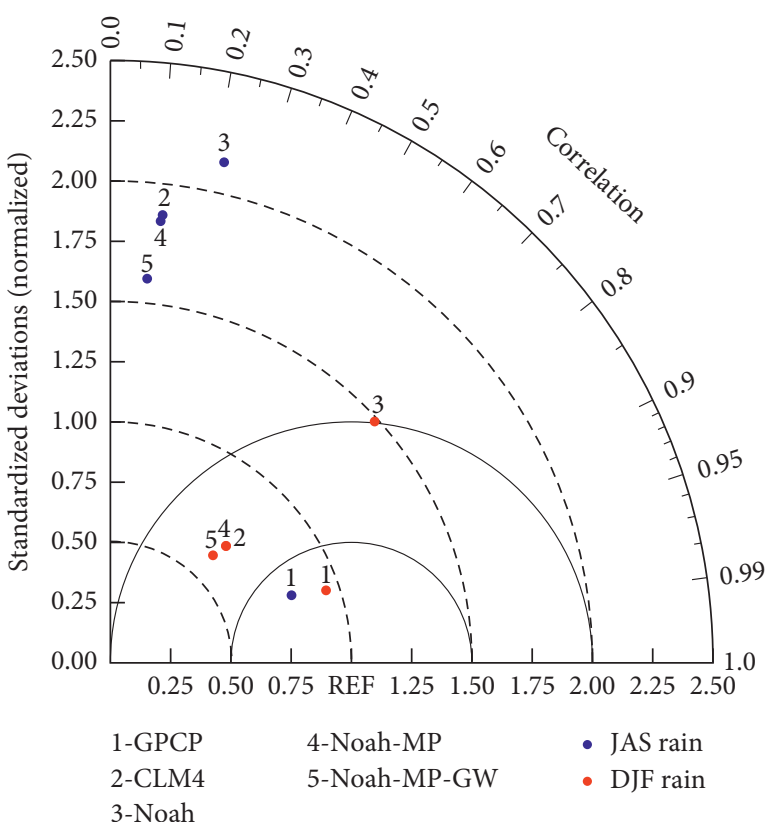

(a)

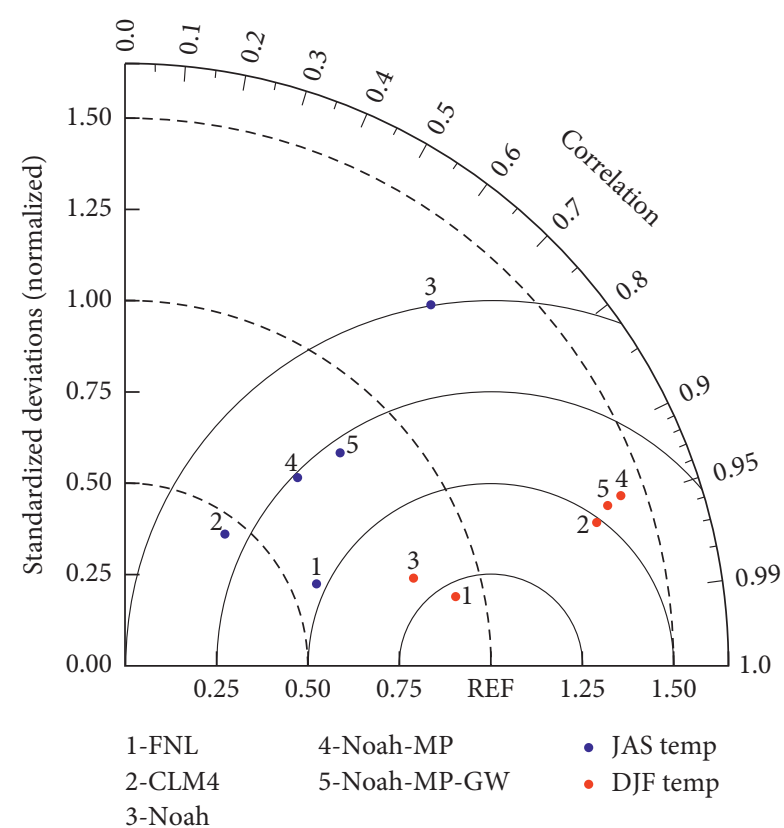

(b)

FIgURE 12: Taylor diagrams for comparison: (a) precipitation (REF is TRMM); (b) surface air temperature (REF is ERA-Interim) (blue colours are for the rainy season and red colours are for dry season). The RMS error and the standard deviation have been normalized according to [95] before plotting the Taylor diagram.

correlation coefficient ranges between 0.96 and 0.95 during the dry season. The standard deviation ranges from 0.87 to 1.48 for the simulations during the dry season and from 0.45 to 1.30 for the rainy season. Noah LSM however performs best in simulating the dry season surface air temperature while the Noah-MP GW option performs best in simulating the rainy season surface air temperature. On average, from the four compared schemes based on the analysis of $2 \mathrm{~m}$ temperature and precipitation, Noah-MP GW best simulates the rainy season events while CLM4 is good for dry season events over the region.

Although each LSM performed well for some variable and worse for others, but with a view to get the overall best performing LSM for all parameters as shown in Tables 3 and 4 below, a score table was formulated for each set of variables as named A, B, C, and D. Four points were assigned to each model that performed best for each variable, three were assigned for model that came second, two for third, and one for the worst performing model, i.e., fourth position. Noah got the highest score for DJF $2 \mathrm{~m}$ temperature, CLM4 got the highest for DJF precipitation, and Noah-MP GW got the highest score for JAS $2 \mathrm{~m}$ temperature and JAS precipitation. Based on the two most important meteorological parameters, Noah-MP GW is the overall best for all the variables and seasons in combination. However, if this is based on the JAS season (the monsoon season), then Noah-MP GW comes first, Noah-MP second, CLM4 came third, and Noah came fourth. This is also the most important season for weather and climate studies over the region as it is the period for crop growing as most farmers depend on the monsoon rainfall for agricultural activities due to poor mechanised farming and irrigation practices.

\subsection{Mechanism behind the Response of the LSMs}

3.2.1. Atmospheric Circulation. As a means to understand some of the mechanism behind the differences in the simulations with the LSMs, it is necessary to examine the atmospheric circulation and the main mechanism of moisture transport for the West African Monsoon (WAM). The WAM circulation is forced by the Sahara heat low (SHL) $[17,49]$ and the connected midtropospheric high. The SHL drives the near surface and moistened southwesterly winds migrating from the Gulf of Guinea and the high associated with the heat low in turn drives the African Easterly Jet (AEJ), which transports moisture westward out of the Sahel region into the Atlantic Ocean [106, 107]. According to Hagos et al. [61], the meridional temperature gradient together with the dry north-easterlies determines how far north the moisture is transported through the low-level south-westerlies, the latitudinal location of the AEJ, and finally the Sahel precipitation. So, the position and strength of the AEJ could influence the large-scale circulation over West Africa [49]. Also, at about $200 \mathrm{hPa}$, there exists the Tropical Easterly Jet (TEJ), which is associated with the South Asian monsoon outflow and propagates across West Africa during boreal summer [105]. Grist and Nicholson [108] have observed a weaker AEJ shifted to the north and stronger TEJ when rainfall is above average over the Sahel. Furthermore, the southwesterly monsoon wind flow at about $850 \mathrm{hpa}$ is the main source of moisture that migrates from the Atlantic Ocean into West Africa. The strength and position of these systems are known to affect precipitation over West Africa [109] and also affects other connected parameters. 
TABle 3: Positions of each model in regards to their performance.

\begin{tabular}{|c|c|c|c|c|c|}
\hline & Variable & Noah & Noah-MP & Noah-MP-GW & CLM4 \\
\hline 1 & DJF $2 \mathrm{~m}$ temperature & $1^{\text {st }}$ & $4^{\text {th }}$ & $3^{\text {rd }}$ & $2^{\text {nd }}$ \\
\hline 2 & DJF precipitation & $4^{\text {th }}$ & $2^{\text {nd }}$ & $3^{\text {rd }}$ & $1^{\text {st }}$ \\
\hline 3 & JAS $2 \mathrm{~m}$ temperature & $4^{\text {th }}$ & $2^{\text {nd }}$ & $1^{\text {st }}$ & $3^{\text {rd }}$ \\
\hline 4 & JAS precipitation & $4^{\text {th }}$ & $2^{\text {nd }}$ & $1^{\text {st }}$ & $3^{\text {rd }}$ \\
\hline
\end{tabular}

TABLE 4: Score table.

\begin{tabular}{lcccccc}
\hline & $(\mathrm{A})$ & $(\mathrm{B})$ & $(\mathrm{C})$ & $(\mathrm{D})$ & Total & Score \\
\hline Noah & 4 & 1 & 1 & 1 & 3 & $4^{\text {th }}$ \\
Noah-MP & 1 & 3 & 3 & 4 & 10 & $3^{\text {rd }}$ \\
Noah-MP GW & 2 & 2 & 4 & 4 & 12 & $1^{\text {st }}$ \\
CLM4 & 3 & 4 & 2 & 2 & 11 & $2^{\text {nd }}$ \\
\hline
\end{tabular}

(A) DJF $2 \mathrm{~m}$ temperature, (B) DJF precipitation, (C) JAS $2 \mathrm{~m}$ temperature, (D) JAS precipitation.

From Figure 13, the core of the TEJ is located approximately at around $200 \mathrm{hPa}$ in all the model runs. However, there are noticeable differences in terms of the strength of the TEJ, which is strongest in Noah-MP GW and Noah-MP (>16 m/s) compared with CLM4 and Noah (about $14 \mathrm{~m} / \mathrm{s}$ ). This suggests that the inclusion of the new option with interactive groundwater introduced into Noah-MP has the tendency to affect the simulation as West Africa and mostly the semiarid area of the region has a strong landatmosphere interaction (i.e., any change in land properties has a strong influence on the atmospheric conditions). Also, this interaction could increase the soil moisture and increase the latent heat fluxes/evapotranspiration that eventually affects the water vapour and cloud development, leading to precipitation increase as stronger TEJ enhances deep convection, which implies intensified precipitation.

For the AEJ, the strength of the jet $(\sim 8 \mathrm{~m} / \mathrm{s})$ is almost the same across the four simulations and the core is located around $600 \mathrm{hPa}$. There are, however, slight differences in terms of the latitudinal position of the core as AEJ lies around $12^{\circ} \mathrm{N}$ in Noah, the southernmost, and Noah-MP GW resides around $15^{\circ} \mathrm{N}$, the northernmost. This explains the reason why the model simulates low-level monsoon flow in Noah and a more enhanced flow in Noah-MP GW. This could be a reason for the dryer Sahel in Noah LSM, as the AEJ is known to transport more moisture out of the Sahel region and reduce precipitation. This is in line with the findings of Abiodun et al. [110] and Hagos et al. [61]. Figure 14 shows the low-level $(850 \mathrm{hpa})$ wind vector and geopotential height from the simulations using the four LSMs for JAS period. It shows that Noah-MP GW and Noah-MP simulations have stronger influx of moisture advection from the southwesterly monsoonal wind than the CLM4 and Noah with Noah showing the least influx. This is evident as the flow from Noah-MP GW and Noah-MP goes further into the north than that from CLM4 and Noah. Therefore, the weaker influx could also be a good reason why the 1-3 $\mathrm{mm} /$ day precipitation belt stopped around $16^{\circ} \mathrm{N}$ for Noah and $17^{\circ} \mathrm{N}$ in CLM4, while that of Noah$\mathrm{MP}$ and Noah-MP GW extended up to $19-20^{\circ} \mathrm{N}$ as shown in Figure 7. Hence, the characteristics of the two easterly jets (AEJ and TEJ) and monsoon flow (at $\sim 850 \mathrm{hPa}$ ) in Noah-MP GW therefore provide the necessary environment for convective activities that favours the production of more rainfall events than other models.

3.2.2. Surface Energy and Soil Moisture. In order to explain more on the reason or mechanism behind the differences as presented, soil moisture, sensible heat flux, and latent heat flux were also analysed. The LSM affects the energy balance at the land surface, which afterward affects the atmospheric conditions through land-atmosphere interactions [19]. In WRF, surface sensible heat (energy for direct heating of the air from the warmer ground) and latent heat (energy for evapotranspiration) fluxes are computed in the LSM and passed to the planetary boundary layer (PBL) and thus influences the simulation of West African Monsoon (WAM). Also, the LSM modulates the energy partitioning between the SH and LH fluxes which has a crucial impact on the atmospheric circulation as demonstrated in a number of studies $[6,17,111,112]$. Latent energy has been stressed to be the main contributor of differences between LSMs [25]. According to [113], higher latent heat fluxes increase the moist entropy flux and the amount of convective available potential energy in the boundary layer, likely increasing the frequency and magnitude of convective rainfall events. The spatial pattern of JAS latent heat fluxes from the four simulations (Figure 15) matches that of precipitation (Figure 7) and soil moisture (Figure 16). Also, the spatial pattern of JAS sensible heat flux from the four simulations (Figure 17) matches that of $2 \mathrm{~m}$ temperature (Figure 2). Furthermore, the spatial pattern of DJF latent heat fluxes from the four simulations in Figure 18 is in line with that of precipitation in Figure 9. From Figure 19, it is seen that the DJF sensible heat is stronger in Noah-MP and Noah-MP GW than other simulations and also higher as seen in Table 5. This could be one of the reasons we have more DJF precipitation in Noah-MP and Noah-MP GW as increase in sensible heat could lead to increased boundary layer heating, increase convective clouds, and could eventually increase convective precipitation.

From Figures 20(a) and 20(b), it is clear that there were differences in the simulated sensible heat and latent heat flux among all the four simulations. The sensible heat flux on 


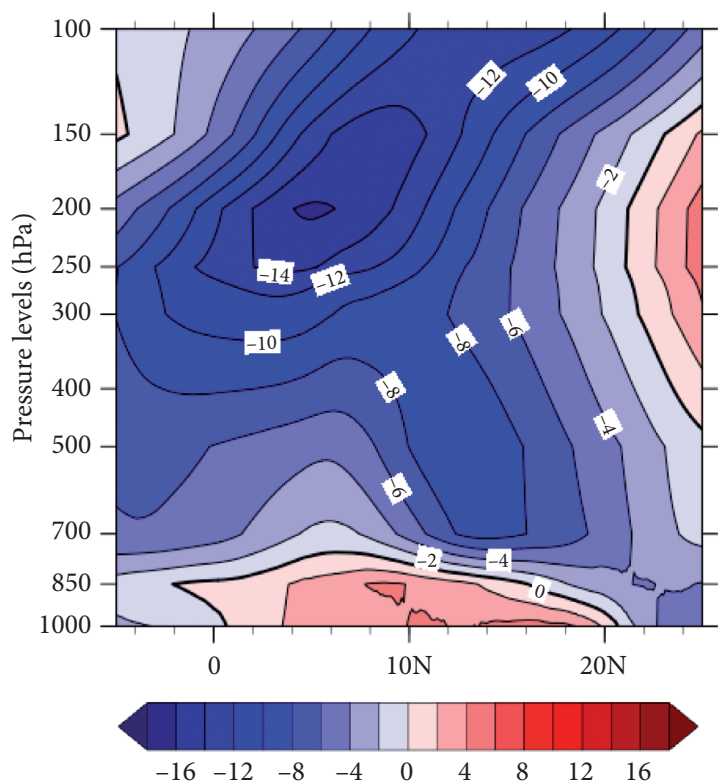

(a)

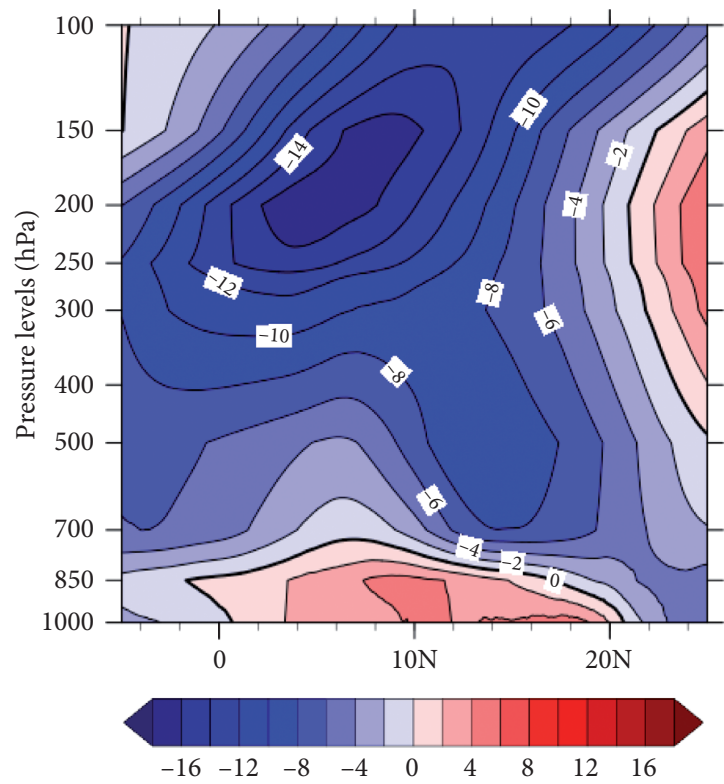

(c)

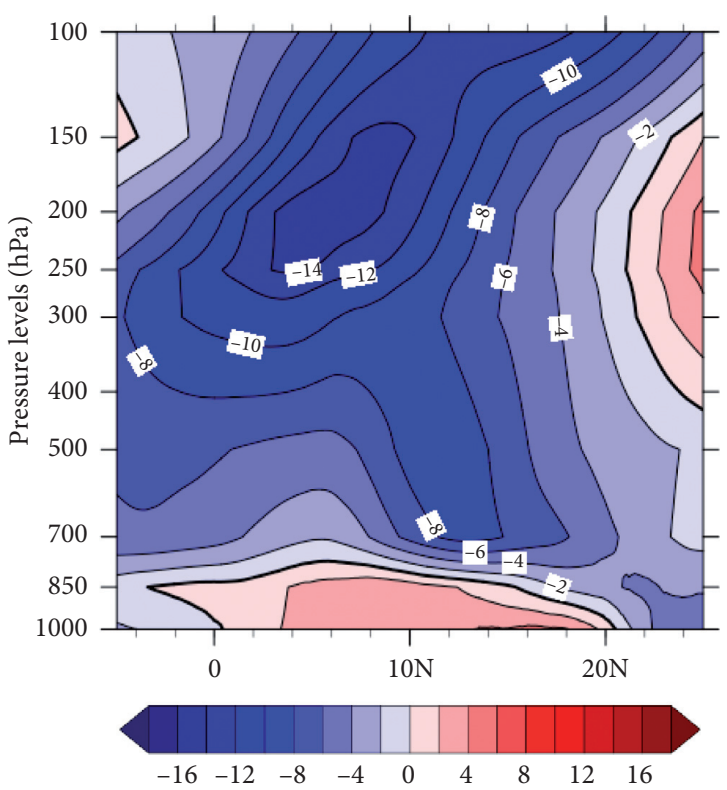

(b)

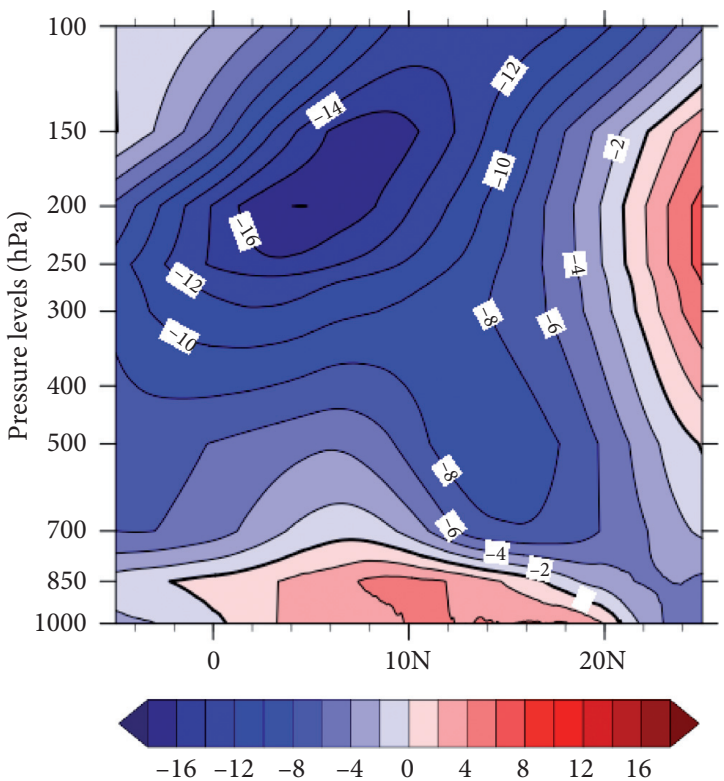

(d)

Figure 13: The vertical cross section of the zonal wind (m/s) over West Africa from July $16^{\text {th }}-$ Sept $29^{\text {th }}$, 2012. (a) CLM4. (b) Naoh. (c) NoahMP. (d) Noah-MP groundwater option.

average increases while the latent heat flux decreases from south to north. This could be due to the effect of the negative gradient in soil moisture from south to north as shown in Figures 16 and 20(d). This is also in line with the findings of Wolters et al. [114]. Also, the meridional variation of sensible heat flux (Figure 20(a)) and temperature (Figure 20(e)) are not very identical. This could be because the temperature is controlled not only by the sensible heat flux but also by advective effects [114]. Figure 20(c) shows the meridional structure of the zonally averaged evaporative fraction (EF). The EF is the ratio of latent heat flux to the sum of the sensible and latent heat fluxes. The southwesterly monsoon flow and local moisture recycling are the principal sources of moisture during the WAM [115]. The latter process contributes about $30 \%$ to the precipitation over the West African subcontinent [116]. From a simple one-dimensional perspective, increased value of evaporative fraction can be linked to higher values of PBL equivalent potential temperature and more favorable conditions for deep convection (e.g., $[117,118])$. Also, according to [61], simulations that show relatively dry conditions of the Sahel tend to shift the steep gradient further to the south and those that are relatively wet shift the gradient further north. This is in line with the sharp gradient from Noah-MP GW and Noah-MP 


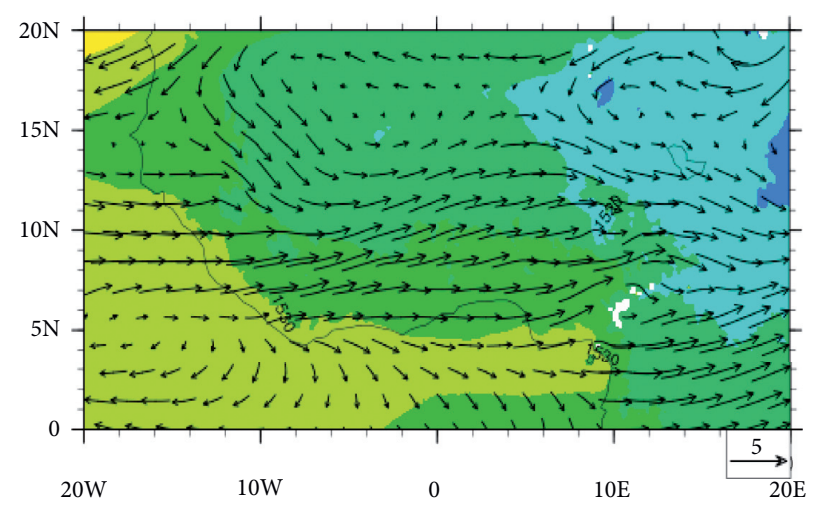

CLM4

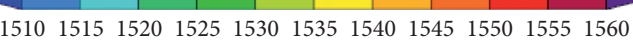

(a)

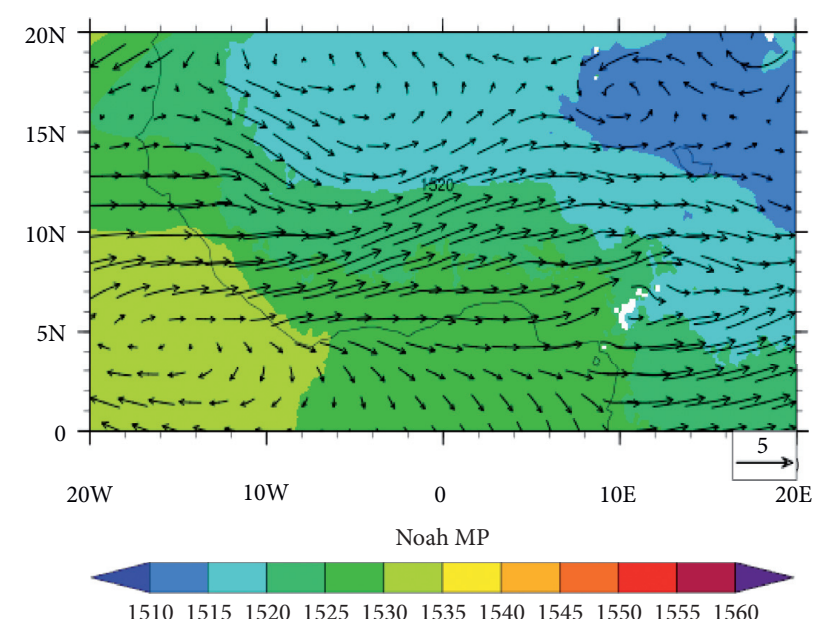

$\begin{array}{lllllllllll}1510 & 1515 & 1520 & 1525 & 1530 & 1535 & 1540 & 1545 & 1550 & 1555 & 1560\end{array}$

(c)

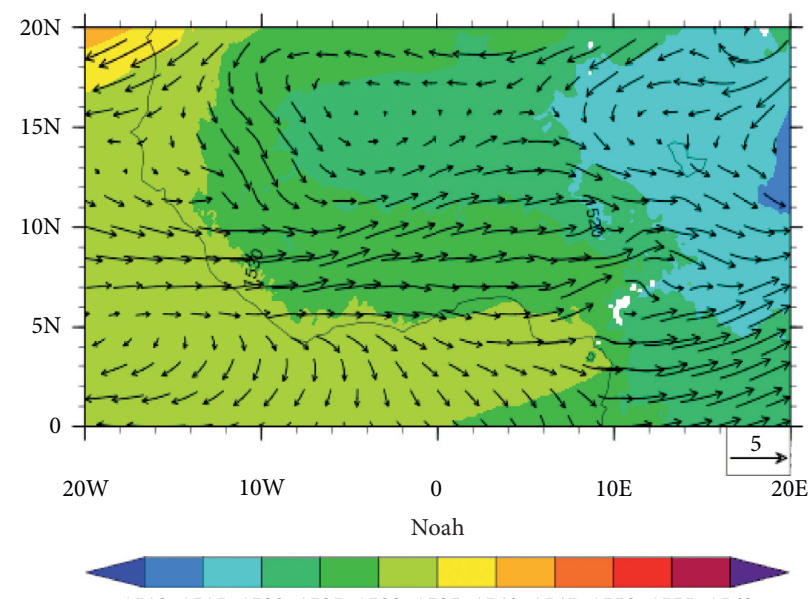

$\begin{array}{lllllllllll}1510 & 1515 & 1520 & 1525 & 1530 & 1535 & 1540 & 1545 & 1550 & 1555 & 1560\end{array}$

(b)

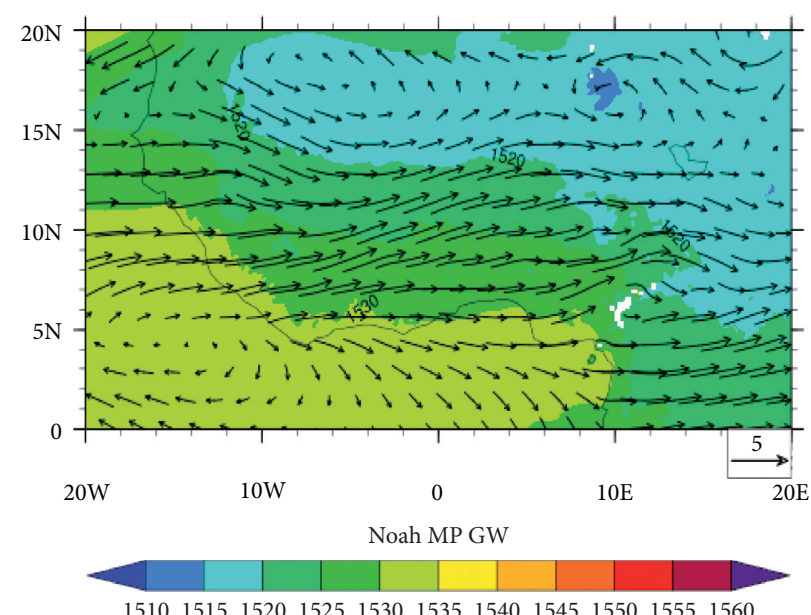

$\begin{array}{lllllllllll}1510 & 1515 & 1520 & 1525 & 1530 & 1535 & 1540 & 1545 & 1550 & 1555 & 1560\end{array}$

(d)

FIGURE 14: Mean JAS wind vectors at the $850 \mathrm{hPa}$ vertical height. Geopotential heights (m) are shown in colours. (a) CLM4. (b) Naoh. (c) Noah-MP. (d) Noah-MP-GW.

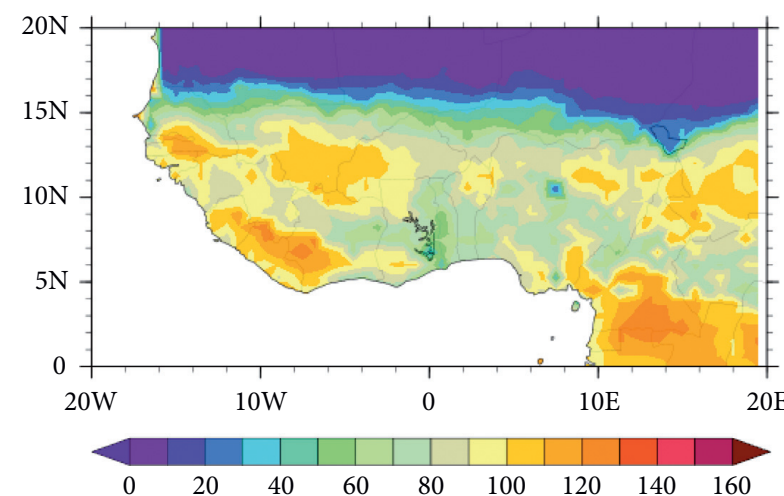

(a)

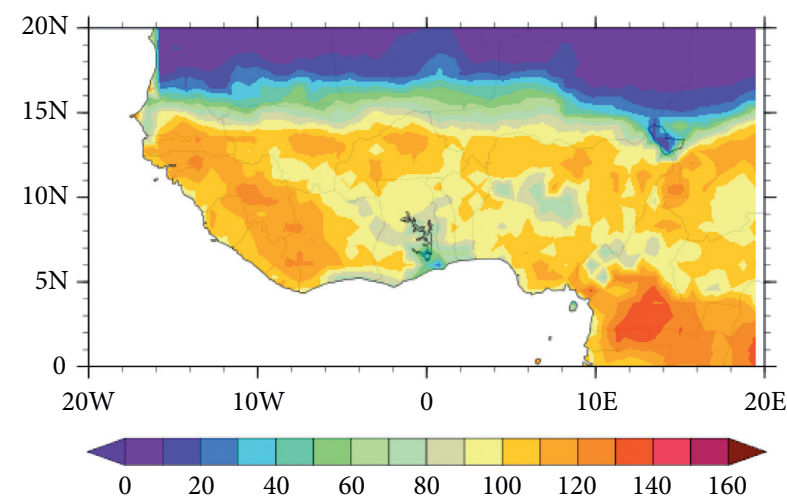

(b)

Figure 15: Continued. 


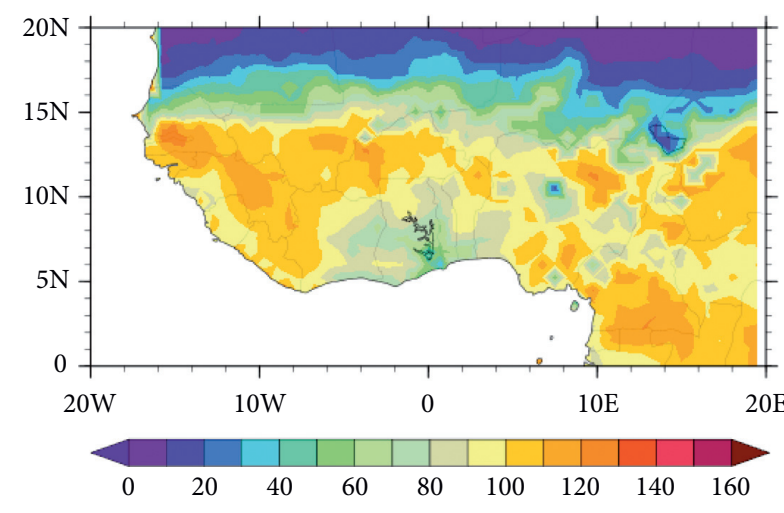

(c)

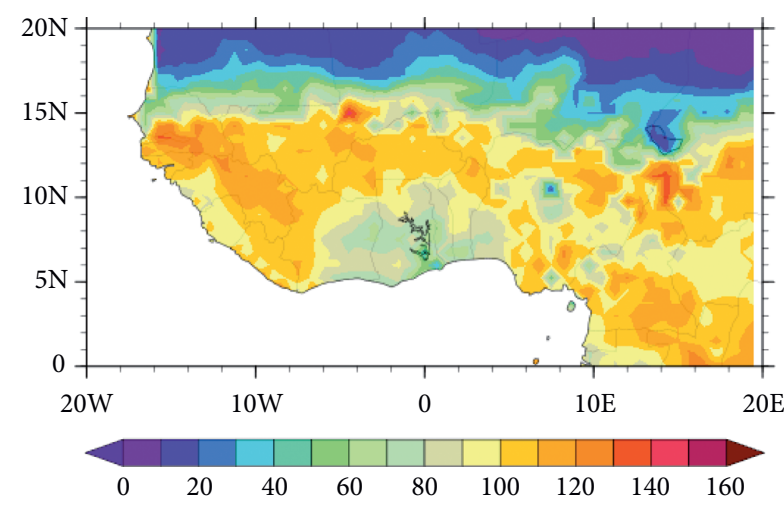

(d)

Figure 15: Spatial distribution of surface latent heat $\left(\mathrm{w} / \mathrm{m}^{2}\right)$ for July $16^{\text {th }}-$ Sept $29^{\text {th }}$, 2012. (a) Naoh. (b) CLM4. (c) NaohMP. (d) NoahMP GW.

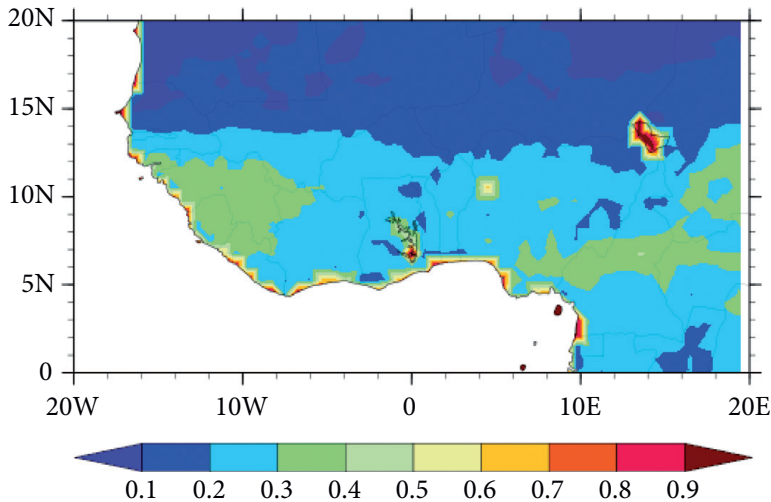

(a)

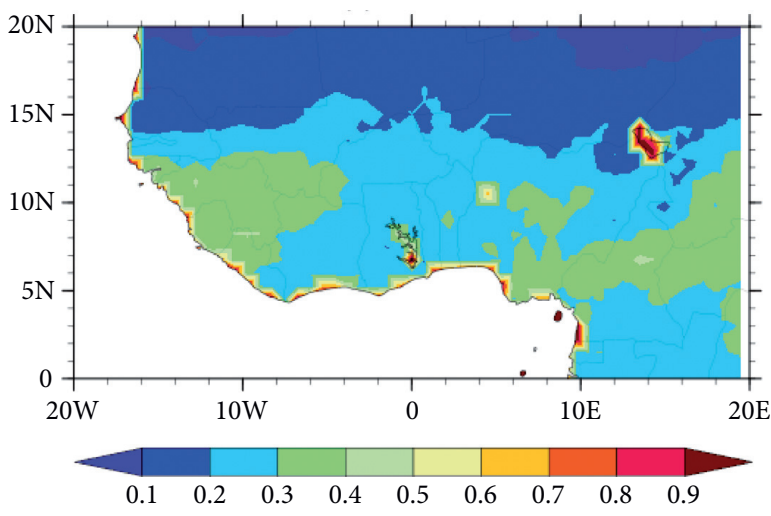

(c)

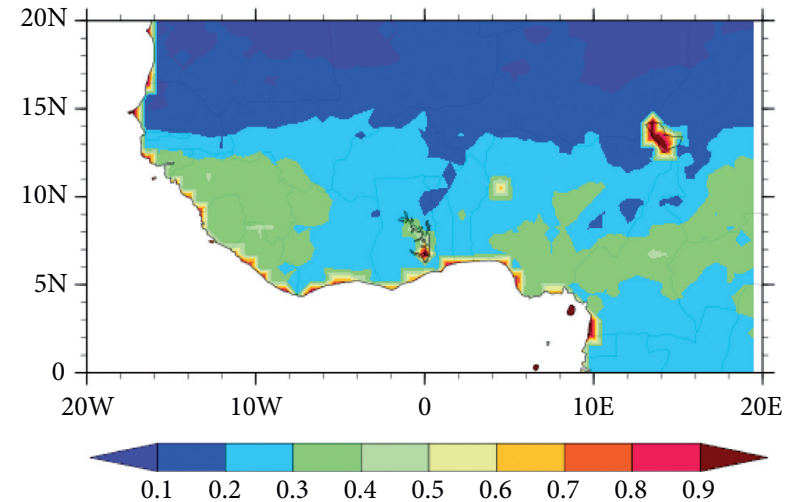

(b)

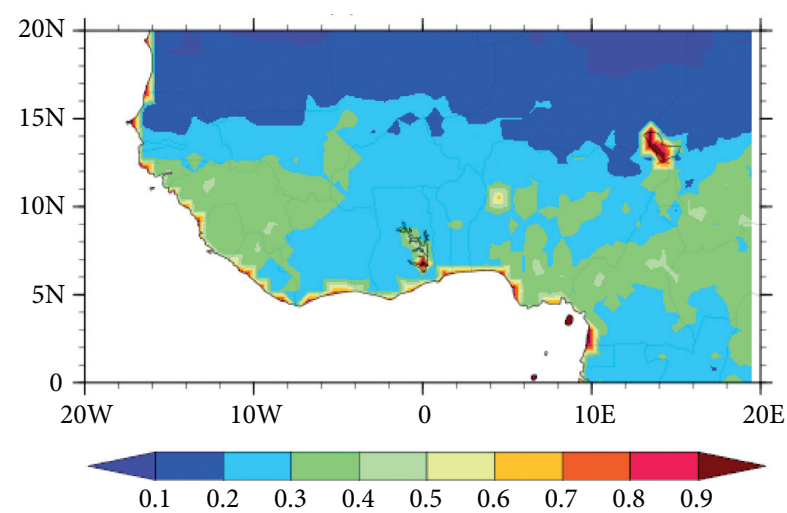

(d)

FIGURE 16: Spatial distribution of average soil moisture $\left(\mathrm{m}^{3} / \mathrm{m}^{3}\right)$ for July $16^{\text {th }}-$ Sept $29^{\text {th }}$, 2012. (a) Naoh. (b) CLM4. (c) NaohMP. (d) NoahMP GW.

(Figure 20(c)) with wetter Sahel further to the north and for Noah, which is further to the south. The situation with the CLM4 is not in line with this as it is further to the north in the Sahel despite having dryer JAS Sahel than Noah-MP and Noah-MP GW.

Differences in simulated precipitation are probably to cause substantial differences in soil moisture. Also, the vegetation composition is different for all the LSMs, which affects the surface zone soil moisture. From Table 5, averaging the SMOIS for the entire soil column for all the simulations, Noah-MP GW has the highest amount of SMOIS while the CLM4 has the least for both the JAS and DJF seasons. The high soil moisture in Noah-MP GW could be attributed to the effect of the interaction with the ground water. The CLM4 has the highest LH for both DJF and JAS seasons but however has the least SH for both DJF and JAS 


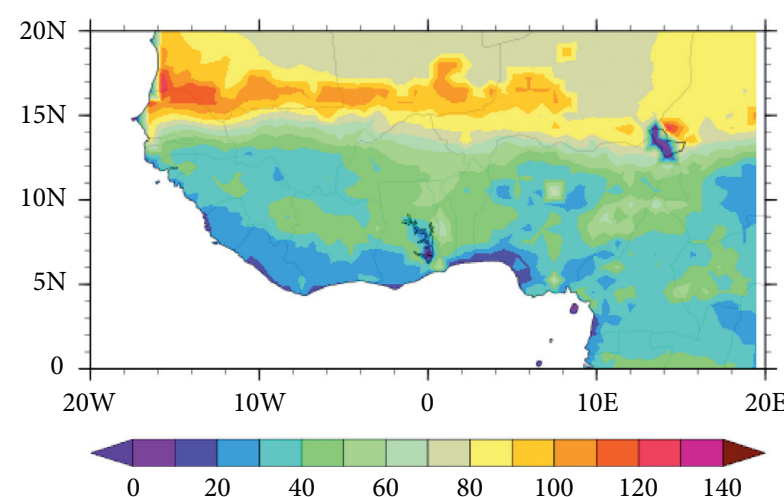

(a)

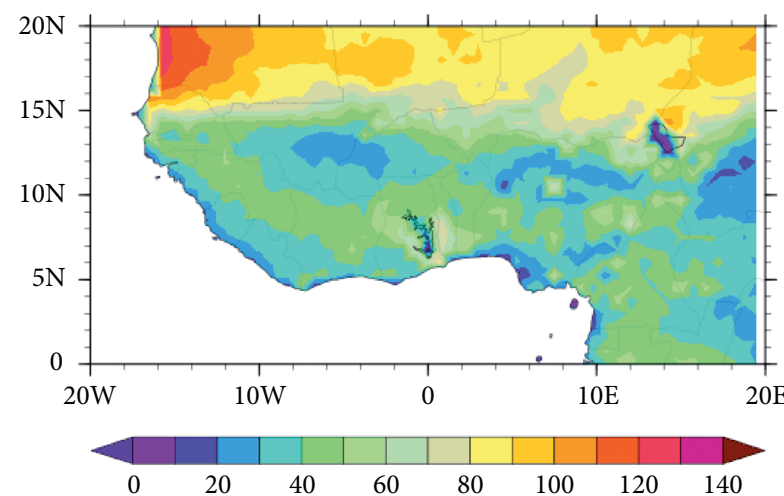

(c)

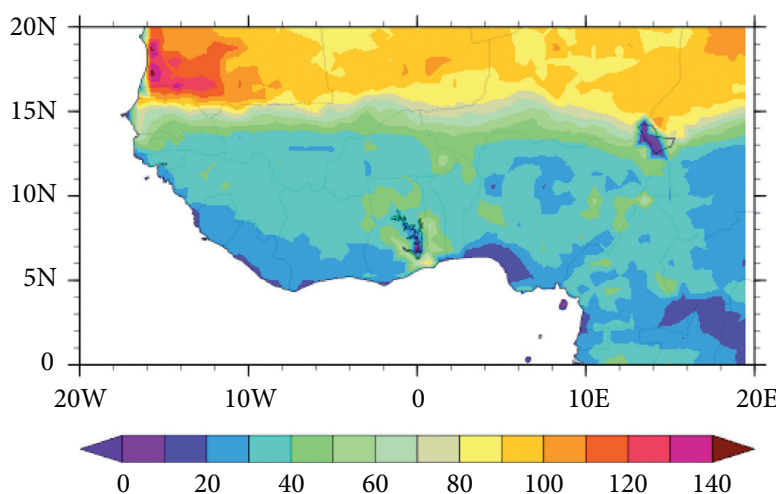

(b)

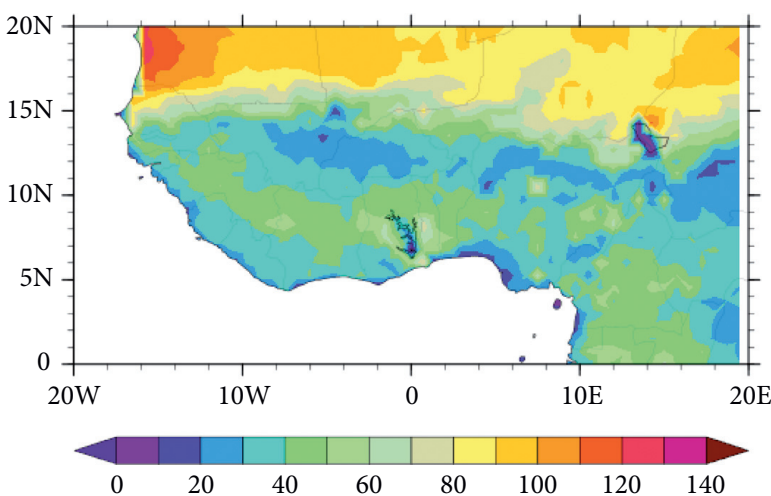

(d)

Figure 17: Spatial distribution of surface sensible heat $\left(\mathrm{w} / \mathrm{m}^{2}\right)$ for July $16^{\text {th }}-$ Sept $29^{\text {th }}$, 2012. (a) Naoh. (b) CLM4. (c) NaohMP. (d) NoahMP GW.

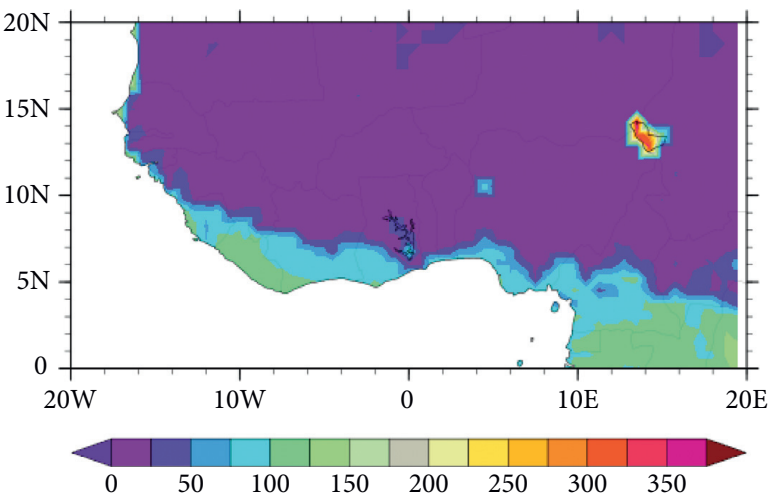

(a)

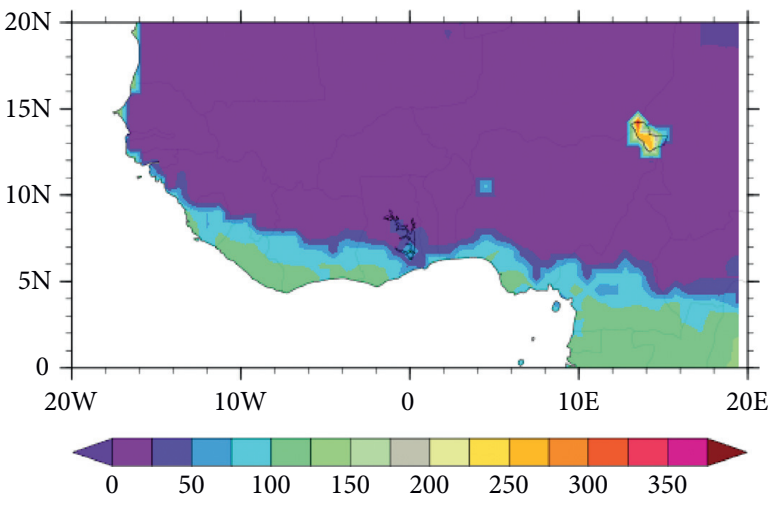

(c)

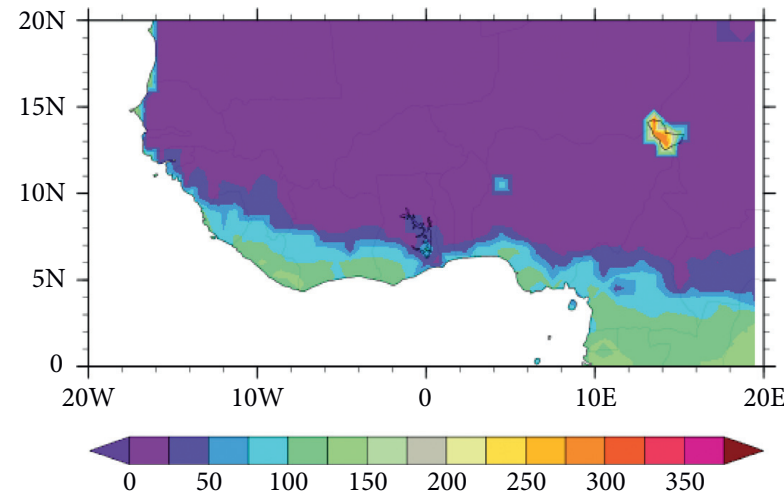

(b)

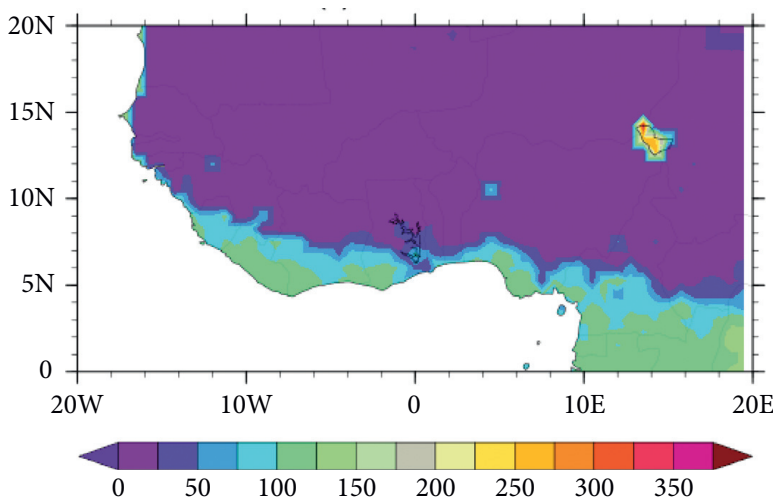

(d)

Figure 18: Spatial distribution of surface latent heat $\left(w / \mathrm{m}^{2}\right)$ for Dec. $16^{\text {th }}, 2011-F e b .28^{\text {th }}$, 2012. (a) Naoh. (b) CLM4. (c) NaohMP. (d) NoahMP GW. 


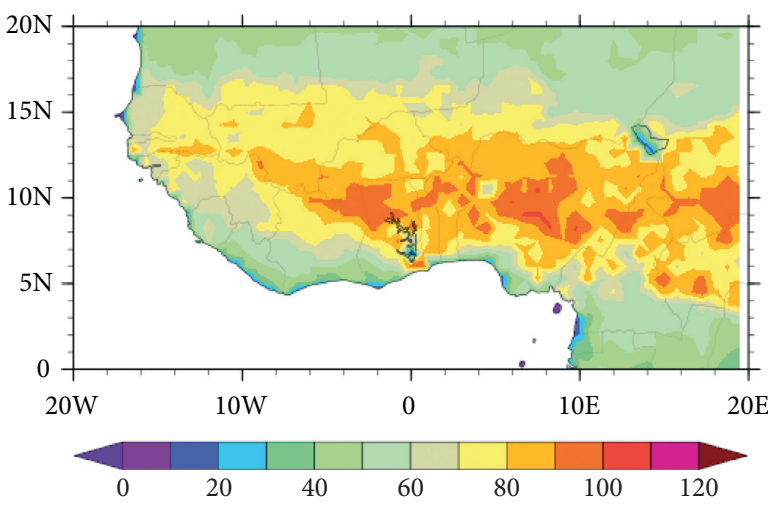

(a)

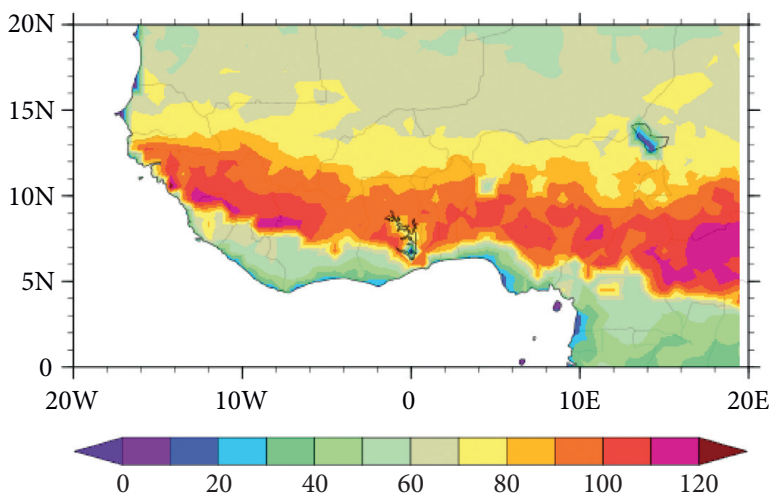

(c)

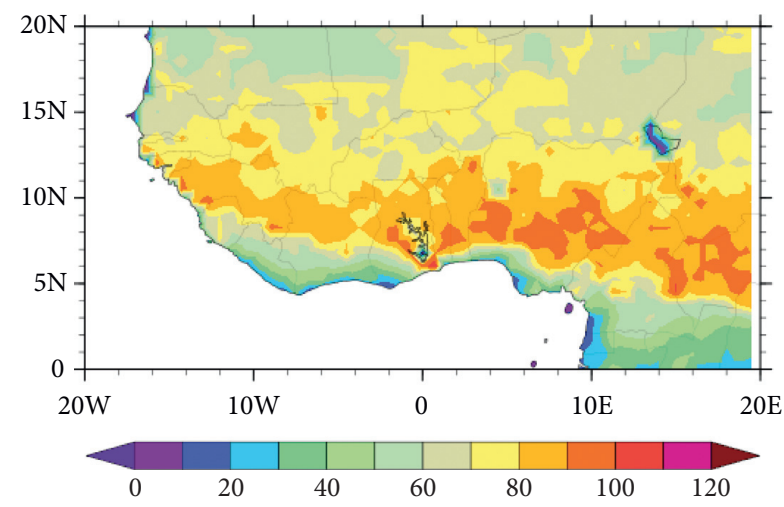

(b)

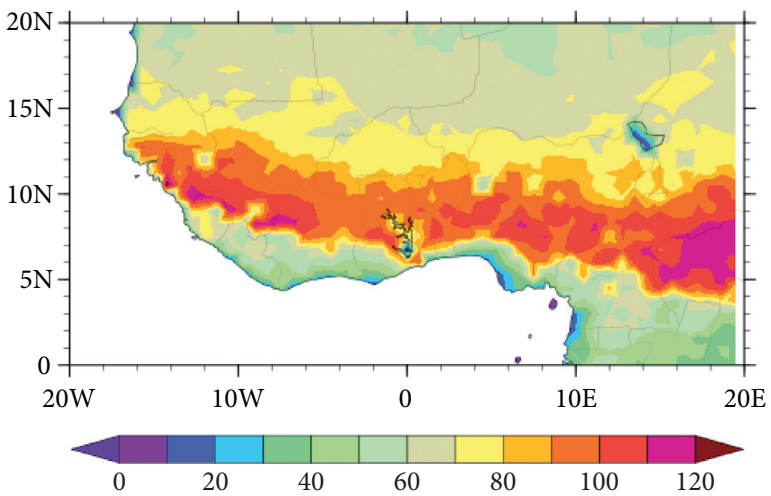

(d)

Figure 19: Spatial distribution of surface sensible heat $\left(\mathrm{w} / \mathrm{m}^{2}\right)$ for Dec $16^{\text {th }}, 2011-F e b 28^{\text {th }}, 2012$. (a) Naoh. (b) CLM4. (c) NaohMP. (d) NoahMP GW.

TABLE 5: Average values of $\mathrm{SH}, \mathrm{LH}$, and soil moisture (SMOIS) over $10^{\circ} \mathrm{W}-10^{\circ} \mathrm{E}$ and $5^{\circ}-15^{\circ} \mathrm{N}$.

\begin{tabular}{lcccccccc}
\hline & \multicolumn{3}{c}{ DJF } & & \multicolumn{3}{c}{ JAS } \\
LSMs & CLM4 & Noah & Noah-MP & Noah-MP-GW & CLM4 & Noah & Noah-MP & Noah-MP-GW \\
\hline LH $\left(\mathrm{W} / \mathrm{m}^{2}\right)$ & 30.54 & 29.03 & 26.39 & 27.47 & 96.72 & 83.18 & 90.62 & 92.79 \\
SH $\left(\mathrm{W} / \mathrm{m}^{2}\right)$ & 71.63 & 73.99 & 76.90 & 76.79 & 36.98 & 44.84 & 41.63 & 38.91 \\
SMOIS average for all levels & 0.199 & 0.206 & 0.216 & 0.223 & 0.268 & 0.288 & 0.297 & 0.305 \\
\hline
\end{tabular}

seasons. It could be deciphered that simulations with higher $\mathrm{LH}$ have lower $\mathrm{SH}$ and vice versa.

The Noah scheme has a combined surface layer of vegetation and surface soil, while the Noah MP has a separated ground surface and canopy layer. Also, the bulk layer of snow/surface vegetation and soil associated with the Noah tends to under estimate the heat flux [77]. An important point for a lower sensible heat flux in Noah could be attributed to the underestimation of surface air temperatures during the dry season. The soil moisture considerably influences the latent heat flux, as high part of the surface energy has a tendency to be shared between sensible heat flux and soil heat flux in a dry condition. Just as the soil in most part of West Africa is practically dry in the DJF season in comparison with the JAS season, it leads to a reduction in the amount of latent heat flux in the DJF season. The reduced latent heat flux associated with the dry condition simulated by Noah MP and NoahMP GW would result in corresponding increment in soil heat flux as against CLM4 with the highest LH in both DJF and JAS but still has the lowest soil moisture. The increased soil moisture content as seen in the Noah-MP GW increases the latent heat flux and decreases sensible heat flux and thereby decreases surface temperature as seen in the JAS period. The transmission of intermodel soil moisture differences to the atmosphere happens through the LH. The Noah-MP GW simulations had wetter soil, produced more LH, and had upward transport of aquifer soil water (to upward flux of moisture) in JJA relative to the other Noah and Noah-MP simulations [119].

West Africa is one of the regions on earth having a strong coupling between soil moisture and precipitation [114], and this strong coupling is generally found mostly in transition 

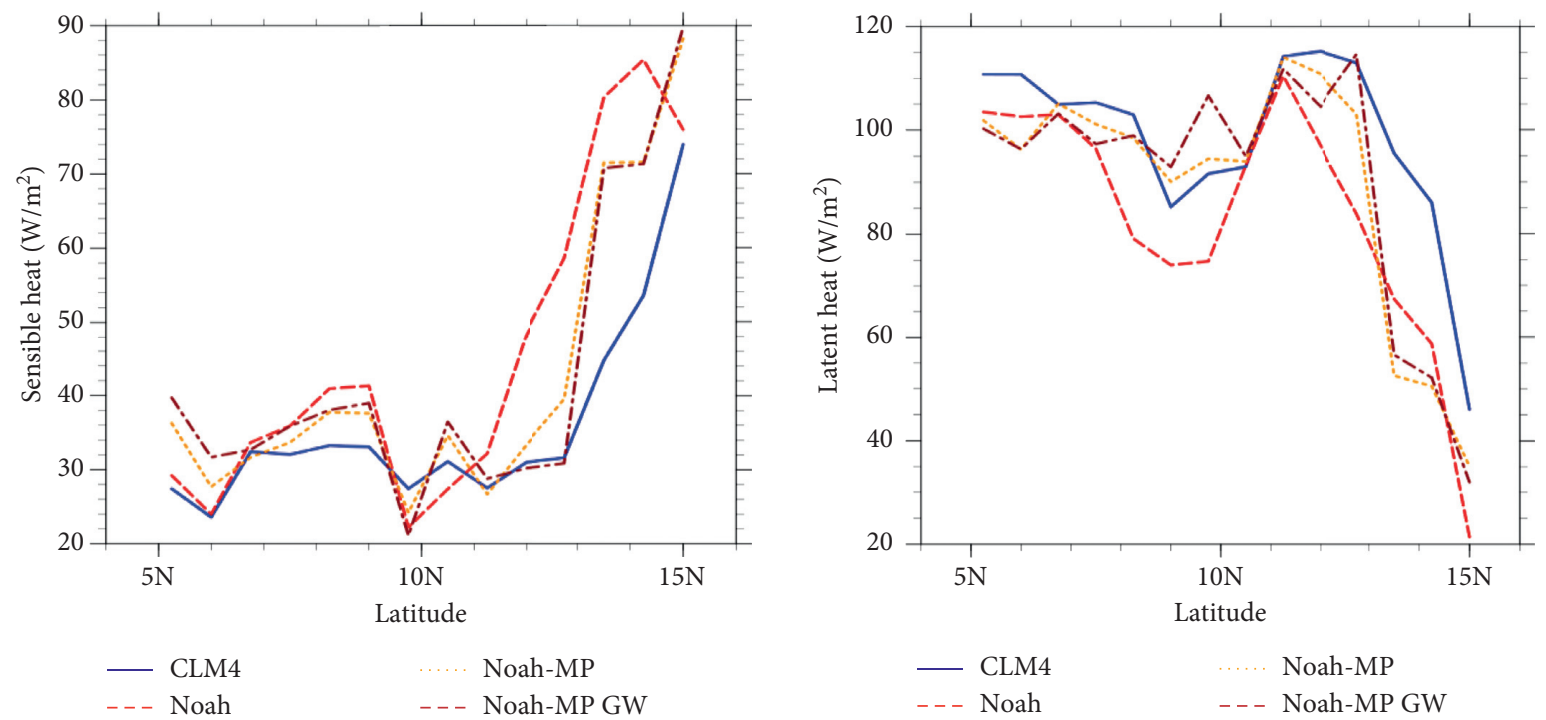

(a)
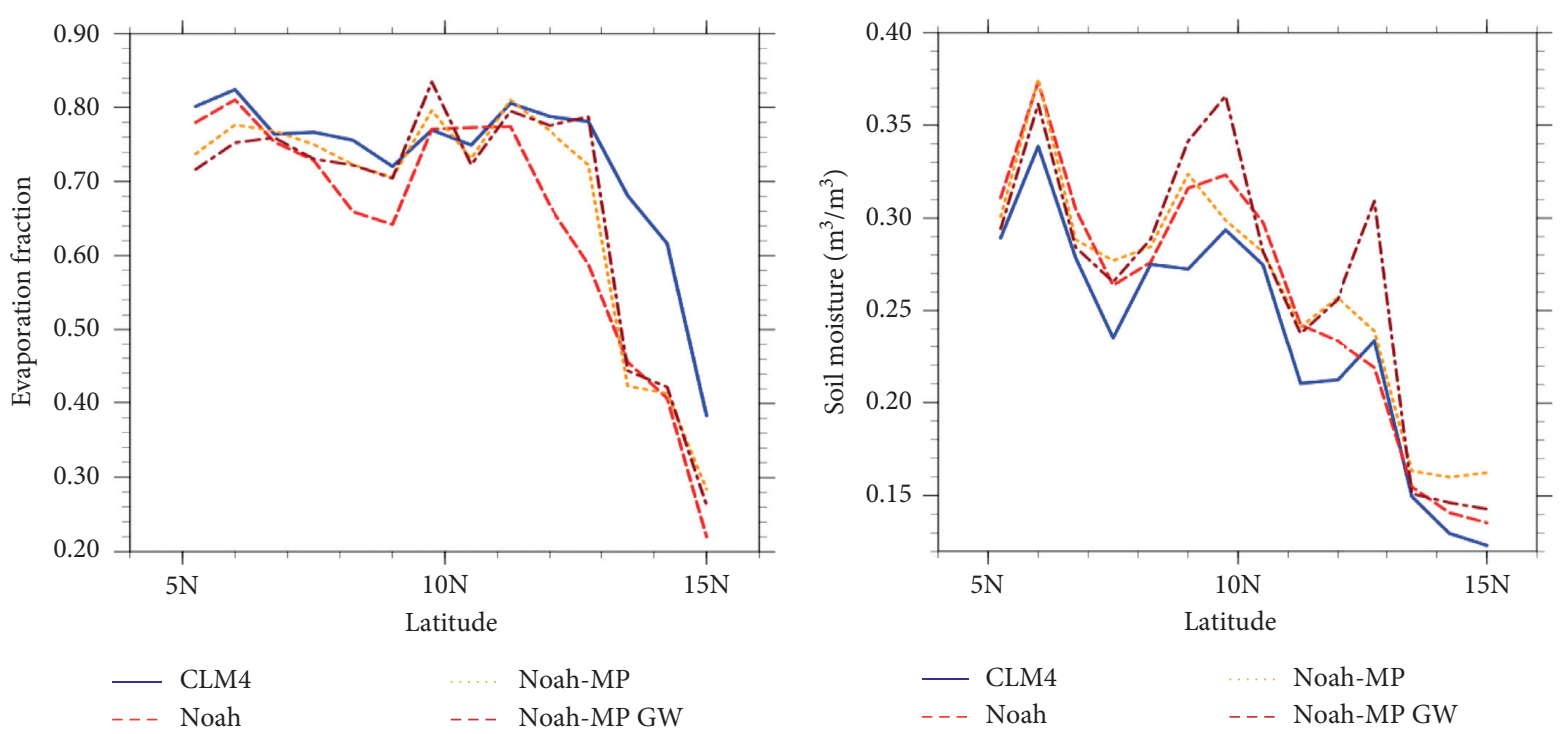

(c)

(d)

FIgUre 20: Continued. 


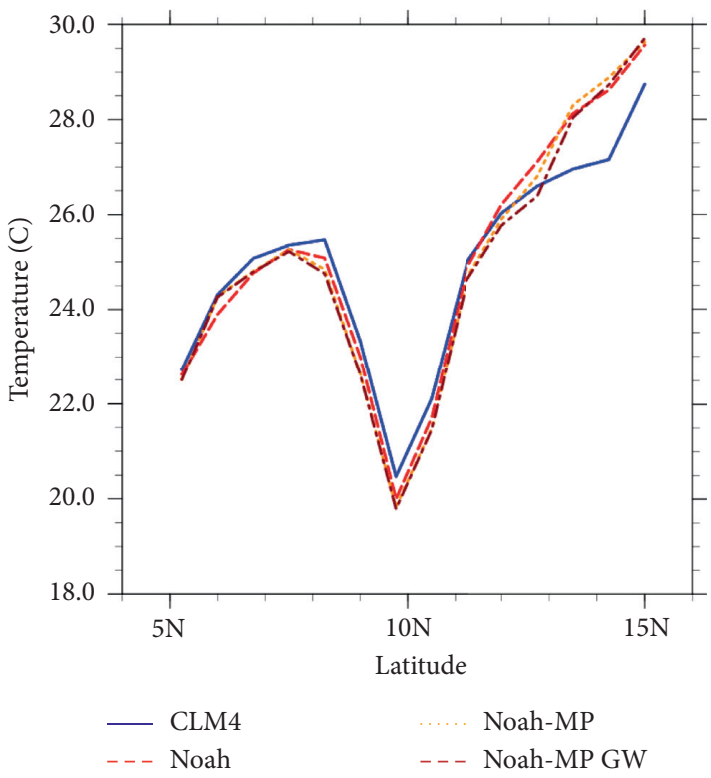

(e)

Figure 20: (a) Sensible heat, (b) latent heat, (c) evaporation fraction, (d) soil moisture, and (e) temperature, averaged over the longitudinal extent of the red box in Figure 1 for the JAS period.

zones between wet and dry climates like the Sahel [10]. The soil moisture controls the albedo and Bowen ratio. Eltahir [118] suggests that a positive feedback mechanism exists between soil moisture and rainfall. According to Wang et al. [120], higher soil moisture increases the latent heat flux, and this is liable to increase the moist entropy flux per unit mass of air and the amount of convective available potential energy in the boundary layer. These processes probably increase the frequency and magnitude of convective precipitation events [113]. According to Steiner et al. [25], during the monsoon season, wetter soils and increased moisture advection could lead to an increase in the release of water vapor to the atmosphere, increasing the amount of latent energy from the surface. Wolters et al. [114] also concluded that soil moisture modifications could influence the $850 \mathrm{hPa}$ flow pattern causing deviations in the path of the squall line over West Africa. These results are in line with the conclusions of Hacker [121], who discussed the influence of soil moisture initialization in NWP on the predictability of winds in the PBL. This is also in line with our findings, as simulation with higher soil moisture tends to have higher precipitation as in the case with Noah, Noah-MP, and NoahMP GW.

Changes in the distribution of roots can dramatically change the amount of soil moisture available to plants to transpire as the increase in root depth could increase water uptake, increase transpiration, increase water vapour, increase cloud formation, and increase rainfall [122]. While evaporation from bare soil and transpiration from short vegetation is mostly dependent on soil moisture conditions in the surface soil layer, tall vegetation can additionally access water in deeper layers [123]. However, despite having the lowest average amount of SMOIS (Table 5), the CLM4 has high average precipitation corroborated with high average LH. This could be explained as CLM4 has total soil depth of about $3.8 \mathrm{~m}$ and thus gives room for deeper penetration of plant roots to access deeper soil moisture, which could influence the LH. This also has the tendency to increase the transpiration and hence could explain why CLM4 has higher LH and EF than other LSMs and higher precipitation than Noah LSM. The difficulty in comparing CLM4 with the other tested LSMs here would be as a result of the differences in mostly the number of soil levels and might bring about some inconsistencies in averaging for better comparison. Also, the high average LH fluxes in CLM4 could lead to a greater evapotranspiration per unit precipitation which tends to return more water to the atmosphere, thereby leading to the drier soils/reduced soil moisture as seen for both DJF and JAS season. However, other factors beyond the scope of this study could be in operation.

Land surface models have become more important in numerical weather prediction models like WRF as more complex and sensitive planetary boundary layer schemes are used. The principal difference between the models is in the vegetation representation, the description, and parameterization of the soil water column in each model. Vegetation substantially influences the exchange of momentum, energy, moisture, and trace gases between the surface and the atmosphere and hence affects all other parameter in one way or the other. Therefore, it is recommended that improvement on the treatment of surface parameters in the models should be paramount, as this will go long in improving the simulations especially in areas of strong land-atmosphere interaction. 


\section{Conclusion}

In all, eight simulations with 4 LSMs (Noah, Noah-MP, CLM4, and Noah-MP GW) using the WRF model were carried out for two sets of 3 months' (December-February 2011/2012 and July-September 2012) period over West Africa. These were done using the 3.9.1.1 version of WRF model to assess the performance of the listed LSMs over West Africa. The models' air temperature was evaluated using ERA-Interim, while precipitation was evaluated using TRMM. In order to provide a succinct statistical summary, the results were plotted in the Taylor diagram.

On average within the red box in Figure 1, CLM4, NoahMP, and Noah-MP GW all overestimated the precipitation during both DJF and JAS seasons, while Noah underestimated it. The strength of the Tropical Easterly Jet (TEJ) is strongest in Noah-MP GW and Noah-MP compared with CLM4 and Noah. The core of the African Easterly Jet AEJ lies at the southernmost position in Noah and northernmost for Noah-MP GW. The Noah-MP GW and Noah-MP simulations have stronger influx of wind than the CLM4 and Noah with Noah showing the least influx. Also, the number of soil layers and the depth was a considerable factor as regards the cause of the differences between the models as CLM4 with higher soil depth behaved differently by having low soil moisture with high latent heat.

The variable of interest is also a factor to be considered in the selection of LSMs. However, each LSM performed differently for different variables as a result of the difference in the model physics, soil layers, and columns, vegetation structure, and level of model sophistication. Therefore, based on precipitation and $2 \mathrm{~m}$ temperatures, Noah-MP GW is the overall best for all the variables and seasons in combination. If this is based on the JAS season (the monsoon season), then Noah-MP GW will also come first, Noah-MP second, CLM4 third, and Noah will come fourth.

The West African Monsoon (WAM) controls the rainy season in West Africa. Researchers like [124] have stressed that it supplies most of the precipitation because it transports rich moisture into the region through the southwest trade wind coming from the Atlantics. However, the WAM is a very complex large-scale circulation system, which entails the interactions of the elements of many scale atmospheric circulations, thereby making the close to accurate simulation of precipitation and other variables in the region a bit more demanding. So long as the improvement of the land surface models can result into a better simulation of the weather parameters, a more in-depth analysis of the impact of the recent WRF land surface models on major features of the general circulation of West Africa which includes the intertropical convergent zone (ITCZ), the monsoon depth and strength, the AEJ, TEJ, and AEW, and the deep convective systems is recommended as a good area for future research.

Precipitation could be better simulated more extensively by testing with several other sets of physics combinations like the radiation schemes, cumulus schemes, microphysics, and planetary boundary layer schemes in the WRF model. Also, a longer period of simulation to accommodate more seasons for better comparison between same seasons across each zone in West Africa could lead to a better simulation. From the study, it can be concluded that differences in land surface have the tendency to alter the weather parameters. Earlier studies have shown that the West African land surface is an important part in the region's climate dynamics. This has been confirmed in this study, as the studied parameters are very sensitive to each LSM used. However, differences between the land use in the model and the actual land use could cause discrepancies in the simulations. Also, the accuracy of initial and boundary conditions is crucial to the successful production of WRF simulations [45] as the difference could propagate through the atmosphere and have an effect on the simulation of the dynamical features in West Africa. Hence, future research would also incorporate a real-time land use data products into the model over West Africa with various initial and boundary conditions and probably compare with an in situ data (if made available) in order to improve the simulations and have a perfect comparison.

Finally, despite having constant roughness length values for all season, Noah-MP still performed better than Noah over West Africa. This could be due to the other improvements and modifications in the model, but the constant roughness length in the model is a factor to look into. This could be a good area for future improvement as to reduce uncertainties in the model for better simulations and forecasts.

\section{Data Availability}

The data used for the research are archived in the NCAR HPSS storage. This could only be made available from the corresponding author upon reasonable request.

\section{Conflicts of Interest}

The authors declare no conflicts of interest.

\section{Acknowledgments}

The authors would like to thank the Mesoscale and Microscale Meteorology (MMM) Laboratory, NCAR, for supporting the research and also acknowledge the NCAR's Computational and Information System Laboratory for providing the computing facilities for the research. Also, thanks are due to Ming Chen, Micheal Duda, Micheal Barlage, Mike Dixon, and other NCAR staff who provided technical support. The research work was primarily funded by the German Federal Ministry of Education and Research (BMBF) via the WACS-GRP FUTA.

\section{References}

[1] W. Zhao and A. Li, "A review on land surface processes modelling over complex terrain," Advances in Meteorology, vol. 2015, Article ID 607181, 17 pages, 2015.

[2] P. Viterbo, "The role of the land surface in the climate system," in Meteorological Training Course Lecture Series, European Centre for Medium Range Weather Forecasting 
(ECMWF), Reading, United Kingdom, 2002, https://www. ecmwf.int/node/16961.

[3] P. R. Tiwari, S. C. Kar, S. C. Kar et al., "The role of land surface schemes in the regional climate model (RegCM) for seasonal scale simulations over Western Himalaya," Atmósfera, vol. 28, no. 2, pp. 129-142, 2015.

[4] S. B. Trier, C. A. Davis, and D. A. Ahijevych, "Environmental controls on the simulated diurnal cycle of warm-season precipitation in the Continental United States," Journal of the Atmospheric Sciences, vol. 67, no. 4, pp. 1066-1090, 2010.

[5] S. Wharton, M. Simpson, J. Osuna, J. Newman, and S. Biraud, Assessment of Land Surface Model Performance in WRF for Simulating Wind at Heights Relevant to the Wind Energy Community, U.S. Department of Energy Office of Scientific and Technical Information, Oak Ridge, TN, USA, S. LLNL-TR-643914, 2013.

[6] A. K. Betts, J. H. Ball, A. C. M. Beljaars, M. J. Miller, and P. A. Viterbo, "The land surface-atmosphere interaction: a review based on observational and global modeling perspectives," Journal of Geophysical Research: Atmospheres, vol. 101, no. D3, pp. 7209-7225, 1996.

[7] C. Klein, J. Bliefernicht, D. Heinzeller, U. Gessner, I. Klein, and H. Kunstmann, "Feedback of observed interannual vegetation change: a regional climate model analysis for the West African monsoon," Climate Dynamics, vol. 48, no. 910, pp. 2837-2858, 2016.

[8] X. Y. Zheng and E. A. B. Eltahir, "The role of vegetation in the dynamics of West African monsoons," Journal of Climate, vol. 12, pp. 1368-1381, 1998.

[9] E. A. B. Eltahir and C. Gong, "Dynamics of wet and dry years in West Africa," Journal of Climate, vol. 9, no. 5, pp. 10301042, 1996.

[10] R. D. Koster, P. A. Dirmeyer, Z. Guo et al., "Regions of strong coupling between soil moisture and precipitation," Science, vol. 305, no. 5687, pp. 1138-1140, 2004.

[11] Y. Xue, R. W. A. Hutjes, R. J. Harding et al., "The sahelian climate (chapter A5)," in Vegetation, Water, Humans and the Climate, P. Kabat, Ed., pp. 59-77, Springer-Verlag, Berlin, Germany, 2004.

[12] C. A. Nobre, M. A. Silva Dias, A. D. Culf et al., "The Amazon climate," in Vegetation, Water, Humans and the Climate, P. Kabat, Ed., pp. 79-92, Springer-Verlag, Berlin, Germany, 2004.

[13] C. Fu, T. Yasunari, and S. Lütkemeier, "The Asian monsoon climate," in Vegetation, Water, Humans and the Climate, P. Kabat, Ed., pp. 115-127, Springer-Verlag, Berlin, Germany, 2004

[14] A. A. Sörensson, C. G. Menéndez, P. Samuelsson, U. Willén, and U. Hansson, "Soil-precipitation feedbacks during the South American monsoon as simulated by a regional climate model," Climatic Change, vol. 98, no. 3-4, pp. 429-447, 2010.

[15] T. Sato and Y. Xue, "Validating a regional climate model's downscaling ability for East Asian summer monsoonal interannual variability," Climate Dynamics, vol. 41, no. 9-10, pp. 2411-2426, 2013.

[16] Y. Lu and L. M. Kueppers, "Surface energy partitioning over four dominant vegetation types across the United States in A coupled regional climate model (weather research and forecasting model 3-community land model 3.5)," Journal of Geophysical Research: Atmospheres, vol. 117, no. D6, 2012.

[17] Y. Xue, F. De Sales, R. Vasic, C. R. Mechoso, A. Arakawa, and S. Prince, "Global and seasonal assessment of interactions between climate and vegetation biophysical processes: a
GCM study with different land-vegetation representations," Journal of Climate, vol. 23, no. 6, pp. 1411-1433, 2010.

[18] R. D. Koster, P. A. Dirmeyer, A. N. Hahmann et al., "Comparing the degree of land-atmosphere interaction in four atmospheric general circulation models," Journal of Hydrometeorology, vol. 3, no. 3, pp. 363-375, 2002.

[19] W. Li, W. Guo, Y. Xue, C. Fu, and B. Qiu, "Sensitivity of a regional climate model to land surface parameterization schemes for East Asian summer monsoon simulation," Climate Dynamics, vol. 47, no. 7-8, pp. 2293-2308, 2015.

[20] A. A. Boone, Y. Xue, F. De Sales et al., "The regional impact of land-use land-cover change (LULCC) over West Africa from an ensemble of global climate models under the auspices of the WAMME2 project," Climate Dynamics, vol. 47, no. 11, pp. 3547-3573, 2016.

[21] S. E. Nicholson, "The West african Sahel: a review of recent studies on the rainfall regime and its interannual variability," ISRN Meteorology, vol. 2013, Article ID 453521, 32 pages, 2013.

[22] J. L. Redelsperger, C. D. Thorncroft, A. Diedhiou, T. Lebel, D. J. Parker, and J. Polcher, "African monsoon multidisciplinary analysis an international research project and field campaign," Bulletin of the American Meteorological Society, vol. 87, no. 12, pp. 1739-1746, 2006.

[23] P. A. Dirmeyer, "The terrestrial segment of soil moistureclimate coupling," Geophysical Research Letters, vol. 38, no. 16, 2011.

[24] Y. Xue, A. Boone, and C. M. Taylor, "Review of recent developments and the future prospective in West african atmosphere/land interaction studies," International Journal of Geophysics, vol. 2012, Article ID 748921, 12 pages, 2012.

[25] A. L. Steiner, J. S. Pal, S. A. Rauscher et al., "Land surface coupling in regional climate simulations of the West African monsoon," Climate Dynamics, vol. 33, no. 6, pp. 869-892, 2009.

[26] S. L. Lavender, C. M. Taylor, and A. J. Matthews, "Coupled land-atmosphere intraseasonal variability of the West african monsoon in a GCM," Journal of Climate, vol. 23, no. 21, pp. 5557-5571, 2010

[27] J. G. Charney, "Dynamics of deserts and drought in the Sahel," Quarterly Journal of the Royal Meteorological Society, vol. 101, no. 428, pp. 193-202, 1975.

[28] K. Laval and L. Picon, "Effect of a change of the surface albedo of the Sahel on climate," Journal of the Atmospheric Sciences, vol. 43, no. 21, pp. 2418-2429, 1986.

[29] Y. C. Sud and M. Fennessy, "A study of the influence of surface albedo on July circulation in semi-arid regions using the glas GCM," Journal of Climatology, vol. 2, no. 2, pp. 105-125, 1982.

[30] W. Li, Y. Xue, and I. Poccard, "Numerical investigation of the impact of vegetation indices on the variability of West African summer monsoon," Journal of the Meteorological Society of Japan, vol. 85A, pp. 363-383, 2007.

[31] Y. Xue, "Biosphere feedback on regional climate in tropical north Africa," Quarterly Journal of the Royal Meteorological Society, vol. 123, no. 542, pp. 1483-1515, 1997.

[32] Y. Xue, K.-N. Liou, and A. Kasahara, "Investigation of biogeophysical feedback on the african climate using a twodimensional model," Journal of Climate, vol. 3, no. 3, pp. 337-352, 1990.

[33] X. Zheng and E. A. B. Eltahir, "The response to deforestation and desertification in a model of West african monsoons," Geophysical Research Letters, vol. 24, no. 2, pp. 155-158, 1997. 
[34] R. Borge, V. Alexandrov, J. José del Vas, J. Lumbreras, and E. Rodríguez, "A comprehensive sensitivity analysis of the WRF model for air quality applications over the Iberian Peninsula," Atmospheric Environment, vol. 42, no. 37, pp. 8560-8574, 2008.

[35] J. Crétat, B. Pohl, Y. Richard, and P. Drobinski, "Uncertainties in simulating regional climate of Southern Africa: sensitivity to physical parameterizations using WRF," Climate Dynamics, vol. 38, no. 3-4, pp. 613-634, 2012.

[36] S. K. Deb, T. P. Srivastava, and C. M. Kishtawal, “The WRF model performance for the simulation of heavy precipitating events over Ahmedabad during August 2006," Journal of Earth System Science, vol. 117, no. 5, pp. 589-602, 2008.

[37] J. P. Evans, M. Ekström, and F. Ji, "Evaluating the performance of a WRF physics ensemble over South-East Australia," Climate Dynamics, vol. 39, no. 6, pp. 1241-1258, 2012.

[38] W. A. Gallus Jr. and J. F. Bresch, "Comparison of impacts of WRF dynamic core, physics package, and initial conditions on warm season rainfall forecasts," Monthly Weather Review, vol. 134, no. 9, pp. 2632-2641, 2006.

[39] M. García-Díez, J. Fernández, L. Fita, and C. Yagüe, "Seasonal dependence of WRF model biases and sensitivity to PBL schemes over Europe," Quarterly Journal of the Royal Meteorological Society, vol. 139, no. 671, pp. 501-514, 2013.

[40] S.-Y. Hong, K.-S. Sunny Lim, J.-H. Kim, J.-O. Jade Lim, and J. Dudhia, "Sensitivity study of cloud-resolving convective simulations with WRF using two bulk microphysical parameterizations: ice-phase microphysics versus sedimentation effects," Journal of Applied Meteorology and Climatology, vol. 48, no. 1, pp. 61-76, 2009.

[41] I. Jankov, W. A. Gallus Jr., M. Segal, B. Shaw, and S. E. Koch, "The impact of different WRF model physical parameterizations and their interactions on warm season MCS rainfall," Weather and Forecasting, vol. 20, no. 6, pp. 1048-1060, 2005.

[42] J. S. Kain, S. J. Weiss, J. J. Levit, M. E. Baldwin, and D. R. Bright, "Examination of convection-allowing configurations of the WRF model for the prediction of severe convective weather: the SPC/NSSL spring program 2004," Weather and Forecasting, vol. 21, no. 2, pp. 167-181, 2006.

[43] J. H. Kwun, Y.-K. Seo Kim, J. W. Seo, J. H. Jeong, and S.-H. You, "Sensitivity of MM5 and WRF mesoscale model predictions of surface winds in a typhoon to planetary boundary layer parameterizations," Natural Hazards, vol. 51, no. 1, pp. 63-77, 2009.

[44] X. Li and Z. Pu, "Sensitivity of numerical simulations of the early rapid intensification of Hurricane Emily to cumulus parameterization schemes in different model horizontal resolutions," Journal of the Meteorological Society of Japan, vol. 87, no. 3, pp. 403-421, 2009.

[45] L. Liu, Y. Ma, M. Menenti, X. Zhang, and W. Ma, "Evaluation of WRF modeling in relation to different land surface schemes and initial and boundary conditions: a snow event simulation over the Tibetan plateau," Journal of Geophysical Research: Atmospheres, vol. 124, no. 1, pp. 209-226, 2019.

[46] S. Lu, W. Guo, Y. Xue, and F. Huang, "Sensitivity of high resolution WRF model to land surface schemes in simulating boreal summer climate over Central Asia," EGU, 2020.

[47] D. S. Nolan, J. A. Zhang, and D. P. Stern, "Evaluation of planetary boundary layer parameterizations in tropical cyclones by comparison of in situ observations and highresolution simulations of Hurricane Isabel (2003). Part I: initialization, maximum winds, and the outer-core boundary layer," Monthly Weather Review, vol. 137, no. 11, pp. 3651-3674, 2009.
[48] G. Zittis, P. Hadjinicolaou, and J. Lelieveld, "Comparison of WRF model physics parameterizations over the MENA-CORDEX domain," American Journal of Climate Change, vol. 3, no. 5, pp. 490-511, 2014

[49] K. H. Cook, "Generation of the african easterly jet and its role in determining West African precipitation," Journal of Climate, vol. 12, no. 5, pp. 1165-1184, 1999.

[50] A. A. Boone, I. Poccard-Leclercq, Y. Xue, J. Feng, and P. de Rosnay, "Evaluation of the WAMME model surface fluxes using results from the AMMA land-surface model intercomparison project," Climate Dynamics, vol. 35 , no. 1, pp. 127-142, 2009.

[51] P. M. Ruti, J. E. Williams, F. Hourdin et al., "The West African climate system: a review of the AMMA model intercomparison initiatives," Atmospheric Science Letters, vol. 12, no. 1, pp. 116-122, 2011.

[52] J. A. Okalebo, R. J. Oglesby, S. Feng et al., "An evaluation of the community land model (version 3.5) and Noah land surface models for temperature and precipitation over Nebraska (central great plains): Implications for agriculture in simulations of future climate change and adaptation," in Climate Change Adaptation, Resilience and Hazards, Climate Change Management, W. L. Filho, H. Filho, and G. Cavan, Eds., Springer, Cham, Switzerland, 2016.

[53] J. Jin, N. L. Miller, and N. Schlegel, "Sensitivity study of four land surface schemes in the WRF model," Advances in Meteorology, vol. 2010, Article ID 167436, 11 pages, 2010.

[54] J.-F. Miao, D. Chen, and K. Borne, "Evaluation and comparison of Noah and pleim-xiu land surface models in MM5 using GÖTE2001 data: spatial and temporal variations in near-surface air temperature," Journal of Applied Meteorology and Climatology, vol. 46, no. 10, pp. 1587-1605, 2007.

[55] J. R. Rajeswari, C. V. Srinivas, T. N. Rao, and B. Venkatraman, "Impact of land surface physics on the simulation of boundary layer characteristics at a tropical coastal station," Atmospheric Research, vol. 238, Article ID 104888, 2020.

[56] A. P. Singh, U. C. Mohanty, P. Sinha, and M. Mandal, "Influence of different land-surface processes on Indian summer monsoon circulation," Natural Hazards, vol. 42, no. 2, pp. 423-438, 2007.

[57] X. Chen, T. Yang, X. Wang, C.-Y. Xu, and Z. Yu, "Uncertainty intercomparison of different hydrological models in simulating extreme flows," Water Resources Management, vol. 27, no. 5, pp. 1393-1409, 2012.

[58] J. L. Case, F. J. LaFontaine, S. V. Kumar, and C. D. PetersLidard, "Using the NASA-Unified WRF to assess the impacts of real-time vegetation on simulations of severe weather," in Proceedings of the 13th Annual WRF User's Workshop, p. 69, Boulder, CO, USA, 2012.

[59] J. Miller, M. Barlage, X. Zeng, H. Wei, K. Mitchell, and D. Tarpley, "Sensitivity of the NCEP/Noah land surface model to the MODIS green vegetation fraction data set," Geophysical Research Letters, vol. 33, 2006.

[60] E. Sertel, C. Ormeci, and A. Robock, "Modelling land cover change impact on the summer climate of the Marmara Region, Turkey," International Journal of Global Warming, vol. 3, no. 1-2, pp. 194-202, 2011.

[61] S. Hagos, L. R. Leung, Y. Xue et al., "Assessment of uncertainties in the response of the African monsoon precipitation to land use change simulated by a regional model," Climate Dynamics, vol. 43, no. 9-10, pp. 2765-2775, 2014.

[62] D. P. Dee, S. M. Uppala, A. J. Simmons et al., "The ERAInterim reanalysis: configuration and performance of the 
data assimilation system," Quarterly Journal of the Royal Meteorological Society, vol. 137, no. 656, pp. 553-597, 2011.

[63] U.S. Department of Commerce National Centers for Environmental Prediction/National Weather Service/NOAA/, "Updated daily NCEP FNL operational model global tropospheric analyses, continuing from July 1999," Research Data Archive at the National Center for Atmospheric Research, Computational and Information Systems Laboratory, 2000.

[64] M. J. Iacono, J. S. Delamere, E. J. Mlawer, M. W. Shephard, S. A. Clough, and W. D. Collins, "Radiative forcing by longlived greenhouse gases: calculations with the AER radiative transfer models," Journal of Geophysical Research, vol. 113, no. D13, p. D13103, 2008.

[65] M. Nakanishi and H. Niino, "An improved mellor-yamada level-3 model: its numerical stability and application to a regional prediction of advection fog," Boundary-Layer Meteorology, vol. 119, no. 2, pp. 397-407, 2006.

[66] C. Zhang, Y. Wang, and K. Hamilton, "Improved representation of boundary layer clouds over the southeast pacific in ARW-WRF using a modified Tiedtke cumulus parameterization scheme," Monthly Weather Review, vol. 139, no. 11, pp. 3489-3513, 2011.

[67] S. Y. Hong and J. O. J. Lim, "The WRF single-moment 6-class microphysics scheme (WSM6)," Journal Korean of Meteorological Society, vol. 42, no. 2, pp. 129-151, 2006.

[68] I. E. Gbode, J. Dudhia, K. O. Ogunjobi, and V. O. Ajayi, "Sensitivity of different physics schemes in the wrf model during a west african monsoon regime," Theoretical and Applied Climatology, vol. 136, no. 1-2, pp. 733-751, 2018.

[69] F. Chen and J. Dudhia, "Coupling an advanced land surfacehydrology model with the penn state-NCAR MM5 modeling system. Part I: model implementation and sensitivity," Monthly Weather Review, vol. 129, no. 4, pp. 569-585, 2001.

[70] A. K. Betts, F. Chen, K. E. Mitchell, and Z. I. Janjić, "Assessment of the land surface and boundary layer models in two operational versions of the NCEP Eta Model using FIFE data," Monthly Weather Review, vol. 125, no. 11, pp. 2896-2916, 1997.

[71] M. Ek, K. Mitchell, L. Yin et al., "Implementation of Noah land-surface model advances in the NCEP operational mesoscale Eta model," Journal of Geophysical Research: Atmospheres, vol. 108, no. D22, p. 8851, 2003.

[72] A. Robock, L. Luo, E. F. Wood et al., "Evaluation of the north American land data assimilation system over the southern great plains during the warm season," Journal of Geophysical Research: Atmospheres, vol. 108, no. D22, p. 8846, 2003.

[73] C. A. Schlosser, A. G. Slater, A. Robock et al., "Simulations of a boreal grassland hydrology at Valdai, Russia: PILPS phase 2 (d)," Monthly Weather Review, vol. 128, no. 2, pp. 301-321, 2000.

[74] E. F. Wood, D. P. Lettenmaier, X. Liang et al., "The project for intercomparison of land-surface parameterization schemes (PILPS) phase 2(c) red-Arkansas river basin experiment:," Global and Planetary Change, vol. 19, no. 1-4, pp. 115-135, 1998.

[75] J. C. Schaake, Q. Duan, V. Koren et al., “An intercomparison of soil moisture fields in the north American land data assimilation system (NLDAS)," Journal of Geophysical Research, vol. 109, Article ID D01S90, 2004.

[76] A. McNally, K. Arsenault, S. Kumar et al., "A land data assimilation system for sub-Saharan Africa food and water security applications," Scientific Data, vol. 4, no. 1, Article ID 170012, 2017.
[77] G.-Y. Niu, Z.-L. Yang, K. E. Mitchell et al., "The community Noah land surface model with multiparameterization options (Noah-MP): 1. Model description and evaluation with local-scale measurements," Journal of Geophysical Research, vol. 116, no. D12, 2011.

[78] G.-Y. Niu and Z.-L. Yang, "Effects of vegetation canopy processes on snow surface energy and mass balances," Journal of Geophysical Research: Atmospheres, vol. 109, no. D23, p. D23111, 2004.

[79] R. Yang and M. A. Friedl, "Modeling the effects of threedimen- sional vegetation structure on surface radiation and energy balance in boreal forests," Journal of Geophysical Research, vol. 108, no. D16, p. 8615, 2003.

[80] G. B. Bonan, "A land surface model (LSM version 1.0) for ecological," Hydrological, and Atmospheric Studies: Technical Description and User's Guide, NCAR Tech. Note NCAR/TN$417+S T R$, p. 150, National Center for Atmospheric Research, Boulder, CO, USA, 1996.

[81] G. Collatz, M. Ribas-Carbo, and J. Berry, "Coupled photosynthesis-stomatal conductance model for leaves of C4 plants," Functional Plant Biology, vol. 19, no. 5, pp. 519-538, 1992.

[82] P. J. Sellers, D. A. Randall, G. J. Collatz et al., "A revised land surface parameterization (SiB2) for atmospheric GCMS. Part I: model formulation," Journal of Climate, vol. 9, no. 4, pp. 676-705, 1996.

[83] R. E. Dickinson, M. Shaikh, R. Bryant, and L. Graumlich, "Interactive canopies for a climate model," Journal of Climate, vol. 11, no. 11, pp. 2823-2836, 1998.

[84] Z.-L. Yang and G.-Y. Niu, "The Versatile integrator of surface and atmosphere processes," Global and Planetary Change, vol. 38, no. 1-2, pp. 175-189, 2003.

[85] G.-Y. Niu and Z.-L. Yang, "An observation-based formulation of snow cover fraction and its evaluation over large North American river basins," Journal of Geophysical Research, vol. 112, no. D21, Article ID D21101, 2007.

[86] K. W. Oleson, D. M. Lawrence, G. B. Bonan et al., "Technical description of version 4.0 of the community land model (CLM)," Tech- Nical Note NCAR/TN-478+STR, p. 257, National Center for Atmos- pheric Research, Boulder, CO, USA, 2010.

[87] W. C. Skamarock, J. B. Klemp, J. Dudhia et al., A Description of the Advanced Research WRF Version 3, NCAR Technical Note NCAR/TN-475+STR, Mesoscale and Microscale Meteorology Division, National Center for Atmospheric Research, Boulder, CO, USA, 2008.

[88] X. Zeng and M. Decker, "Improving the numerical solution of soil moisture-based Richards equation for land models with a deep or shallow water table," Journal of Hydrometeorology, vol. 10, no. 1, pp. 308-319, 2009.

[89] G.-Y. Niu and Z.-L. Yang, "Effects of frozen soil on snowmelt runoff and soil water storage at a continental scale," Journal of Hydrometeorology, vol. 7, no. 5, pp. 937-952, 2006.

[90] A. Wang and X. Zeng, "Improving the treatment of the vertical snow burial fraction over short vegetation in the NCAR CLM3," Advances in Atmospheric Sciences, vol. 26, no. 5, pp. 877-886, 2009.

[91] D. M. Lawrence, K. W. Oleson, M. G. Flanner et al., "Parameterization improvements and functional and structural advances in version 4 of the community land model," Journal of Advances in Modeling Earth Systems, vol. 3, pp. 1942-2466, 2011.

[92] G. J. Huffman, D. T. Bolvin, E. J. Nelkin et al., “The TRMM multisatellite precipitation analysis (TMPA): quasi-global, 
multiyear, combined-sensor precipitation estimates at fine scales," Journal of Hydrometeorology, vol. 8, no. 1, pp. 38-55, 2007.

[93] G. J. Huffman, D. T. Bolvin, and R. F. Adler, "GPCP version 1.2 one- degree daily precipitation data set," Research Data Archive at the National Center for Atmospheric Research, Computational and Information Systems Laboratory, 2016.

[94] G. J. Huffman, R. F. Adler, D. T. Bolvin, and G. Gu, "Improving the global precipitation record: GPCP version 2.1," Geophysical Research Letters, vol. 36, no. 17, 2009.

[95] K. E. Taylor, "Summarizing multiple aspects of model performance in a single diagram," Journal of Geophysical Research: Atmospheres, vol. 106, no. D7, pp. 7183-7192, 2001.

[96] J. Houghton, Y. Ding, D. J. Griggs, M. Noguer, P. J. van der Linden, and D. Xiaosu, "Climate change 2001: the scientific basis. Contribution of working group i to the 3rd assessment report of the intergovernmental panel on climate change," Cambridge University Press, Cambridge, UK, 2001.

[97] X. Liang, Z. Xie, and M. Huang, "A new parameterization for surface and groundwater interactions and its impact on water budgets with the variable infiltration capacity (VIC) land surface model," Journal of Geophysical Research, vol. 108, no. D16, p. 8613, 2003.

[98] G. S. Jenkins, A. Kamga, A. Garba, A. Diedhiou, V. Morris, and E. Joseph, "Investigating the West African climate system using global/regional climate models," Bulletin of the American Meteorological Society, vol. 83, no. 4, pp. 583-595, 2002.

[99] C. Jones, F. Giorgi, and G. Asrar, "The coordinated regional downscaling experiment: CORDEX, an international downscaling link to CMIP5," CLIVAR Exchanges, vol. 16, no. 2, pp. 34-40, 2011.

[100] J. Milovac, K. Warrach-Sagi, A. Behrendt, F. Späth, J. Ingwersen, and V. Wulfmeyer, "Investigation of PBL schemes combining the WRF model simulations with scanning water vapor differential absorption lidar measurements," Journal of Geophysical Research: Atmospheres, vol. 121, no. 2, pp. 624-649, 2016.

[101] Y. Jiao and D. Caya, "An investigation of summer precipitation simulated by the Canadian regional climate model," Monthly Weather Review, vol. 134, no. 3, pp. 919-932, 2006.

[102] C. Chotamonsak, E. P. Salathe, J. Kreasuwan, and S. Chantara, "Evaluation of precipitation simulations over Thailand using a WRF regional climate model," Chiang Mai Journal of Science, vol. 39, no. 4, pp. 623-628, 2012.

[103] I. Chawla, K. K. Osuri, P. P. Mujumdar, and D. Niyogi, "Assessment of the Weather Research and Forecasting (WRF) model for simulation of extreme rainfall events in the upper Ganga Basin," Hydrology and Earth System Sciences, vol. 22, no. 2, pp. 1095-1117, 2018.

[104] J. Pongratz, C. H. Reick, T. Raddatz, and M. Claussen, "Biogeophysical versus biogeochemical climate response to historical anthropogenic land cover change," Geophysical Research Letters, vol. 37, no. 8, 2010.

[105] A. A. Akinsanola and W. Zhou, "Understanding the variability of West african summer monsoon rainfall: contrasting tropospheric features and monsoon index," Atmosphere, vol. 11 , no. 3 , p. 309, 2020.

[106] S. M. Hagos and K. H. Cook, "Ocean warming and latetwentieth-century sahel drought and recovery," Journal of Climate, vol. 21, no. 15, pp. 3797-3814, 2008.

[107] S. Hagos and C. Zhang, "Diabatic heating, divergent circulation and moisture transport in the African monsoon system," Quarterly Journal of the Royal Meteorological Society, vol. 136, no. S1, pp. 411-425, 2010.

[108] J. P. Grist and S. E. Nicholson, "A study of the dynamic factors influencing the rainfall variability in the West African Sahel," Journal of Climate, vol. 14, no. 7, pp. 1337-1359, 2001.

[109] A. A. Akinsanola and K. O. Ogunjobi, "Evaluation of present-day rainfall simulations over West Africa in CORDEX regional climate models," Environmental Earth Sciences, vol. 76, no. 10, p. 366, 2017.

[110] B. J. Abiodun, J. S. Pal, E. A. Afiesimama, W. J. Gutowski, and A. Adedoyin, "Simulation of West african monsoon using RegCM3 Part II: impacts of deforestation and desertification," Theoretical and Applied Climatology, vol. 93, no. 3-4, pp. 245-261, 2008.

[111] A. Berg, B. R. Lintner, K. L. Findell, S. Malyshev, P. C. Loikith, and P. Gentine, "Impact of soil moisture-atmosphere interactions on surface temperature distribution," Journal of Climate, vol. 27, no. 21, pp. 7976-7993, 2014.

[112] E. M. Fischer, S. I. Seneviratne, L. Vidale P, D. Lüthi, and C. Schär, "Soil moisture-atmosphere interactions during the 2003 European summer heat wave," Journal of Climate, vol. 20, no. 20, pp. 5081-5099, 2007.

[113] J. S. Pal and E. A. B. Eltahir, "Pathways relating soil moisture conditions to future summer rainfall within a model of the land-atmosphere system," Journal of Climate, vol. 14, no. 6, pp. 1227-1242, 2001.

[114] D. Wolters, C. C. van Heerwaarden, J. V.-G. de Arellano, B. Cappelaere, and D. Ramier, "Effects of soil moisture gradients on the path and the intensity of a West African squall line," Quarterly Journal of the Royal Meteorological Society, vol. 136, no. 653, pp. 2162-2175, 2010.

[115] C. D. Thorncroft, H. Nguyen, C. Zhang, and P. Peyrillé, "Annual cycle of the West African monsoon: regional circulations and associated water vapour transport," Quarterly Journal of the Royal Meteorological Society, vol. 137, no. 654, pp. 129-147, 2011.

[116] C. Klein, Interactions of regional atmospheric and land surface processes with the West African monsoon system, Faculty of Applied Computer Science of the University of Augsburg, Augsburg, Germany, https://www.researchgate.net/publication/ 316071934_Interactions_of_regional_atmospheric_and_land_ surface_processes_with_the_West_African_monsoon_system, Ph.D. thesis, 2016.

[117] A. K. Betts and J. H. Ball, "FIFE surface climate and siteaverage data set 1987-1989," Journal of the Atmospheric Sciences, vol. 55, no. 7, pp. 1091-1108. in press, 1998.

[118] E. A. B. Eltahir, "A soil moisture-rainfall feedback mechanism: 1. Theory and observations," Water Resources Research, vol. 34, no. 4, pp. 765-776, 1998.

[119] M. Barlage, M. Tewari, F. Chen, G. Miguez-Macho, Z.-L. Yang, and G.-Y. Niu, "The effect of groundwater interaction in North American regional climate simulations with WRF/Noah-MP," Climatic Change, vol. 129, no. 3-4, pp. 485-498, 2015.

[120] J. Wang, Y. Cui, X. He, J. Zhang, and S. Yan, "Surface albedo variation and its influencing factors over dongkemadi glacier, central Tibetan plateau," Advances in Meteorology, vol. 2015, Article ID 852098, 10 pages, 2015.

[121] J. P. Hacker, "Spatial and temporal scales of boundary layer wind predictability in response to small-amplitude land surface uncertainty," Journal of the Atmospheric Sciences, vol. 67, no. 1, pp. 217-233, 2010. 
[122] A. J. Pitman, "The evolution of, and revolution in, land surface schemes designed for climate models," International Journal of Climatology, vol. 23, no. 5, pp. 479-510, 2003.

[123] C. Schwingshackl, M. Hirschi, and S. I. Seneviratne, "A theoretical approach to assess soil moisture-climate coupling across CMIP5 and GLACE-CMIP5 experiments," Earth System Dynamics, vol. 9, no. 4, pp. 1217-1234, 2018.

[124] J.-L. Redelsperger, A. Diongue, A. Diedhiou et al., "Multiscale description of a Sahelian synoptic weather system representative of the West African monsoon," Quarterly Journal of the Royal Meteorological Society, vol. 128, no. 582, pp. 1229-1257, 2002. 